\title{
Analysis of key genes and pathways associated with the pathogenesis of Type 2 diabetes mellitus
}

Varun Alur ${ }^{1}$, Varshita Raju ${ }^{2}$, Basavaraj Vastrad ${ }^{3}$, Chanabasayya Vastrad ${ }^{* 4}$, Shivakumar Kotturshetti ${ }^{4}$

1. Department of Endocrinology, J.J. M Medical College, Davanagere, Karnataka 577004, India.

2. Department of Obstetrics and Gynecology, J.J. M Medical College, Davanagere, Karnataka 577004, India.

3. Department of Biochemistry, Basaveshwar College of Pharmacy, Gadag, Karnataka 582103, India.

4. Biostatistics and Bioinformatics, Chanabasava Nilaya, Bharthinagar, Dharwad 580001, Karnataka, India.

* Chanabasayya Vastrad

channu.vastrad@gmail.com

Ph: +919480073398

Chanabasava Nilaya, Bharthinagar,

Dharwad 580001 , Karanataka, India 


\begin{abstract}
Type 2 diabetes mellitus (T2DM) is the most common endocrine disorder which poses a serious threat to human health. This investigation aimed to screen the candidate genes differentially expressed in T2DM by bioinformatics analysis. The expression profiling by high throughput sequencing of GSE81608 dataset was retrieved from the gene expression omnibus (GEO) database and analyzed to identify the differentially expressed genes (DEGs) between T2DM and normal controls. Then, Gene Ontology (GO) and pathway enrichment analysis, proteinprotein interaction (PPI) network, modules, miRNA-hub gene regulatory network construction and TF-hub gene regulatory network construction, and topological analysis were performed. Receiver operating characteristic curve (ROC) analysis was also performed to verify the diagnostics value and expression of identified hub genes. A total of 927 DEGs (461 were up regulated and 466 down regulated genes) were identified in T2DM. GO and REACTOME results showed that DEGs mainly enriched in protein metabolic process, establishment of localization, metabolism of proteins and metabolism. The top centrality hub genes APP, MYH9, TCTN2, USP7, SYNPO, GRB2, HSP90AB1, UBC, HSPA5 and SQSTM1 were screened out as the critical genes among the DEGs from the PPI network, modules, miRNAhub gene regulatory network construction and TF-hub gene regulatory network. ROC analysis provide diagnostics value of hub genes. This study identified key genes, signal pathways and therapeutic agents, which might help us, improve our understanding of the mechanisms of HGPS and identify some new therapeutic agents for T2DM.
\end{abstract}

Keywords: bioinformatics analysis; differentially expressed genes; hub genes; Type 2 diabetes mellitus; protein-protein interaction network 


\section{Introduction}

Type 2 diabetes mellitus (T2DM) is a complex metabolic disorder and is characterized primarily by a decrease in insulin secretion, typically accompanied by insulin resistance [1]. Globally, it is predicted that 25 million adults (20-79 years) have diabetes, projected to reach 629 million by 2045 and is the ninth leading cause of death [2-3]. T2DM is mainly associated with macrovascular complications include stroke, coronary artery disease and peripheral arterial disease, and microvascular include diabetic retinopathy, diabetic nephropathy, and diabetic neuropathy, and non-vascular diabetes complications include nonalcoholic fatty liver disease, psychiatric disease, obesity, cancer, cognitive impairment, infections and disability [4]. There are several important risk factors for T2DM, such as age, sex, family history of diabetes, hypertension, obesity, abdominal obesity, stress in the workplace or home, a sedentary lifestyle, smoking, insufficient fruit and vegetable consumption, physical activity, genetic and environmental [5]. Our understanding of the occurrence and development mechanism of T2DM has been greatly improved; however, the cause and potential molecular mechanism of T2DM are still unclear [6]. Therefore, it is necessary to identify key genes and pathways for understanding the molecular mechanism and discovering potential biomarkers for T2DM.

In recent decades, more and more researchers have devoted themselves to exploring the potential mechanisms for progression of T2DM. For instance, it has been demonstrated that the HHEX, CDKN2A/B, and IGF2BP2 [7], CDKAL1 and HHEX/IDE [8], ADIPOQ, PPAR- $\gamma$, and RXR- $\alpha$ [9], ABCC8 and KCNJ11 [10], TCF7L2, SLC30A8, PCSK1 and PCSK2 [11], PI3K/AKT-and AMPK signaling pathway [12], mTOR signaling pathway [13], insulin signaling pathway [14], AGE/RAGE/JNK, STAT3/SCOS3 and RAS signaling pathway [15] and ERK signaling pathway [16] were involved in progression of T2DM. Therefore, it is of great practical significance to explore the genes and signaling pathways of T2DM on islet cells.

RNA sequencing technology can rapidly detect gene expression on a global basis and are particularly useful in screening for differentially expressed genes (DEGs) in diseases [17]. RNA sequencing which allow the investigation of gene expression in a high throughput manner with high sensitivity, specificity and 
repeatability. Significant amounts of data have been produced via the use of RNA sequencing and the majority of such data has been uploaded and stored in public databases. Previous investigations concerning T2DM gene expression profiling have identified hundreds of DEGs [18]. However, the comparative analysis of DEGs across a range of independent investigation might yield only a relatively limited amount of useful data with regard to T2DM advancement. The disadvantages of these single investigations might be overcome by bioinformatics analysis, as this approach would make it possible to analyze the signaling pathways and interaction networks linked with the identified DEGs. This knowledge might help in elucidating the molecular mechanisms underlying T2DM.

In the present investigation, expression profiling by high throughput sequencing dataset was downloaded from the Gene Expression Omnibus (GEO) (GEO, http://www.ncbi.nlm.nih.gov/geo/) [19]: GSE81608 [20]. DEGs were identified in T2DM. Additionally, gene ontology (GO), REACTOME pathway enrichment analysis was performed and protein-protein interaction (PPI) networks, modules, miRNA-hub gene regulatory network construction and TF-hub gene regulatory network were constructed to identify the hub genes, miRNA and TFs in T2DM. Finally, hub genes were validated by receiver operating characteristic curve (ROC). Collectively, the findings of the present investigation highlighted crucial genes and signaling pathways that might contribute to the pathology of T2DM. These may provide a basis for the advancement of future diagnostic, prognostic and therapeutic tools for T2DM.

\section{Materials and Methods}

\section{Data resources}

Expression profiling by high throughput sequencing dataset GSE81608 [20] was downloaded from the GEO database. The data was produced using a GPL16791 Illumina HiSeq 2500 (Homo sapiens). The GSE81608 dataset contained data from 1600 samples, including 949 T2DM, and 651 healthy control samples.

\section{Identification of DEGs}

Limma package in $\mathrm{R}$ software [21] is a tool to identify DEGs by comparing samples from GEO series. Limma package in R software was used to search for in 
messenger RNAs (mRNAs; DEGs) that were differentially expressed between T2DM and healthy control samples. The cutoff criteria were an adjusted p-value of $<0.05$, whereas the $\operatorname{logFC}$ value were $>0.181$ for up regulated genes and < 0.27 for down regulated genes. DEG of this dataset was visualized with volcano map and hierarchical clustering heat map. The volcano plot was drawn using ggplot2 package in $\mathrm{R}$ software. Hierarchical clustering heat maps of DEG expression (up regulated genes and down regulated genes) were visualized with gplots package in R software.

\section{GO and REACTOME pathway enrichment analysis of DEGs}

GO enrichment analysis (http://geneontology.org/) [22] implement the annotation of biological processes (BP), cellular components (CC) and molecular functions (MF) of DEGs. REACTOME (https://reactome.org/) [23] is a database that stores large amounts of data on genomics, biological pathways, signaling pathways, diseases, drugs, and chemicals. The present investigation used Database for g:Profiler (http://biit.cs.ut.ee/gprofiler/) [24] to perform GO and REACTOME pathway enrichment analysis. $\mathrm{P}<0.05$ was considered to indicate a statistically significant difference.

\section{Construction of the PPI network and module analysis}

The IID interactome database (http://iid.ophid.utoronto.ca/) may be searched for associations between known and predicted proteins, and is commonly used to predict PPI information in molecular biology [25]. Cytoscape 3.8.2 (http://www.cytoscape.org/) [26] was used to visualize the results from the PPI network In this investigation, node degree [27], betweenness centrality [28], stress centrality [29] and closeness centrality [30], which constitutes a fundamental parameter in network theory, was adopted to evaluate the nodes in a network. The node degree betweenness centrality, stress centrality and closeness centrality methods were calculated using Cytoscape plugin Network Analyzer. Module analysis on the PPI network results was performed using the PEWCC1 (http://apps.cytoscape.org/apps/PEWCC1) [31] clustering algorithm that comes with Cytoscape. Module analysis might be used to find out more connected gene groups. In addition, the module analysis were further analyzed for GO and pathway enrichment analysis. 


\section{MiRNA-hub gene regulatory network construction}

Prediction of miRNA-hub genes was performed by miRNet database (https://www.mirnet.ca/) [32]. According to the regulatory interaction, miRNAhub gene regulatory network was constructed based on miRNet by Cytoscape 3.8.2 software [26].

\section{TF-hub gene regulatory network construction}

Prediction of TF-hub genes was performed by NetworkAnalyst database (https://www.networkanalyst.ca/) [33]. According to the regulatory interaction, TFhub gene regulatory network was constructed based on NetworkAnalyst by Cytoscape 3.8.2 software [26].

\section{Validation of hub genes by receiver operating characteristic curve (ROC) analysis}

ROC curve analysis was performed to evaluate the sensitivity and specificity of the hub genes for T2DM diagnosis using the R package "pROC" [34]. An area under the curve (AUC) value was determined and used to label the ROC effect.

\section{Results}

\section{Identification of DEGs}

A total of 927 genes were identified to be differentially expressed between T2DM and normal control samples with the threshold of adjusted p-value of $<0.05$, and $\log \mathrm{FC}$ value were $>0.181$ for up regulated genes and $<-0.27$ for down regulated genes. Among these DEGs, 461 were up regulated and 466 down regulated genes in T2DM compared with normal control samples and are listed in Table 1. A heat map (Fig. 1) and a volcano plot (Fig. 2) for the identified DEGs was generated.

\section{GO and REACTOME pathway enrichment analysis of DEGs}

To identify the pathways which had the most significant involvement with the genes identified, up regulated and down regulated genes were submitted into g:Profiler for GO and REACTOME pathway enrichment analysis and are listed in Table 2 and Table 3. GO enrichment analysis revealed that in BP terms, the up regulated genes were mainly enriched in protein metabolic process and positive 
regulation of biological process. Down regulated genes were mainly enriched in establishment of localization and cellular metabolic process. In CC terms, up regulated genes were mainly enriched in intracellular anatomical structure and endomembrane system, whereas down regulated genes were mainly enriched in cytoplasm and intracellular anatomical structure. In MF terms, up regulated genes were mainly enriched in heterocyclic compound binding and protein binding, whereas down regulated genes were mainly enriched in catalytic activity and protein binding. REACTOME pathway enrichment analysis demonstrated that up regulated genes were significantly enriched in metabolism of proteins and NR1H3 \& NR1H2 regulate gene expression linked to cholesterol transport and efflux. Down regulated genes were significantly enriched in the metabolism and the citric acid (TCA) cycle and respiratory electron transport.

\section{Construction of the PPI network and module analysis}

Following the analysis based on the PPI networks, 4424 nodes and 8670 edges were identified in Cytoscape (Fig. 3). The genes with higher scores were the hub genes, as the genes of higher node degree, betweenness centrality, stress centrality and closeness centrality might be linked with T2DM. The top hub genes were APP, MYH9, TCTN2, USP7, SYNPO, GRB2, HSP90AB1, UBC, HSPA5 and SQSTM1, and are listed in Table 4. A total of two modules were selected through PEWCC1 analysis, and module 1 had nodes 98 and edges 117 (Fig. 4A) and module 2 had nodes 81 and edges 248 (Fig. 4B). Enrichment analysis demonstrated that modules 1 and 2 might be linked with RNA polymerase II transcription, intracellular anatomical structure, metabolism of proteins, protein metabolic process, positive regulation of biological process, metabolism, immune system, establishment of localization, cytoplasm, neutrophil degranulation, cellular metabolic process, intracellular anatomical structure and protein binding.

\section{MiRNA-hub gene regulatory network construction}

The hub genes of the DEGs in T2DM were performed by online databases miRNet. Based on the miRNAs, a miRNA -hub gene regulatory network was constructed with 2630 nodes (miRNA: 2345 and hub gene: 285) and 20765 interaction pairs (Fig. 5). PRKDC was the gene targets of 163 miRNAs (ex; hsamir-142-5p), MYH9 was the gene targets of 126 miRNAs (ex; hsa-mir-181b-3p), 
APP was the gene targets of 125 miRNAs (ex; hsa-mir-216b-5p), ILF3 was the gene targets of 107 miRNAs (ex; hsa-mir-3157-3p), SKIL was the gene targets 91 of miRNAs (ex; hsa-mir-1294), HSPA8 was the gene targets of 116 of miRNAs (ex; hsa-mir-3661), HSP90AB1 was the gene targets of 103 of miRNAs (ex; hsamir-200a-3p), SQSTM1 was the gene targets of 94 of miRNAs (ex; hsa-mir-520d5p), HSPA5 was the gene targets of 88 of miRNAs (ex; hsa-mir-573) and GRB2 was the gene targets of 65 of miRNAs (ex; hsa-mir-1291), and are listed in Table 5 .

\section{TF-hub gene regulatory network construction}

The hub genes of the DEGs in T2DM were performed by online databases NetworkAnalyst. Based on the TFs, a TF -hub gene regulatory network was constructed with 477 nodes (TF: 192 and hub gene: 285) and 8507 interaction pairs (Fig. 6). BCL6 was the gene targets of 60 TFs (ex; NOTCH1), MYH9 was the gene targets of 53 TFs (ex; PPARD), NCOR2 was the gene targets of 50 TFs (ex; HIF1A), APP was the gene targets of 45 TFs (ex; SMARCA4), NDRG1 was the gene targets of 44 TFs (ex; SUZ12), UBC was the gene targets of 64 TFs (ex; TAF7L), HSP90AB1 was the gene targets of 49 TFs (ex; RUNX2), TUBA1C was the gene targets of 47 TFs (ex; MITF), HSPA5 was the gene targets of 44 TFs (ex; YAP1) and HSPA8 was the gene targets of 39 TFs (ex; E2F1), and are listed in Table 5.

Validation of hub genes by receiver operating characteristic curve (ROC) analysis

Validated by ROC curves, we found that 10 hub genes had high sensitivity and specificity, including APP (AUC $\square=\square 0.853$ ), MYH9 (AUC $\square=0.852$ ), TCTN2 (AUC $\square=\square 0.881$ ), USP7 (AUC $\square=\square 0.862$ ), SYNPO (AUC $\square=0.893$ ), GRB2 (AUC $\square=\square 0.850$ ), HSP90AB1 (AUC $\square=\square 0.870$ ), UBC (AUC $\square=0.865$ ), HSPA5 (AUC $\square=0.902$ ) and SQSTM1 (AUC $\square=\square 0.875$ ) (Fig. 7). The hub genes might be biomarkers of T2DM and have positive implications for early medical intervention of the disease.

\section{Discussion}


Although there are various investigations on T2DM have been conducted, the mortality of T2DM is still high. This might be due to the lack of valid biomarkers for detection of early stage T2DM and of valid treatment for T2DM. Therefore, molecular mechanisms of T2DM are necessary for scientists to find the treat and diagnosis method of T2DM. Because of the fast advancement of RNA sequencing technology, it is more convenient to find out the genetic modification of development of diseases. RNA sequencing facilitates us to examine the gene, the genetic modification in T2DM, which had been proved to be a better approach to find novel biomarkers in other metabolic diseases.

In the present investigation, we observed whether there were more beneficial genes which could be better biomarkers for the diagnosis, prognosis and therapeutic for T2DM. In order to find out the significant gene of T2DM, we analyzed the T2DM expression profiling by high throughput sequencing of GSE81608 in limma, where a total number of 927 DEGs were obtained between T2DM and normal control, comprising was 461 up regulated and 466 down regulated genes. CTBP1 [35] and TRNC [36] are involved in the pathogenesis of T2DM. Previous studies have demonstrated that SST (somatostatin) serve an essential role in obesity [37], but this gene might be novel target for T2DM.

Then, databases including GO and REACTOME were selected to do gene enrichment analysis. Metabolism of proteins [38], metabolism [39], the citric acid (TCA) cycle and respiratory electron transport [40], gluconeogenesis [41], immune system [42], heterocyclic compound binding [43], protein binding [44], establishment of localization [45], cellular metabolic process [46], cytoplasm [47] and catalytic activity [48] were the GO terms and signaling pathways responsible for the advancement of T2DM. A previous study showed that IGFBP2 [49], APOH (apolipoprotein H) [50], ANXA2 [51], BAX (BCL2 associated X, apoptosis regulator) [52], PCSK1N [53], PDK4 [54], CPE (carboxypeptidase E) [55], OCLN (occludin) [56], CD44 [57], NDN (necdin, MAGE family member) [58], MLXIPL (MLX interacting protein like) [59], CD36 [60], SREBF1 [61], NR4A1 [62], PCSK2 [63], CHGB (chromogranin B) [64], PDK3 [65], PDCD4 [66], EIF5A [67], NRP1 [68], ABCA1 [69], DNMT1 [70], MYH9 [71], HMGB1 [72], B4GALT5 [73], B2M [74], MAP3K12 [75], KSR2 [76], NPY (neuropeptide Y) [77], CHGA (chromogranin A) [78], CD47 [79], DLK1 [80], PDK4 [81], CPE (carboxypeptidase E) [82], OCLN (occludin) [83], CXXC4 [84], PEMT 
(phosphatidylethanolamine N-methyltransferase) [85], FADS2 [86], RREB1 [87], HNRNPAB (heterogeneous nuclear ribonucleoprotein A/B) [88], CPT1A [89], ALDH1B1 [90], ESRRA (estrogen related receptor alpha) [91], NISCH (nischarin) [92], SSTR3 [93], ND1 [94], NCOR2 [95], RBP4 [96], GSTP1 [97], CYB5A [98], G6PC2 [99], DNAJC15 [100], TMED6 [101], PSMD6 [102], CLU (clusterin) [103], TTR (transthyretin) [104], TXN (thioredoxin) [105], LAMTOR1 [106], GLUL (glutamate-ammonia ligase) [107], NEU1 [108], HSPA8 [109], AP3S2 [110], COX4I1 [111], MT2A [112] MTCH2 [113], ESD (esterase D) [114], UBE2L6 [115], SCD (stearoyl-CoA desaturase) [116], MGST3 [117], NQO1 [118] NSMCE2 [119] and PRSS1 [120] played an important role in T2DM. Quintela et al [121], Yuan et al [122], Cacace et al [123], Hao et al [124], Beckelman et al [125], Liu et al [126], Sekiguchi et al [127], Castillon et al [128], O'Donnell-Luria et al [129], Coupland et al [130], Koufaris et al [131], Qvist et al [132], Richter et al [133], Torres et al [134], Jeong et al [135], Bermejo-Bescós et al [136], RamonDuaso et al [137], Guilarte, [138], Mukaetova-Ladinska et al [139], Fazeli et al [140], Butler et al [141], Nackenoff et al [142], Konyukh et al [143], Hu et al [144], Kaur et al [145], Nakamura et al [146], Liu et al [147], Obara et al [148], Herrmann et al [149], Ozgen et al [150], Masciullo et al [151], Perrone et al [152], Su et al [153], Zhao et al [154], Iqbal et al [155], Gal et al [156], Wang et al [157], Stefanović et al [158], Zahola et al [159], Bik-Multanowski et al [160], Mata et al [161], Li et al [162], Payton et al [163] and Chai et al [164] indicated that UBA6, TIA1, DPP6, USP7, EEF2, ITM2B, DPH1, PAK3, KMT2E, MAPT (microtubule associated protein tau), HCFC1, BRD1, TAOK2, PHF1, STMN2, APP (amyloid beta precursor protein), MBNL2, APLP1, MAP2, SRRM2 CST3, SRRM2, CST3, PLD3, SEZ6L2, DOC2A, PI4KA, GNAO1, TRA2A, MIDN (midnolin), HOOK3, MCPH1, SACS (sacsin molecular chaperone), TUBA4A, ASAH1, ATP6V1B2, SVBP (small vasohibin binding protein), AIFM1, UBC (ubiquitin C), IFI30, SCGN (secretagogin, EF-hand calcium binding protein), MTRNR2L12, GBA (glucosylceramidase beta), TXN2, NQO2 and PPIL1 were involved in the development and progression of cognitive impairment, but these genes might be novel target for T2DM. RPS3A [165], PGAM5 [166], RPL7 [167], TLK1 [168], DDR1 [169], ILF3 [170], TNRC6A [171], GGCX (gamma-glutamyl carboxylase) [172], S100A6 [173], LSAMP (limbic system associated membrane protein) [174], KCNA5 [175], LUC7L3 [176], ATAD3C [177], SRSF3 [178], MCU (mitochondrial calcium uniporter) [179], ATP2A2 [180], GAA (glucosidase 
alpha, acid) [181], MAGI1 [182], WIPF2 [183], VAMP8 [184], UCHL1 [185], CLIC1 [186], PSMB5 [187], GRB2 [188], ZMPSTE24 [189], COX6B1 [190], SQSTM1 [191], COTL1 [192], CD63 [193], NDUFB7 [194], BEX1 [195] and MTRNR2L8 [196] plays a major role in mediating cardiovascular diseases progression, but these genes might be novel target for T2DM. HLA-A [197], VEGFA (vascular endothelial growth factor A) [198], RPS26 [199], BMP6 [200], HLA-B [201], IER3IP1 [202], MT1E [203], ACADM (acyl-CoA dehydrogenase medium chain) [204] and GAPDH (glyceraldehyde-3-phosphate dehydrogenase) [205] are associated with progression of type 1 diabetes mellitus, but these genes might be novel target for T2DM. PEMT (phosphatidylethanolamine Nmethyltransferase) [206], INSM1 [207], BCL6 [208], RUNX1T1 [209], PGRMC2 [210], ARID1B [211], CITED2 [212], KLF13 [213], PPT1 [214], ARRDC3 [215], HSPA5 [216], MDH2 [217] and COA3 [218] have been previously reported to be a key biomarkers for the early detection of obesity, but these genes might be novel target for T2DM. A previous study demonstrated that IGFBP5 [219], PRDX6 [220], PKM (pyruvate kinase M1/2) [221], PRDX1 [222] and USP22 [223] were more highly expressed in diabetic nephropathy, but these genes might be novel target for T2DM. Durgin et al [224], Zhang et al [225], Hamada et al [226], Gong et al [227], Li et al [228], Lin et al [229] and Schweigert et al [230] suggested that CYB5R3, CACNA1A, GLCCI1, CAP1, HSP90AB1, BLVRA (biliverdinreductase A) and CRIP1 were involved in the progression of hypertension, but these genes might be novel target for T2DM.

By PPI network and module analysis, we identified the hub genes that might affect the origin or advancement of T2DM. TCTN2, SYNPO (synaptopodin), PSMD12, PSMC4, TUBA1C, PSMC5, PSMD7 and RAD23A were novel biomarkers for the progression of T2DM.

In addition, miRNA-hub gene regulatory network construction and TF-hub gene regulatory network were constructed. In addition, miRNA-mRNA networks were constructed. The roles of hub genes, miRNA and TF in the pathogenesis of T2DM are discussed. Hsa-mir-142-5p [231], hsa-mir-1291 [232], NOTCH1 [233], PPARD (peroxisome proliferator-activated receptor delta) [234], HIF1A [235], RUNX2 [236] and E2F1 [237] levels are correlated with disease severity in patients with T2DM. Previous studies have demonstrated that hsa-mir-216b-5p [238] and hsa-mir-200a-3p [239] appears to be expressed in type 1 diabetes, but 
these genes might be novel target for T2DM. Hsa-mir-1294 [240], SUZ12 [241] and YAP1 [242] were responsible for progression of cognitive impairment, but these genes might be novel target for T2DM. Hsa-mir-573 [243] and SMARCA4 [244] were linked with progression of hypertension, but these genes might be novel target for T2DM. PRKDC (protein kinase, DNA-activated, catalytic subunit), SKIL (SKI like proto-oncogene), NDRG1, hsa-mir-181b-3p, hsa-mir-3157-3p, hsa-mir-3661, hsa-mir-520d-5p, TAF7L and MITF (Microphthalmia-associated transcription factor) were novel biomarkers for the progression of T2DM.

In conclusion, the present study identified ten hub genes (APP, MYH9, TCTN2, USP7, SYNPO, GRB2, HSP90AB1, UBC, HSPA5 and SQSTM1) with crucial role in progression of T2DM; our results suggested these genes could add a new dimension to our understanding of the T2DM and might be served as potential biomarkers that will be assisting endocrinologist in developing novel therapeutic strategies for T2DM patients. However, there are some limitations in this study. Further larger clinical sample size and in-depth clinical experiment are needed to clarify the clear mechanism and warrant the prognostic value of these DEGs in T2DM.

\section{Acknowledgement}

I thank Yurong Xin, Regeneron Pharmaceuticals, Inc., Tarrytown, New York, USA, very much, the author who deposited their profiling by high throughput sequencing dataset GSE81608, into the public GEO database.

\section{Conflict of interest}

The authors declare that they have no conflict of interest.

\section{Ethical approval}

This article does not contain any studies with human participants or animals performed by any of the authors.

\section{Informed consent}

No informed consent because this study does not contain human or animals participants. 


\section{Availability of data and materials}

The datasets supporting the conclusions of this article are available in the GEO (Gene Expression Omnibus) (https://www.ncbi.nlm.nih.gov/geo/) repository. [(GSE81608) (https://www.ncbi.nlm.nih.gov/geo/query/acc.cgi?acc=GSE81608)]

\section{Consent for publication}

Not applicable.

\section{Competing interests}

The authors declare that they have no competing interests.

\section{Author Contributions}

V. A - Methodology and validation

V. R - Formal analysis and validation

B. V - Writing original draft, and review and editing

C. V - Software and investigation

S. K - Supervision and resources

\section{Authors}

Varun Alur

ORCID ID: 0000-0002-0536-5223

Varshita Raju

ORCID ID: 0000-0003-1525-8453

Basavaraj Vastrad

ORCID ID: $\underline{0000-0003-2202-7637}$

Chanabasayya Vastrad

ORCID ID: $\underline{0000-0003-3615-4450}$

Shivakumar Kotturshetti

ORCID ID: 0000-0003-0504-1197

\section{References}

1. Caruso R, Magon A, Baroni I, Dellafiore F, Arrigoni C, Pittella F, Ausili D. Health literacy in type 2 diabetes patients: a systematic review of systematic reviews. Acta Diabetol. 2018;55(1):1-12. doi:10.1007/s00592-017-1071-1 
2. Gruss SM, Nhim K, Gregg E, Bell M, Luman E, Albright A. Public Health Approaches to Type 2 Diabetes Prevention: the US National Diabetes Prevention Program and Beyond. Curr Diab Rep. 2019;19(9):78. doi:10.1007/s11892-019-1200-z

3. Khan MAB, Hashim MJ, King JK, Govender RD, Mustafa H, Al Kaabi J. Epidemiology of Type 2 Diabetes - Global Burden of Disease and Forecasted Trends. J Epidemiol Glob Health. 2020;10(1):107-111. doi:10.2991/jegh.k.191028.001

4. Magliano DJ, Sacre JW, Harding JL, Gregg EW, Zimmet PZ, Shaw JE. Young-onset type 2 diabetes mellitus - implications for morbidity and mortality. Nat Rev Endocrinol. 2020;16(6):321-331. doi:10.1038/s41574020-0334-Z

5. Borzouei S, Soltanian AR. Application of an artificial neural network model for diagnosing type 2 diabetes mellitus and determining the relative importance of risk factors. Epidemiol Health. 2018;40:e2018007. doi:10.4178/epih.e2018007

6. Rojas J, Bermudez V, Palmar J, Martínez MS, Olivar LC, Nava M, Tomey D, Rojas M, Salazar J, Garicano C, et al. Pancreatic Beta Cell Death: Novel Potential Mechanisms in Diabetes Therapy. J Diabetes Res. 2018;2018:9601801. doi:10.1155/2018/9601801

7. Grarup N, Rose CS, Andersson EA, Andersen G, Nielsen AL, Albrechtsen A, Clausen JO, Rasmussen SS, Jørgensen T, Sandbaek A, et al. Studies of association of variants near the HHEX, CDKN2A/B, and IGF2BP2 genes with type 2 diabetes and impaired insulin release in 10,705 Danish subjects: validation and extension of genome-wide association studies. Diabetes. 2007;56(12):3105-3111. doi:10.2337/db07-0856

8. Pascoe L, Tura A, Patel SK, Ibrahim IM, Ferrannini E, Zeggini E, Weedon MN, Mari A, Hattersley AT, McCarthy MI, et al. Common variants of the novel type 2 diabetes genes CDKAL1 and HHEX/IDE are associated with decreased pancreatic beta-cell function. Diabetes. 2007;56(12):3101-3104. doi:10.2337/db07-0634

9. Shi H, Lu Y, Du J, Du W, Ye X, Yu X, Ma J, Cheng J, Gao Y, Cao Y, et al. Application of back propagation artificial neural network on genetic variants in adiponectin ADIPOQ, peroxisome proliferator-activated receptor- $\gamma$, and retinoid $X$ receptor- $\alpha$ genes and type 2 diabetes risk in a Chinese Han 
population. Diabetes Technol Ther. 2012;14(3):293-300. doi:10.1089/dia.2011.0071

10.Gloyn AL, Weedon MN, Owen KR, Turner MJ, Knight BA, Hitman G, Walker M, Levy JC, Sampson M, Halford S, et al. Large-scale association studies of variants in genes encoding the pancreatic beta-cell KATP channel subunits Kir6.2 (KCNJ11) and SUR1 (ABCC8) confirm that the KCNJ11 E23K variant is associated with type 2 diabetes. Diabetes. 2003;52(2):568572. doi:10.2337/diabetes.52.2.568

11.Zheng X, Ren W, Zhang S, Liu J, Li S, Li J, Yang P, He J, Su S, Li P. Association of type 2 diabetes susceptibility genes (TCF7L2, SLC30A8, PCSK1 and PCSK2) and proinsulin conversion in a Chinese population. Mol Biol Rep. 2012;39(1):17-23. doi:10.1007/s11033-011-0705-6

12.Li Y, Liu Y, Liang J, Wang T, Sun M, Zhang Z. Gymnemic Acid Ameliorates Hyperglycemia through PI3K/AKT- and AMPK-Mediated Signaling Pathways in Type 2 Diabetes Mellitus Rats. J Agric Food Chem. 2019;67(47):13051-13060. doi:10.1021/acs.jafc.9b04931

13. Suhara T, Baba Y, Shimada BK, Higa JK, Matsui T. The mTOR Signaling Pathway in Myocardial Dysfunction in Type 2 Diabetes Mellitus. Curr Diab Rep. 2017;17(6):38. doi:10.1007/s11892-017-0865-4

14.Mackenzie RW, Elliott BT. Akt/PKB activation and insulin signaling: a novel insulin signaling pathway in the treatment of type 2 diabetes. Diabetes Metab Syndr Obes. 2014;7:55-64. doi:10.2147/DMSO.S48260

15.Abo El-Nasr NME, Saleh DO, Mahmoud SS, Nofal SM, Abdelsalam RM, Safar MM, El-Abhar HS. Olmesartan attenuates type 2 diabetes-associated liver injury: Cross-talk of AGE/RAGE/JNK, STAT3/SCOS3 and RAS signaling pathways. Eur J Pharmacol. 2020;874:173010. doi:10.1016/j.ejphar.2020.173010

16. Ozaki KI, Awazu M, Tamiya M, Iwasaki Y, Harada A, Kugisaki S, Tanimura S, Kohno M. Targeting the ERK signaling pathway as a potential treatment for insulin resistance and type 2 diabetes. Am J Physiol Endocrinol Metab. 2016;310(8):E643-E651. doi:10.1152/ajpendo.00445.2015

17. Mao Y, Shen J, Lu Y, Lin K, Wang H, Li Y, Chang P, Walker MG, Li D. RNA sequencing analyses reveal novel differentially expressed genes and 
pathways in pancreatic cancer. Oncotarget. 2017;8(26):42537-42547. doi:10.18632/oncotarget.16451

18.Li X, Lin Z, Zhan X, Gao J, Sun L, Cao Y, Qiu H.RNA-seq analysis of the transcriptome of the liver of cynomolgus monkeys with type 2 diabetes. Gene. 2018;651:118-125. doi:10.1016/j.gene.2018.02.010

19. Clough E, Barrett T. The Gene Expression Omnibus Database. Methods Mol Biol. 2016;1418:93-110. doi:10.1007/978-1-4939-3578-9_5

20.Xin Y, Kim J, Okamoto H, Ni M, Wei Y, Adler C, Murphy AJ, Yancopoulos GD, Lin C, Gromada J. RNA Sequencing of Single Human Islet Cells Reveals Type 2 Diabetes Genes. Cell Metab. 2016;24(4):608-615. doi:10.1016/j.cmet.2016.08.018

21.Ritchie ME, Phipson B, Wu D, Hu Y, Law CW, Shi W, Smyth GK. limma powers differential expression analyses for RNA-sequencing and microarray studies. Nucleic Acids Res. 2015;43(7):e47. doi:10.1093/nar/gkv007

22. Thomas PD. The Gene Ontology and the Meaning of Biological Function. Methods Mol Biol. 2017;1446:15 $\square 24$. doi:10.1007/978-1-4939-3743-1_2

23.Fabregat A, Jupe S, Matthews L, Sidiropoulos K, Gillespie M, Garapati P, Haw R, Jassal B, Korninger F, May B et al The Reactome Pathway Knowledgebase. Nucleic Acids Res. 2018;46(D1):D649-D655. doi:10.1093/nar/gkx1132

24.Reimand J, Kull M, Peterson H, Hansen J, Vilo J. g:Profiler--a web-based toolset for functional profiling of gene lists from large-scale experiments. Nucleic Acids Res. 2007;35(Web Server issue):W193-W200. doi:10.1093/nar/gkm226

25.Kotlyar M, Pastrello C, Malik Z, Jurisica I. IID 2018 update: contextspecific physical protein-protein interactions in human, model organisms and domesticated species. Nucleic Acids Res. 2019;47(D1):D581-D589. doi:10.1093/nar/gky1037

26. Shannon P, Markiel A, Ozier O, Baliga NS, Wang JT, Ramage D, Amin N, Schwikowski B, Ideker T Cytoscape: a software environment for integrated models of biomolecular interaction networks. Genome Res 2003;13(11):2498-2504. doi:10.1101/gr.1239303

27.Przulj N, Wigle DA, Jurisica I. Functional topology in a network of protein interactions. Bioinformatics. 2004;20(3):340-348. doi:10.1093/bioinformatics/btg415 
28.Nguyen TP, Liu WC, Jordán F. Inferring pleiotropy by network analysis: linked diseases in the human PPI network. BMC Syst Biol. 2011;5:179. doi:10.1186/1752-0509-5-179

29. Shi Z, Zhang B. Fast network centrality analysis using GPUs. BMC Bioinformatics. 2011;12:149. doi:10.1186/1471-2105-12-149

30.Fadhal E, Gamieldien J, Mwambene EC. Protein interaction networks as metric spaces: a novel perspective on distribution of hubs. BMC Syst Biol. 2014;8:6. doi:10.1186/1752-0509-8-6

31.Zaki N, Efimov D, Berengueres J. Protein complex detection using interaction reliability assessment and weighted clustering coefficient. BMC Bioinformatics. 2013;14:163. doi:10.1186/1471-2105-14

32.Fan Y, Xia J (2018) miRNet-Functional Analysis and Visual Exploration of miRNA-Target Interactions in a Network Context. Methods Mol Biol 1819:215-233. doi:10.1007/978-1-4939-8618-7_10

33.Zhou G, Soufan O, Ewald J, Hancock REW, Basu N, Xia J (2019) NetworkAnalyst 3.0: a visual analytics platform for comprehensive gene expression profiling and meta-analysis. Nucleic Acids Res 47:W234-W241. doi:10.1093/nar/gkz240

34.Robin X, Turck N, Hainard A, Tiberti N, Lisacek F, Sanchez JC, Müller M. pROC: an open-source package for $\mathrm{R}$ and $\mathrm{S}+$ to analyze and compare ROC curves. BMC Bioinformatics 2011;12:77. doi:10.1186/1471-2105-12-77

35.Erfanian Omidvar M, Ghaedi H, Kazerouni F, Kalbasi S, Shanaki M, Miraalamy G, Zare A, Rahimipour A. Clinical significance of long noncoding RNA VIM-AS1 and CTBP1-AS2 expression in type 2 diabetes. J Cell Biochem. 2019;120(6):9315-9323. doi:10.1002/jcb.28206

36. Duraisamy P, Elango S, Vishwanandha VP, Balamurugan R. Prevalence of mitochondrial tRNA gene mutations and their association with specific clinical phenotypes in patients with type 2 diabetes mellitus of Coimbatore. Genet Test Mol Biomarkers. 2010;14(1):49-55. doi:10.1089/gtmb.2009.0024

37. Kumar U, Singh S. Role of Somatostatin in the Regulation of Central and Peripheral Factors of Satiety and Obesity. Int J Mol Sci. 2020;21(7):2568. doi:10.3390/ijms21072568

38.Gougeon R, Marliss EB, Jones PJ, Pencharz PB, Morais JA. Effect of exogenous insulin on protein metabolism with differing nonprotein energy 
intakes in Type 2 diabetes mellitus. Int $\mathbf{J}$ Obes Relat Metab Disord. 1998;22(3):250-261. doi:10.1038/sj.ijo.0800577

39. Yao K, Zeng L, He Q, Wang W, Lei J, Zou X. Effect of Probiotics on Glucose and Lipid Metabolism in Type 2 Diabetes Mellitus: A MetaAnalysis of 12 Randomized Controlled Trials. Med Sci Monit. 2017;23:3044-3053. doi:10.12659/msm.902600

40.Gaster M, Nehlin JO, Minet AD. Impaired TCA cycle flux in mitochondria in skeletal muscle from type 2 diabetic subjects: marker or maker of the diabetic phenotype?. Arch Physiol Biochem. 2012;118(3):156-189. doi:10.3109/13813455.2012.656653

41.Chung ST, Hsia DS, Chacko SK, Rodriguez LM, Haymond MW. Increased gluconeogenesis in youth with newly diagnosed type 2 diabetes. Diabetologia. 2015;58(3):596-603. doi:10.1007/s00125-014-3455-x

42.Daryabor G, Atashzar MR, Kabelitz D, Meri S, Kalantar K. The Effects of Type 2 Diabetes Mellitus on Organ Metabolism and the Immune System. Front Immunol. 2020;11:1582. doi:10.3389/fimmu.2020.01582

43.Wu WL, Hao J, Domalski M, Burnett DA, Pissarnitski D, Zhao Z, Stamford A, Scapin G, Gao YD, Soriano A, et al. Discovery of Novel Tricyclic Heterocycles as Potent and Selective DPP-4 Inhibitors for the Treatment of Type 2 Diabetes. ACS Med Chem Lett. 2016;7(5):498-501. doi:10.1021/acsmedchemlett.6b00027

44.Shoukry A, Bdeer Sel-A, El-Sokkary RH. Urinary monocyte chemoattractant protein-1 and vitamin D-binding protein as biomarkers for early detection of diabetic nephropathy in type 2 diabetes mellitus. Mol Cell Biochem. 2015;408(1-2):25-35. doi:10.1007/s11010-015-2479-y

45.Hearn T, Spalluto C, Phillips VJ, Renforth GL, Copin N, Hanley NA, Wilson DI. Subcellular localization of ALMS1 supports involvement of centrosome and basal body dysfunction in the pathogenesis of obesity, insulin resistance, and type 2 diabetes. Diabetes. 2005;54(5):1581-1587. doi:10.2337/diabetes.54.5.1581

46.Bouché C, Serdy S, Kahn CR, Goldfine AB. The cellular fate of glucose and its relevance in type 2 diabetes. Endocr Rev. 2004;25(5):807-830. doi:10.1210/er.2003-0026

47.Turner R, Stratton I, Horton V, Manley S, Zimmet P, Mackay IR, Shattock M, Bottazzo GF, Holman R. UKPDS 25: autoantibodies to islet-cell 
cytoplasm and glutamic acid decarboxylase for prediction of insulin requirement in type 2 diabetes. Lancet. 1997;350(9087):1288-1293. doi:10.1016/s0140-6736(97)03062-6

48. Cheung A, Kusari J, Jansen D, Bandyopadhyay D, Kusari A, Bryer-Ash M. Marked impairment of protein tyrosine phosphatase 1B activity in adipose tissue of obese subjects with and without type 2 diabetes mellitus. J Lab Clin Med. 1999;134(2):115-123. doi:10.1016/s0022-2143(99)90115-4

49. Wittenbecher C, Ouni M, Kuxhaus O, Jähnert M, Gottmann P, Teichmann A, Meidtner K, Kriebel J, Grallert H, Pischon T, et al. Insulin-Like Growth Factor Binding Protein 2 (IGFBP-2) and the Risk of Developing Type 2 Diabetes. Diabetes. 2019;68(1):188-197. doi:10.2337/db18-0620

50. Castro A, Lázaro I, Selva DM, Céspedes E, Girona J, NúriaPlana, Guardiola M, Cabré A, Simó R, Masana L. APOH is increased in the plasma and liver of type 2 diabetic patients with metabolic syndrome. Atherosclerosis. 2010;209(1):201-205. doi:10.1016/j.atherosclerosis.2009.09.072

51.Caron D, Boutchueng-Djidjou M, Tanguay RM, Faure RL. Annexin A2 is SUMOylated on its N-terminal domain: regulation by insulin. FEBS Lett. 2015;589(9):985-991. doi:10.1016/j.febslet.2015.03.007

52.Podestà F, Romeo G, Liu WH, Krajewski S, Reed JC, Gerhardinger C, Lorenzi M. Bax is increased in the retina of diabetic subjects and is associated with pericyte apoptosis in vivo and in vitro. Am J Pathol. 2000;156(3):1025-1032. doi:10.1016/S0002-9440(10)64970-X

53.Liu T, Zhao Y, Tang N, Feng R, Yang X, Lu N, Wen J, Li L. Pax6 directly down-regulates Pcsk1n expression thereby regulating $\mathrm{PC} 1 / 3$ dependent proinsulin processing. PLoS One. 2012;7(10):e46934. doi:10.1371/journal.pone.0046934

54.Kim YI, Lee FN, Choi WS, Lee S, Youn JH. Insulin regulation of skeletal muscle PDK4 mRNA expression is impaired in acute insulin-resistant states. Diabetes. 2006;55(8):2311-2317. doi:10.2337/db05-1606

55.Alsters SI, Goldstone AP, Buxton JL, Zekavati A, Sosinsky A, Yiorkas AM, Holder S, Klaber RE, Bridges N, van Haelst MM, et al. Truncating Homozygous Mutation of Carboxypeptidase E (CPE) in a Morbidly Obese Female with Type 2 Diabetes Mellitus, Intellectual Disability and Hypogonadotrophic Hypogonadism. PLoS One. 2015;10(6):e0131417. Published 2015 Jun 29. doi:10.1371/journal.pone.0131417 
56. Yu T, Lu XJ, Li JY, Shan TD, Huang CZ, Ouyang H, Yang HS, Xu JH, Zhong W, Xia ZS, et al. Overexpression of miR-429 impairs intestinal barrier function in diabetic mice by down-regulating occludin expression. Cell Tissue Res. 2016;366(2):341-352. doi:10.1007/s00441-016-2435-5

57.Kodama K, Horikoshi M, Toda K, Yamada S, Hara K, Irie J, Sirota M, Morgan AA, Chen R, Ohtsu $\mathrm{H}$, et al. Expression-based genome-wide association study links the receptor CD44 in adipose tissue with type 2 diabetes. Proc Natl Acad Sci U S A. 2012;109(18):7049-7054. doi:10.1073/pnas.1114513109

58. Goldfine AB, Crunkhorn S, Costello M, Gami H, Landaker EJ, Niinobe M, Yoshikawa K, Lo D, Warren A, Jimenez-Chillaron J, et al. Necdin and E2F4 are modulated by rosiglitazone therapy in diabetic human adipose and muscle tissue. Diabetes. 2006;55(3):640-650. doi:10.2337/diabetes.55.03.06.db05-1015

59.Mtiraoui N, Turki A, Nemr R, Echtay A, Izzidi I, Al-Zaben GS, IraniHakime N, Keleshian SH, Mahjoub T, Almawi WY. Contribution of common variants of ENPP1, IGF2BP2, KCNJ11, MLXIPL, PPAR $\gamma$, SLC30A8 and TCF7L2 to the risk of type 2 diabetes in Lebanese and Tunisian Arabs. Diabetes Metab. 2012;38(5):444-449. doi:10.1016/j.diabet.2012.05.002

60. Castelblanco E, Sanjurjo L, Falguera M, Hernández M, Fernandez-Real JM, Sarrias MR, Alonso N, Mauricio D.Circulating Soluble CD36 is Similar in Type 1 and Type 2 Diabetes Mellitus versus Non-Diabetic Subjects. J Clin Med. 2019;8(5):710. doi:10.3390/jcm8050710

61.Krause C, Sievert H, Geißler C, Grohs M, El Gammal AT, Wolter S, Ohlei O, Kilpert F, Krämer UM, Kasten M, et al. Critical evaluation of the DNAmethylation markers ABCG1 and SREBF1 for Type 2 diabetes stratification. Epigenomics. 2019;11(8):885-897. doi:10.2217/epi-2018-0159

62.Huang Q, Xue J, Zou R, Cai L, Chen J, Sun L, Dai Z, Yang F, Xu Y. NR4A1 is associated with chronic low-grade inflammation in patients with type 2 diabetes. Exp Ther Med. 2014;8(5):1648-1654. doi:10.3892/etm.2014.1958

63. Chang TJ, Chiu YF, Sheu WH, Shih KC, Hwu CM, Quertermous T, Jou YS, Kuo SS, Chang YC, Chuang LM. Genetic polymorphisms of PCSK2 are 
associated with glucose homeostasis and progression to type 2 diabetes in a Chinese population. Sci Rep. 2015;5:14380. doi:10.1038/srep14380

64.Herold Z, Herold M, Rosta K, Doleschall M, Somogyi A. Lower serum chromogranin B level is associated with type 1 diabetes and with type 2 diabetes patients with intensive conservative insulin treatment. Diabetol Metab Syndr. 2020;12:61. doi:10.1186/s13098-020-00569-5

65.Mayer AE, Löffler MC, Loza Valdés AE, Schmitz W, El-Merahbi R, Viera JT, Erk M, Zhang T, Braun U, Heikenwalder M, et al. The kinase PKD3 provides negative feedback on cholesterol and triglyceride synthesis by suppressing insulin signaling. Sci Signal. 2019;12(593):eaav9150. doi:10.1126/scisignal.aav9150

66.Zhang J, Zhang M, Yang Z, Huang S, Wu X, Cao L, Wang X, Li Q, Li N, Gao F. PDCD4 deficiency ameliorates left ventricular remodeling and insulin resistance in a rat model of type 2 diabetic cardiomyopathy. BMJ Open Diabetes Res Care. 2020;8(1):e001081. doi:10.1136/bmjdrc-2019001081

67.Mastracci TL, Colvin SC, Padgett LR, Mirmira RG. Hypusinated eIF5A is expressed in the pancreas and spleen of individuals with type 1 and type 2 diabetes. PLoS One. 2020;15(3):e0230627. doi:10.1371/journal.pone.0230627

68.Hoseini-Aghdam M, Sheikh V, Eftekharian MM, Rezaeepoor M, Behzad M. Enhanced expression of TIGIT but not neuropilin-1 in patients with type 2 diabetes mellitus. Immunol Lett. 2020;225:1-8. doi:10.1016/j.imlet.2020.06.003

69. Yoon HY, Lee MH, Song Y, Yee J, Song G, Gwak HS. ABCA1 69C>T Polymorphism and the Risk of Type 2 Diabetes Mellitus: A Systematic Review and Updated Meta-Analysis. Front Endocrinol (Lausanne). 2021;12:639524. doi:10.3389/fendo.2021.639524

70.Chen YT, Lin WD, Liao WL, Tsai YC, Liao JW, Tsai FJ. NT5C2 methylation regulatory interplay between DNMT1 and insulin receptor in type 2 diabetes. Sci Rep. 2020;10(1):16087. doi:10.1038/s41598-020-713369

71.Zhao H, Ma L, Yan M, Wang Y, Zhao T, Zhang H, Liu P, Liu Y, Li P. Association between MYH9 and APOL1 Gene Polymorphisms and the Risk of Diabetic Kidney Disease in Patients with Type 2 Diabetes in a Chinese 
Han Population. J Diabetes Res. 2018;2018:5068578. doi:10.1155/2018/5068578

72.Huang J, Zeng T, Tian Y, Wu Y, Yu J, Pei Z, Tan L. Clinical significance of high-mobility group box-1 (HMGB1) in subjects with type 2 diabetes mellitus (T2DM) combined with chronic obstructive pulmonary disease (COPD). J Clin Lab Anal. 2019;33(6):e22910. doi:10.1002/jcla.22910

73.Li SF, Zhu CS, Wang YM, Xie XX, Xiao LL, Zhang ZC, Tang QQ, Li X. Downregulation of $\beta 1,4$-galactosyltransferase 5 improves insulin resistance by promoting adipocyte commitment and reducing inflammation. Cell Death Dis. 2018;9(2):196. doi:10.1038/s41419-017-0239-5

74.Kim MK, Yun KJ, Chun HJ, Jang EH, Han KD, Park YM, Baek KH, Song $\mathrm{KH}$, Cha BY, Park CS, et al. Clinical utility of serum beta-2-microglobulin as a predictor of diabetic complications in patients with type 2 diabetes without renal impairment. Diabetes Metab. 2014;40(6):459-465. doi:10.1016/j.diabet.2014.08.002

75. Ye M, Li D, Yang J, Xie J, Yu F, Ma Y, Zhu X, Zhao J, Lv Z. MicroRNA130a Targets MAP3K12 to Modulate Diabetic Endothelial Progenitor Cell Function. Cell Physiol Biochem. 2015;36(2):712-726. doi:10.1159/000430132

76.Pearce LR, Atanassova N, Banton MC, Bottomley B, van der Klaauw AA, Revelli JP, Hendricks A, Keogh JM, Henning E, Doree D, et al. KSR2 mutations are associated with obesity, insulin resistance, and impaired cellular fuel oxidation. Cell. 2013;155(4):765-777. doi:10.1016/j.cell.2013.09.058

77.Nakhate KT, Yedke SU, Bharne AP, Subhedar NK, Kokare DM. Evidence for the involvement of neuropeptide $\mathrm{Y}$ in the antidepressant effect of imipramine in type 2 diabetes. Brain Res. 2016;1646:1-11. doi:10.1016/j.brainres.2016.05.035

78. Kogawa EM, Grisi DC, Falcão DP, Amorim IA, Rezende TM, da Silva IC, Silva ON, Franco OL, de Amorim RF. Impact of glycemic control on oral health status in type 2 diabetes individuals and its association with salivary and plasma levels of chromogranin A. Arch Oral Biol. 2016;62:10-19. doi:10.1016/j.archoralbio.2015.11.005 
79. Bitar MS. Diabetes Impairs Angiogenesis and Induces Endothelial Cell Senescence by Up-Regulating Thrombospondin-CD47-Dependent Signaling. Int J Mol Sci. 2019;20(3):673. doi:10.3390/ijms20030673

80.Kameswaran V, Golson ML, Ramos-Rodríguez M, Ou K, Wang YJ, Zhang J, Pasquali L, Kaestner KH. The Dysregulation of the DLK1-MEG3 Locus in Islets From Patients With Type 2 Diabetes Is Mimicked by Targeted Epimutation of Its Promoter With TALE-DNMT Constructs. Diabetes. 2018;67(9):1807-1815. doi:10.2337/db17-0682

81. Mori J, Alrob OA, Wagg CS, Harris RA, Lopaschuk GD, Oudit GY. ANG II causes insulin resistance and induces cardiac metabolic switch and inefficiency: a critical role of PDK4. Am J Physiol Heart Circ Physiol. 2013;304(8):H1103-H1113. doi:10.1152/ajpheart.00636.2012

82. Alsters SI, Goldstone AP, Buxton JL, Zekavati A, Sosinsky A, Yiorkas AM, Holder S, Klaber RE, Bridges $\mathrm{N}$, van Haelst $\mathrm{MM}$ et al. Truncating Homozygous Mutation of Carboxypeptidase E (CPE) in a Morbidly Obese Female with Type 2 Diabetes Mellitus, Intellectual Disability and Hypogonadotrophic Hypogonadism. PLoS One. 2015;10(6):e0131417. doi:10.1371/journal.pone.0131417

83. Yu T, Lu XJ, Li JY, Shan TD, Huang CZ, Ouyang H, Yang HS, Xu JH, Zhong W, Xia ZS, et al. Overexpression of miR-429 impairs intestinal barrier function in diabetic mice by down-regulating occludin expression. Cell Tissue Res. 2016;366(2):341-352. doi:10.1007/s00441-016-2435-5

84.Guan B, Zhan Z, Wang L, Wang L, Liu L. CXXC4 mediates glucoseinduced $\beta$-cell proliferation. Acta Diabetol. 2020;57(9):1101-1109. doi:10.1007/s00592-020-01525-5

85.Hartz CS, Nieman KM, Jacobs RL, Vance DE, Schalinske KL. Hepatic phosphatidylethanolamine $\mathrm{N}$-methyltransferase expression is increased in diabetic rats. J Nutr. 2006;136(12):3005-3009. doi:10.1093/jn/136.12.3005

86. Mazoochian L, Mohammad Sadeghi HM, Pourfarzam M. The effect of FADS2 gene rs174583 polymorphism on desaturase activities, fatty acid profile, insulin resistance, biochemical indices, and incidence of type 2 diabetes. J Res Med Sci. 2018;23:47. doi:10.4103/jrms.JRMS_961_17

87.Bonomo JA, Guan M, Ng MC, Palmer ND, Hicks PJ, Keaton JM, Lea JP, Langefeld CD, Freedman BI, Bowden DW. The ras responsive transcription factor RREB1 is a novel candidate gene for type 2 diabetes associated end- 
stage kidney disease. Hum Mol Genet. 2014;23(24):6441-6447. doi: $10.1093 / \mathrm{hmg} / \mathrm{ddu} 362$

88.Ghosh A, Abdo S, Zhao S, Wu CH, Shi Y, Lo CS, Chenier I, Alquier T, Filep JG, Ingelfinger JR, et al. Insulin Inhibits Nrf2 Gene Expression via Heterogeneous Nuclear Ribonucleoprotein $\mathrm{F} / \mathrm{K}$ in Diabetic Mice. Endocrinology. 2017;158(4):903-919. doi:10.1210/en.2016-1576

89.Hirota Y, Ohara T, Zenibayashi M, Kuno S, Fukuyama K, Teranishi T, Kouyama K, Miyake K, Maeda E, Kasuga M. Lack of association of CPT1A polymorphisms or haplotypes on hepatic lipid content or insulin resistance in Japanese individuals with type 2 diabetes mellitus. Metabolism. 2007;56(5):656-661. doi:10.1016/j.metabol.2006.12.014

90.Singh S, Chen Y, Matsumoto A, Orlicky DJ, Dong H, Thompson DC, Vasiliou V. ALDH1B1 links alcohol consumption and diabetes. Biochem Biophys Res Commun. 2015;463(4):768-773. doi:10.1016/j.bbrc.2015.06.011

91.Larsen LH, Rose CS, Sparsø T, Overgaard J, Torekov SS, Grarup N, Jensen DP, Albrechtsen A, Andersen G, Ek J, et al. Genetic analysis of the estrogen-related receptor alpha and studies of association with obesity and type 2 diabetes. Int J Obes (Lond). 2007;31(2):365-370. doi:10.1038/sj.ijo.0803408

92.Dong S, Blüher M, Zhang Y, Wu H, Alahari SK. Development of insulin resistance in Nischarin mutant female mice. Int $\mathbf{J}$ Obes (Lond). 2019;43(5):1046-1057. doi:10.1038/s41366-018-0241-8

93. Shah SK, He S, Guo L, Truong Q, Qi H, Du W, Lai Z, Liu J, Jian T, Hong Q, et al. Discovery of MK-1421, a Potent, Selective sstr3 Antagonist, as a Development Candidate for Type 2 Diabetes. ACS Med Chem Lett. 2015;6(5):513-517. Published 2015 Mar 18. doi:10.1021/ml500514w

94.Hattori Y, Nakajima K, Eizawa T, Ehara T, Koyama M, Hirai T, Fukuda Y, Kinoshita M. Heteroplasmic mitochondrial DNA 3310 mutation in NADH dehydrogenase subunit 1 associated with type 2 diabetes, hypertrophic cardiomyopathy, and mental retardation in a single patient. Diabetes Care. 2003;26(3):952-953. doi:10.2337/diacare.26.3.952

95.Cividini F, Scott BT, Suarez J, Casteel DE, Heinz S, Dai A, Diemer T, Suarez JA, Benner CW, Ghassemian M, et al. Ncor2/PPAR $\alpha$-Dependent Upregulation of MCUb in the Type 2 Diabetic Heart Impacts Cardiac 
Metabolic Flexibility and Function. Diabetes. 2021;70(3):665-679. doi: 10.2337/db20-0779

96.Zhang L, Cheng YL, Xue S, Xu ZG. The Role of Circulating RBP4 in the Type 2 Diabetes Patients with Kidney Diseases: A Systematic Review and Meta-Analysis. Dis 2020;2020:8830471. doi: $10.1155 / 2020 / 8830471$

97.Abbas S, Raza ST, S Mir S, Siddiqi Z, Mahdi F. No association of SNP $313 \mathrm{~A} \rightarrow \mathrm{G}$ in GSTP1 with nephropathy, hypertension and dyslipidemia in type 2 diabetes mellitus. $\mathrm{Br} \mathrm{J}$ Biomed Sci. 2019;76(3):153-155. doi:10.1080/09674845.2019.1595870

98.Huang K, Nair AK, Muller YL, Piaggi P, Bian L, Del Rosario M, Knowler WC, Kobes S, Hanson RL, Bogardus C, et al. Whole exome sequencing identifies variation in CYB5A and RNF10 associated with adiposity and type 2 diabetes. Obesity (Silver Spring). 2014;22(4):984-988. doi:10.1002/oby.20647

99. Shi Y, Li Y, Wang J, Wang C, Fan J, Zhao J, Yin L, Liu X, Zhang D, Li L. Meta-analyses of the association of G6PC2 allele variants with elevated fasting glucose and type 2 diabetes. PLoS One. 2017;12(7):e0181232. doi:10.1371/journal.pone.0181232

100. Minchenko DO, Davydov VV, Budreiko OA, Moliavko OS, Kulieshova DK, Tiazhka OV, Minchenko OH. The expression of CCN2, IQSEC, RSPO1, DNAJC15, RIPK2, IL13RA2, IRS1, and IRS2 genes in blood of obese boys with insulin resistance. Fiziol Zh. 2015;61(1):10-18. doi:10.15407/fz61.01.010

101. Wang X, Yang R, Jadhao SB, Yu D, Hu H, Glynn-Cunningham N, Sztalryd C, Silver KD, Gong DW. Transmembrane emp24 protein transport domain 6 is selectively expressed in pancreatic islets and implicated in insulin secretion and diabetes. Pancreas. 2012;41(1):10-14. doi:10.1097/MPA.0b013e318223c7e4

102. Chen M, Hu C, Zhang R, Jiang F, Wang J, Peng D, Tang S, Sun X, Yan J, Wang S, et al. A variant of PSMD6 is associated with the therapeutic efficacy of oral antidiabetic drugs in Chinese type 2 diabetes patients. Sci Rep. 2015;5:10701. doi:10.1038/srep10701

103. Cai R, Han J, Sun J, Huang R, Tian S, Shen Y, Dong X, Xia W, Wang S. Plasma Clusterin and the CLU Gene rs11136000 Variant Are Associated 
with Mild Cognitive Impairment in Type 2 Diabetic Patients. Front Aging Neurosci. 2016;8:179. doi:10.3389/fnagi.2016.00179

104. Kwanbunjan K, Panprathip P, Phosat C, Chumpathat N, Wechjakwen N, Puduang S, Auyyuenyong R, Henkel I, Schweigert FJ. Association of retinol binding protein 4 and transthyretin with triglyceride levels and insulin resistance in rural thais with high type 2 diabetes risk. BMC Endocr Disord. 2018;18(1):26. doi:10.1186/s12902-018-0254-2

105. Wondafrash DZ, Nire'a AT, Tafere GG, Desta DM, Berhe DA, Zewdie KA. Thioredoxin-Interacting Protein as a Novel Potential Therapeutic Target in Diabetes Mellitus and Its Underlying Complications. Diabetes Metab Syndr Obes. 2020;13:43-51. doi:10.2147/DMSO.S232221 106. Ying L, Zhang M, Ma X, Si Y, Li X, Su J, Yin J, Bao Y. Macrophage LAMTOR1 Deficiency Prevents Dietary Obesity and Insulin Resistance Through Inflammation-Induced Energy Expenditure. Front Cell Dev Biol. 2021;9:672032. doi:10.3389/fcell.2021.672032

107. Griffin JWD, Liu Y, Bradshaw PC, Wang K. In Silico Preliminary Association of Ammonia Metabolism Genes GLS, CPS1, and GLUL with Risk of Alzheimer's Disease, Major Depressive Disorder, and Type 2 Diabetes. J Mol Neurosci. 2018;64(3):385-396. doi:10.1007/s12031-0181035-0

108. Fougerat A, Pan X, Smutova V, Heveker N, Cairo CW, Issad T, Larrivée B, Medin JA, Pshezhetsky AV. Neuraminidase 1 activates insulin receptor and reverses insulin resistance in obese mice. Mol Metab. 2018;12:76-88. doi:10.1016/j.molmet.2018.03.017

109. Chiva-Blanch G, Peña E, Cubedo J, García-Arguinzonis M, Pané A, Gil PA, Perez A, Ortega E, Padró T, Badimon L. Molecular mapping of platelet hyperreactivity in diabetes: the stress proteins complex HSPA8/Hsp90/CSK2 $\alpha$ and platelet aggregation in diabetic and normal platelets. Transl Res. 2021;S1931-5244(21)00085-2. doi:10.1016/j.trs1.2021.04.003

110. Kazakova EV, Zghuang T, Li T, Fang Q, Han J, Qiao H. The Gas6 gene rs8191974 and Ap3s2 gene rs2028299 are associated with type 2 diabetes in the northern Chinese Han population. Acta Biochim Pol. 2017;64(2):227-231.doi:10.18388/abp.2016_1299 
111. Van der Schueren B, Vangoitsenhoven R, Geeraert B, De Keyzer D, Hulsmans M, Lannoo M, Huber HJ, Mathieu C, Holvoet P. Low cytochrome oxidase 4I1 links mitochondrial dysfunction to obesity and type 2 diabetes in humans and mice. Int $\mathbf{J}$ Obes (Lond). 2015;39(8):1254-1263. doi:10.1038/ijo.2015.58

112. Haynes V, Connor T, Tchernof A, Vidal H, Dubois S. Metallothionein 2a gene expression is increased in subcutaneous adipose tissue of type 2 diabetic patients. Mol Genet Metab. 2013;108(1):90-94. doi:10.1016/j.ymgme.2012.10.012

113. Ng MC, Tam CH, So WY, Ho JS, Chan AW, Lee HM, Wang Y, Lam VK, Chan JC, Ma RC. Implication of genetic variants near NEGR1, SEC16B, TMEM18, ETV5/DGKG, GNPDA2, LIN7C/BDNF, MTCH2, BCDIN3D/FAIM2, SH2B1, FTO, MC4R, and KCTD15 with obesity and type 2 diabetes in 7705 Chinese. J Clin Endocrinol Metab. 2010;95(5):24182425. doi:10.1210/jc.2009-2077

114. Subramanian VS, Krishnaswami CV, Damodaran C. HLA, ESD, GLOI, C3 and HP polymorphisms and juvenile insulin dependent diabetes mellitus in Tamil Nadu (south India). Diabetes Res Clin Pract. 1994;25(1):51-59. doi:10.1016/0168-8227(94)90161-9

115. Wei W, Li Y, Li Y, Li D. Adipose-specific knockout of ubiquitinconjugating enzyme E2L6 (Ube216) reduces diet-induced obesity, insulin resistance, and hepatic steatosis. J Pharmacol Sci. 2021;145(4):327-334. doi:10.1016/j.jphs.2020.12.008

116. Jacobs S, Schiller K, Jansen EH, Boeing H, Schulze MB, Kröger J. Evaluation of various biomarkers as potential mediators of the association between $\Delta 5$ desaturase, $\Delta 6$ desaturase, and stearoyl-CoA desaturase activity and incident type 2 diabetes in the European Prospective Investigation into Cancer and Nutrition-Potsdam Study. Am J Clin Nutr. 2015;102(1):155-164. doi:10.3945/ajcn.114.102707

117. Thameem F, Yang X, Permana PA, Wolford JK, Bogardus C, Prochazka M. Evaluation of the microsomal glutathione S-transferase 3 (MGST3) locus on 1q23 as a Type 2 diabetes susceptibility gene in Pima Indians. Hum Genet. 2003;113(4):353-358. doi:10.1007/s00439-003-0980-y 118. Ramprasath T, Murugan PS, Kalaiarasan E, Gomathi P, Rathinavel A, Selvam GS. Genetic association of Glutathione peroxidase-1 (GPx-1) and 
NAD(P)H:Quinone Oxidoreductase 1(NQO1) variants and their association of CAD in patients with type-2 diabetes. Mol Cell Biochem. 2012;361(12):143-150. doi:10.1007/s11010-011-1098-5

119. Payne F, Colnaghi R, Rocha N, Seth A, Harris J, Carpenter G, Bottomley WE, Wheeler E, Wong S, Saudek V, et al. Hypomorphism in human NSMCE2 linked to primordial dwarfism and insulin resistance. J Clin Invest. 2014;124(9):4028-4038. doi:10.1172/JCI73264

120. Liu QC, Zhuang ZH, Zeng K, Cheng ZJ, Gao F, Wang ZQ.

Prevalence of pancreatic diabetes in patients carrying mutations or polymorphisms of the PRSS1 gene in the Han population. Diabetes Technol Ther. 2009;11(12):799-804. doi:10.1089/dia.2009.0051

121. Quintela I, Barros F, Fernandez-Prieto M, Martinez-Regueiro R, Castro-Gago M, Carracedo A, Gomez-Lado C, Eiris J. Interstitial microdeletions including the chromosome band 4q13.2 and the UBA6 gene as possible causes of intellectual disability and behavior disorder. Am J Med Genet A. 2015;167A(12):3113-3120. doi:10.1002/ajmg.a.37291

122. Yuan Z, Jiao B, Hou L, Xiao T, Liu X, Wang J, Xu J, Zhou L, Yan X, Tang B, et al. Mutation analysis of the TIA1 gene in Chinese patients with amyotrophic lateral sclerosis and frontotemporal dementia. Neurobiol Aging. 2018;64:160.e9-160.e12. doi:10.1016/j.neurobiolaging.2017.12.017

123. Cacace R, Heeman B, Van Mossevelde S, De Roeck A, Hoogmartens J, De Rijk P, Gossye H, De Vos K, De Coster W, Strazisar M, et al. Loss of DPP6 in neurodegenerative dementia: a genetic player in the dysfunction of neuronal excitability. Acta Neuropathol. 2019;137(6):901-918. doi:10.1007/s00401-019-01976-3

124. Hao YH, Fountain MD Jr, Fon Tacer K, Xia F, Bi W, Kang SH, Patel A, Rosenfeld JA, Le Caignec C, Isidor B, et al. USP7 Acts as a Molecular Rheostat to Promote WASH-Dependent Endosomal Protein Recycling and Is Mutated in a Human Neurodevelopmental Disorder. Mol Cell. 2015;59(6):956-969. doi:10.1016/j.molcel.2015.07.033

125. Beckelman BC, Yang W, Kasica NP, Zimmermann HR, Zhou X, Keene CD, Ryazanov AG, Ma T. Genetic reduction of eEF2 kinase alleviates pathophysiology in Alzheimer's disease model mice. J Clin Invest. 2019;129(2):820-833. doi:10.1172/JCI122954 
126. Liu X, Chen KL, Wang Y, Huang YY, Chen SD, Dong Q, Cui M, Yu JT. A Novel ITM2B Mutation Associated with Familial Chinese Dementia. J Alzheimers Dis. 2021;10.3233/JAD-210176. doi:10.3233/JAD-210176

127. Sekiguchi F, Nasiri J, Sedghi M, Salehi M, Hosseinzadeh M, Okamoto N, Mizuguchi T, Nakashima M, Miyatake S, Takata A, et al. A novel homozygous DPH1 mutation causes intellectual disability and unique craniofacial features. J Hum Genet. 2018;63(4):487-491. doi:10.1038/s10038-017-0404-9

128. Castillon C, Gonzalez L, Domenichini F, Guyon S, Da Silva K, Durand C, Lestaevel P, Vaillend C, Laroche S, Barnier JV, et al. The intellectual disability PAK3 R67C mutation impacts cognitive functions and adult hippocampal neurogenesis. Hum Mol Genet. 2020;29(12):1950-1968. doi:10.1093/hmg/ddz296

129. O'Donnell-Luria AH, Pais LS, Faundes V, Wood JC, Sveden A, Luria V, Abou Jamra R, Accogli A, Amburgey K, Anderlid BM, et al. Heterozygous Variants in KMT2E Cause a Spectrum of Neurodevelopmental Disorders and Epilepsy. Am J Hum Genet. 2019;104(6):1210-1222. doi:10.1016/j.ajhg.2019.03.021

130. Coupland KG, Kim WS, Halliday GM, Hallupp M, Dobson-Stone C, Kwok JB. Role of the Long Non-Coding RNA MAPT-AS1 in Regulation of Microtubule Associated Protein Tau (MAPT) Expression in Parkinson's Disease. PLoS One. 2016;11(6):e0157924. doi:10.1371/journal.pone.0157924

131. Koufaris C, Alexandrou A, Tanteles GA, Anastasiadou V, Sismani C. A novel HCFC1 variant in male siblings with intellectual disability and microcephaly in the absence of cobalamin disorder. Biomed Rep. 2016;4(2):215-218. doi:10.3892/br.2015.559

132. Qvist P, Rajkumar AP, Redrobe JP, Nyegaard M, Christensen JH, Mors O, Wegener G, Didriksen M, Børglum AD. Mice heterozygous for an inactivated allele of the schizophrenia associated Brd1 gene display selective cognitive deficits with translational relevance to schizophrenia. Neurobiol Learn Mem. 2017;141:44-52. doi:10.1016/j.nlm.2017.03.009

133. Richter M, Murtaza N, Scharrenberg R, White SH, Johanns O, Walker S, Yuen RKC, Schwanke B, Bedürftig B, Henis M, et al. Altered TAOK2 activity causes autism-related neurodevelopmental and cognitive 
abnormalities through RhoA signaling. Mol Psychiatry. 2019;24(9):13291350. doi:10.1038/s41380-018-0025-5

134. Torres AK, Jara C, Olesen MA, Tapia-Rojas C. Pathologically phosphorylated tau at S396/404 (PHF-1) is accumulated inside of hippocampal synaptic mitochondria of aged Wild-type mice. Sci Rep. 2021;11(1):4448. doi:10.1038/s41598-021-83910-w

135. Jeong BH, Kim HJ, Lee KH, Carp RI, Kim YS. RARB and STMN2 polymorphisms are not associated with sporadic Creutzfeldt-Jakob disease (CJD) in the Korean population. Mol Biol Rep. 2014;41(4):2389-2395. doi:10.1007/s11033-014-3093-x

136. Bermejo-Bescós P, Martín-Aragón S, Jiménez-Aliaga K, Benedí J, Felici E, Gil P, Ribera JM, Villar AM. Processing of the platelet amyloid precursor protein in the mild cognitive impairment (MCI). Neurochem Res. 2013;38(7):1415-1423. doi:10.1007/s11064-013-1039-7

137. Ramon-Duaso C, Gener T, Consegal M, Fernández-Avilés C, Gallego JJ, Castarlenas L, Swanson MS, de la Torre R, Maldonado R, Puig MV, et al. Methylphenidate Attenuates the Cognitive and Mood Alterations Observed in Mbnl2 Knockout Mice and Reduces Microglia Overexpression. Cereb Cortex. 2019;29(7):2978-2997. doi:10.1093/cercor/bhy164

138. Guilarte TR. APLP1, Alzheimer's-like pathology and neurodegeneration in the frontal cortex of manganese-exposed non-human primates. $\quad$ Neurotoxicology. 2010;31(5):572-574. doi:10.1016/j.neuro.2010.02.004

139. Mukaetova-Ladinska EB, Xuereb JH, Garcia-Sierra F, Hurt J, Gertz HJ, Hills R, Brayne C, Huppert FA, Paykel ES, McGee MA, et al. Lewy body variant of Alzheimer's disease: selective neocortical loss of t-SNARE proteins and loss of MAP2 and alpha-synuclein in medial temporal lobe. ScientificWorldJournal. 2009;9:1463-1475. doi:10.1100/tsw.2009.151

140. Fazeli S, Motovali-Bashi M, Peymani M, Hashemi MS, Etemadifar M, Nasr-Esfahani MH, Ghaedi K. A compound downregulation of SRRM2 and miR-27a-3p with upregulation of miR-27b-3p in PBMCs of Parkinson's patients is associated with the early stage onset of disease. PLoS One. 2020;15(11):e0240855. doi:10.1371/journal.pone.0240855

141. Butler JM, Sharif U, Ali M, McKibbin M, Thompson JP, Gale R, Yang YC, Inglehearn C, Paraoan L. A missense variant in CST3 exerts a 
recessive effect on susceptibility to age-related macular degeneration resembling its association with Alzheimer's disease. Hum Genet. 2015;134(7):705-715. doi:10.1007/s00439-015-1552-7

142. Nackenoff AG, Hohman TJ, Neuner SM, Akers CS, Weitzel NC, Shostak A, Ferguson SM, Mobley B, Bennett DA, Schneider JA, et al. PLD3 is a neuronal lysosomal phospholipase $\mathrm{D}$ associated with $\beta$-amyloid plaques and cognitive function in Alzheimer's disease. PLoS Genet. 2021;17(4):e1009406. doi:10.1371/journal.pgen.1009406

143. Konyukh M, Delorme R, Chaste P, Leblond C, Lemière N, Nygren G, Anckarsäter H, Rastam M, Ståhlberg O, Amsellem F, et al. Variations of the candidate SEZ6L2 gene on Chromosome 16p11.2 in patients with autism spectrum disorders and in human populations. PLoS One. 2011;6(3):e17289. doi:10.1371/journal.pone.0017289

144. Hu X, Tang J, Lan X, Mi X. Increased expression of DOC2A in human and rat temporal lobe epilepsy. Epilepsy Res. 2019;151:78-84. doi:10.1016/j.eplepsyres.2019.02.008

145. Kaur H, Jajodia A, Grover S, Baghel R, Jain S, Kukreti R. Synergistic association of PI4KA and GRM3 genetic polymorphisms with poor antipsychotic response in south Indian schizophrenia patients with low severity of illness. Am J Med Genet B Neuropsychiatr Genet. 2014;165B(8):635-646. doi:10.1002/ajmg.b.32268

146. Nakamura K, Kodera H, Akita T, Shiina M, Kato M, Hoshino H, Terashima H, Osaka H, Nakamura S, Tohyama J, et al. De Novo mutations in GNAO1, encoding a Gao subunit of heterotrimeric $G$ proteins, cause epileptic encephalopathy. Am J Hum Genet. 2013;93(3):496-505. doi:10.1016/j.ajhg.2013.07.014

147. Liu Q, Zhu L, Liu X, Zheng J, Liu Y, Ruan X, Cao S, Cai H, Li Z, Xue Y. TRA2A-induced upregulation of LINC00662 regulates blood-brain barrier permeability by affecting ELK4 mRNA stability in Alzheimer's microenvironment. RNA Biol. 2020;17(9):1293-1308. doi:10.1080/15476286.2020.1756055

148. Obara Y, Imai T, Sato H, Takeda Y, Kato T, Ishii K. Midnolin is a novel regulator of parkin expression and is associated with Parkinson's Disease. Sci Rep. 2017;7(1):5885. doi:10.1038/s41598-017-05456-0 
149. Herrmann L, Wiegmann C, Arsalan-Werner A, Hilbrich I, Jäger C, Flach K, Suttkus A, Lachmann I, Arendt T, Holzer M. Hook proteins: association with Alzheimer pathology and regulatory role of hook3 in amyloid beta generation. PLoS One. 2015;10(3):e0119423. doi:10.1371/journal.pone.0119423

150. Ozgen HM, van Daalen E, Bolton PF, Maloney VK, Huang S, Cresswell L, van den Boogaard MJ, Eleveld MJ, van 't Slot R, Hochstenbach $\mathrm{R}$, et al. Copy number changes of the microcephalin 1 gene (MCPH1) in patients with autism spectrum disorders. Clin Genet. 2009;76(4):348-356. doi:10.1111/j.1399-0004.2009.01254.x

151. Masciullo M, Modoni A, Fattori F, Santoro M, Denora PS, Tonali P, Santorelli FM, Silvestri G. A novel mutation in the SACS gene associated with a complicated form of spastic ataxia. J Neurol. 2008;255(9):1429-1431. doi:10.1007/s00415-008-0936-1

152. Perrone F, Nguyen HP, Van Mossevelde S, Moisse M, Sieben A, Santens P, De Bleecker J, Vandenbulcke M, Engelborghs S, Baets J, et al. Investigating the role of ALS genes CHCHD10 and TUBA4A in Belgian FTD-ALS spectrum patients. Neurobiol Aging. 2017;51:177.e9-177.e16. doi:10.1016/j.neurobiolaging.2016.12.008

153. Su Y, Yang L, Li Z, Wang W, Xing M, Fang Y, Cheng Y, Lin GN, Cui D. The interaction of ASAH1 and NGF gene involving in neurotrophin signaling pathway contributes to schizophrenia susceptibility and psychopathology. Prog Neuropsychopharmacol Biol Psychiatry. 2021;104:110015. doi:10.1016/j.pnpbp.2020.110015

154. Zhao W, Gao X, Qiu S, Gao B, Gao S, Zhang X, Kang D, Han W, Dai P, Yuan Y. A subunit of V-ATPases, ATP6V1B2, underlies the pathology of intellectual disability. EBioMedicine. 2019;45:408-421. doi:10.1016/j.ebiom.2019.06.035

155. Iqbal Z, Tawamie H, Ba W, Reis A, Halak BA, Sticht H, Uebe S, Kasri NN, Riazuddin S, van Bokhoven $\mathrm{H}$, et al. Loss of function of SVBP leads to autosomal recessive intellectual disability, microcephaly, ataxia, and hypotonia. Genet Med. 2019;21(8):1790-1796. doi:10.1038/s41436-0180415-8

156. Gal J, Chen J, Katsumata Y, Fardo DW, Wang WX, Artiushin S, Price D, Anderson S, Patel E, Zhu H, et al. Detergent Insoluble Proteins and 
Inclusion Body-Like Structures Immunoreactive for PRKDC/DNAPK/DNA-PKcs, FTL, NNT, and AIFM1 in the Amygdala of Cognitively Impaired Elderly Persons. J Neuropathol Exp Neurol. 2018;77(1):21-39. doi:10.1093/jnen/nlx097

157. Wang KK, Yang Z, Sarkis G, Torres I, Raghavan V. Ubiquitin Cterminal hydrolase-L1 (UCH-L1) as a therapeutic and diagnostic target in neurodegeneration, neurotrauma and neuro-injuries. Expert Opin Ther Targets. 2017;21(6):627-638. doi:10.1080/14728222.2017.1321635

158. Stefanović M, Životić I, Stojković L, Dinčić E, Stanković A, Živković M. The association of genetic variants IL2RA rs2104286, IFI30 rs11554159 and IKZF3 rs12946510 with multiple sclerosis onset and severity in patients from Serbia. J Neuroimmunol. 2020;347:577346. doi:10.1016/j.jneuroim.2020.577346

159. Zahola P, Hanics J, Pintér A, Máté Z, Gáspárdy A, Hevesi Z, Echevarria D, Adori C, Barde S, Törőcsik B, et al. Secretagogin expression in the vertebrate brainstem with focus on the noradrenergic system and implications for Alzheimer's disease. Brain Struct Funct. 2019;224(6):20612078. doi:10.1007/s00429-019-01886-w

160. Bik-Multanowski M, Pietrzyk JJ, Midro A. MTRNR2L12: A Candidate Blood Marker of Early Alzheimer's Disease-Like Dementia in Adults with Down Syndrome. J Alzheimers Dis. 2015;46(1):145-150. doi:10.3233/JAD-143030

161. Mata IF, Leverenz JB, Weintraub D, Trojanowski JQ, Chen-Plotkin A, Van Deerlin VM, Ritz B, Rausch R, Factor SA, Wood-Siverio C, Quinn $\mathrm{JF}$, et al. GBA Variants are associated with a distinct pattern of cognitive deficits in Parkinson's disease. Mov Disord. 2016;31(1):95-102. doi:10.1002/mds.26359

162. Li KY, Xiang XJ, Song L, Chen J, Luo B, Wen QX, Zhong BR, Zhou GF, Deng XJ, Ma YL, et al. Mitochondrial TXN2 attenuates amyloidogenesis via selective inhibition of BACE1 expression. J Neurochem. 2021;157(4):1351-1365. doi:10.1111/jnc.15184

163. Payton A, Miyajima F, Ollier W, Rabbitt P, Pickles A, Weiss V, Pendleton N, Horan M. Investigation of a functional quinine oxidoreductase (NQO2) polymorphism and cognitive decline. Neurobiol Aging. 2010;31(2):351-352. doi:10.1016/j.neurobiolaging.2008.04.014 
164. Chai G, Webb A, Li C, Antaki D, Lee S, Breuss MW, Lang N, Stanley V, Anzenberg P, Yang X, et al. Mutations in Spliceosomal Genes PPIL1 and PRP17 Cause Neurodegenerative Pontocerebellar Hypoplasia with $\quad$ Microcephaly. Neuron. 2021;109(2):241-256.e9. doi:10.1016/j.neuron.2020.10.035

165. Tang Y, He Y, Li C, Mu W, Zou Y, Liu C, Qian S, Zhang F, Pan J, Wang $\mathrm{Y}$, et al. RPS3A positively regulates the mitochondrial function of human periaortic adipose tissue and is associated with coronary artery diseases. Cell Discov. 2018;4:52. doi:10.1038/s41421-018-0041-2

166. Zhou H, Li D, Zhu P, Ma Q, Toan S, Wang J, Hu S, Chen Y, Zhang Y. Inhibitory effect of melatonin on necroptosis via repressing the Ripk3PGAM5-CypD-mPTP pathway attenuates cardiac microvascular ischemiareperfusion injury. J Pineal Res. 2018;65(3):e12503. doi:10.1111/jpi.12503

167. Linke AT, Marchant B, Marsh P, Frampton G, Murphy J, Rose ML. Screening of a HUVEC cDNA library with transplant-associated coronary artery disease sera identifies RPL7 as a candidate autoantigen associated with this disease. Clin Exp Immunol. 2001;126(1):173-179. doi:10.1046/j.1365-2249.2001.01654.x

168. Song YF, Zhao L, Wang BC, Sun JJ, Hu JL, Zhu XL, Zhao J, Zheng DK, Ge ZW. The circular RNA TLK1 exacerbates myocardial ischemia/reperfusion injury via targeting miR-214/RIPK1 through TNF signaling pathway. Free Radic Biol Med. 2020;155:69-80. doi:10.1016/j.freeradbiomed.2020.05.013

169. Franco C, Hou G, Ahmad PJ, Fu EY, Koh L, Vogel WF, Bendeck MP. Discoidin domain receptor 1 (ddr1) deletion decreases atherosclerosis by accelerating matrix accumulation and reducing inflammation in lowdensity lipoprotein receptor-deficient mice. Circ Res. 2008;102(10):12021211. doi:10.1161/CIRCRESAHA.107.170662

170. Zhang JY, Yang Z, Fang K, Shi ZL, Ren DH, Sun J. Long noncoding RNA ILF3-AS1 regulates myocardial infarction via the miR-212-3p/SIRT1 axis and PI3K/Akt signaling pathway. Eur Rev Med Pharmacol Sci. 2020;24(5):2647-2658. doi:10.26355/eurrev_202003_20534

171. Li L, Chen Q, Feng C, Jin Y, Xia S. Aberrant expression of TNRC6a and miR-21 during myocardial infarction. 3 Biotech. 2019;9(7):285. doi:10.1007/s13205-019-1812-7 
172. Shyu HY, Fong CS, Fu YP, Shieh JC, Yin JH, Chang CY, Wang HW, Cheng CW. Genotype polymorphisms of GGCX, NQO1, and VKORC1 genes associated with risk susceptibility in patients with large-artery atherosclerotic stroke. Clin Chim Acta. 2010;411(11-12):840-845. doi:10.1016/j.cca.2010.02.071

173. Mofid A, Newman NS, Lee PJ, Abbasi C, Matkar PN, Rudenko D, Kuliszewski MA, Chen HH, Afrasiabi K, Tsoporis JN, et al. Cardiac Overexpression of S100A6 Attenuates Cardiomyocyte Apoptosis and Reduces Infarct Size After Myocardial Ischemia-Reperfusion. J Am Heart Assoc. 2017;6(2):e004738. doi:10.1161/JAHA.116.004738

174. Wang L, Hauser ER, Shah SH, Seo D, Sivashanmugam P, Exum ST, Gregory SG, Granger CB, Haines JL, Jones CJ, et al. Polymorphisms of the tumor suppressor gene LSAMP are associated with left main coronary artery disease. Ann Hum Genet. 2008;72(Pt 4):443-453. doi:10.1111/j.14691809.2008.00433.x

175. Christophersen IE, Olesen MS, Liang B, Andersen MN, Larsen AP, Nielsen JB, Haunsø S, Olesen SP, Tveit A, Svendsen JH, et al. Genetic variation in KCNA5: impact on the atrial-specific potassium current IKur in patients with lone atrial fibrillation. Eur Heart J. 2013;34(20):1517-1525. doi:10.1093/eurheartj/ehs442

176. Gao G, Dudley SC Jr. RBM25/LUC7L3 function in cardiac sodium channel splicing regulation of human heart failure. Trends Cardiovasc Med. 2013;23(1):5-8. doi:10.1016/j.tcm.2012.08.003

177. Frazier AE, Compton AG, Kishita Y, Hock DH, Welch AE, Amarasekera SSC, Rius R, Formosa LE, Imai-Okazaki A, Francis D, et al. Fatal perinatal mitochondrial cardiac failure caused by recurrent de novo duplications in the ATAD3 locus. Med (N Y). 2021;2(1):49-73. doi:10.1016/j.medj.2020.06.004

178. Ortiz-Sánchez P, Villalba-Orero M, López-Olañeta MM, LarrasaAlonso J, Sánchez-Cabo F, Martí-Gómez C, Camafeita E, Gómez-Salinero JM, Ramos-Hernández L, Nielsen PJ, et al. Loss of SRSF3 in Cardiomyocytes Leads to Decapping of Contraction-Related mRNAs and Severe Systolic Dysfunction. Circ Res. 2019;125(2):170-183. doi:10.1161/CIRCRESAHA.118.314515 
179. Zaglia T, Ceriotti P, Campo A, Borile G, Armani A, Carullo P, Prando V, Coppini R, Vida V, Stølen TO, et al. Content of mitochondrial calcium uniporter (MCU) in cardiomyocytes is regulated by microRNA-1 in physiologic and pathologic hypertrophy. Proc Natl Acad Sci U S A. 2017;114(43):E9006-E9015. doi:10.1073/pnas.1708772114

180. Angrisano T, Schiattarella GG, Keller S, Pironti G, Florio E, Magliulo

F, Bottino R, Pero R, Lembo F, Avvedimento EV, et al. Epigenetic switch at atp2a2 and myh7 gene promoters in pressure overload-induced heart failure. PLoS One. 2014;9(9):e106024. doi:10.1371/journal.pone.0106024

181. Zhang J, Ma L, Zhang J, Huang J, Wei G, Liu L, Zhang J, Yan B.Altered expression of lysosomal hydrolase, acid $\alpha$-glucosidase, gene in coronary artery disease. Coron Artery Dis. 2016;27(2):104-108. doi:10.1097/MCA.0000000000000322

182. Zhang Q, Wang F, Wang F, Wu N. Long noncoding RNA MAGI1IT1 regulates cardiac hypertrophy by modulating miR302e/DKK1/Wnt/beta-catenin signaling pathway. J Cell Physiol. 2020;235(1):245-253. doi:10.1002/jcp.28964

183. Tao Z, Cao Z, Wang X, Pan D, Jia Q. Long noncoding RNA SNHG14 regulates ox-LDL-induced atherosclerosis cell proliferation and apoptosis by targeting miR-186-5p/WIPF2 axis. Hum Exp Toxicol. 2021;40(1):47-59. doi:10.1177/0960327120940363

184. Akao H, Polisecki E, Kajinami K, Trompet S, Robertson M, Ford I, Jukema JW, de Craen AJ, Westendorp RG, Shepherd J, et al. KIF6, LPA, TAS2R50, and VAMP8 genetic variation, low density lipoprotein cholesterol lowering response to pravastatin, and heart disease risk reduction in the elderly. Atherosclerosis. 2012;220(2):456-462. doi:10.1016/j.atherosclerosis.2011.11.037

185. Gong Z, Ye Q, Wu JW, Zhou JL, Kong XY, Ma LK. UCHL1 inhibition attenuates cardiac fibrosis via modulation of nuclear factor- $\kappa \mathrm{B}$ signaling in fibroblasts. Eur J Pharmacol. 2021;900:174045. doi:10.1016/j.ejphar.2021.174045

186. Zhu J, Xu Y, Ren G, Hu X, Wang C, Yang Z, Li Z, Mao W, Lu D. Tanshinone IIA Sodium sulfonate regulates antioxidant system, inflammation, and endothelial dysfunction in atherosclerosis by 
downregulation of CLIC1. Eur J Pharmacol. 2017;815:427-436. doi:10.1016/j.ejphar.2017.09.047

187. Cai Y, Yu SS, He Y, Bi XY, Gao S, Yan TD, Zheng GD, Chen TT, Ye JT, Liu PQ. EGCG inhibits pressure overload-induced cardiac hypertrophy via the PSMB5/Nmnat2/SIRT6-dependent signalling pathways. Acta Physiol (Oxf). 2021;231(4):e13602. doi:10.1111/apha.13602

188. Ye M, Guo XJ, Kan KJ, Ni QH, Chen JQ, Wang H, Qian X, Xue GH, Deng HY, Zhang L. Loss of GRB2 associated binding protein 1 in arteriosclerosis obliterans promotes host autophagy. Chin Med J (Engl). 2020;134(1):73-80. doi:10.1097/CM9.0000000000001255

189. Galant D, Gaborit B, Desgrouas C, Abdesselam I, Bernard M, Levy N, Merono F, Coirault C, Roll P, Lagarde A, et al. A Heterozygous ZMPSTE24 Mutation Associated with Severe Metabolic Syndrome, Ectopic Fat Accumulation, and Dilated Cardiomyopathy. Cells. 2016;5(2):21. doi:10.3390/cells5020021

190. Abdulhag UN, Soiferman D, Schueler-Furman O, Miller C, Shaag A, Elpeleg O, Edvardson S, Saada A. Mitochondrial complex IV deficiency, caused by mutated COX6B1, is associated with encephalomyopathy, hydrocephalus and cardiomyopathy. Eur J Hum Genet. 2015;23(2):159-164. doi:10.1038/ejhg.2014.85

191. Jeong SJ, Zhang X, Rodriguez-Velez A, Evans TD, Razani B. p62/SQSTM1 and Selective Autophagy in Cardiometabolic Diseases. Antioxid Redox Signal. 2019;31(6):458-471. doi:10.1089/ars.2018.7649

192. Tan DX, Chen XX, Bai TZ, Zhang J, Li ZF. Sevoflurane up-regulates microRNA-204 to ameliorate myocardial ischemia/reperfusion injury in mice by suppressing Cotl1. Life Sci. 2020;259:118162. doi:10.1016/j.lfs.2020.118162

193. Murakami T, Komiyama Y, Masuda M, Kido H, Nomura S, Fukuhara $\mathrm{S}$, Karakawa M, Iwasaka T, Takahashi H. Flow cytometric analysis of platelet activation markers CD62P and CD63 in patients with coronary artery disease. Eur J Clin Invest. 1996;26(11):996-1003. doi:10.1046/j.13652362.1996.2360585.x

194. Correia SP, Moedas MF, Naess K, Bruhn H, Maffezzini C, CalvoGarrido J, Lesko N, Wibom R, Schober FA, Jemt A, et al. Severe congenital lactic acidosis and hypertrophic cardiomyopathy caused by an intronic 
variant in NDUFB7. Hum Mutat. 2021;42(4):378-384. doi:10.1002/humu.24173

195. Accornero F, Schips TG, Petrosino JM, Gu SQ, Kanisicak O, van Berlo JH, Molkentin JD. BEX1 is an RNA-dependent mediator of cardiomyopathy. Nat Commun. 2017;8(1):1875. doi:10.1038/s41467-01702005-1

196. Shen Y, Peng C, Bai Q, Ding Y, Yi X, Du H, He L, Zhou D, Chen X. Epigenome-Wide Association Study Indicates Hypomethylation of MTRNR2L8 in Large-Artery Atherosclerosis Stroke. Stroke. 2019;50(6):1330-1338. doi:10.1161/STROKEAHA.118.023436

197. Howson JM, Walker NM, Clayton D, Todd JA. Type 1 Diabetes Genetics Consortium. Confirmation of HLA class II independent type 1 diabetes associations in the major histocompatibility complex including HLA-B and HLA-A. Diabetes Obes Metab. 2009;11 Suppl 1(Suppl 1):3145. doi:10.1111/j.1463-1326.2008.01001.x

198. Bus P, Scharpfenecker M, Van Der Wilk P, Wolterbeek R, Bruijn JA, Baelde HJ. The VEGF-A inhibitor sFLT-1 improves renal function by reducing endothelial activation and inflammation in a mouse model of type 1 diabetes. Diabetologia. 2017;60(9):1813-1821. doi:10.1007/s00125-0174322-3

199. Plagnol V, Smyth DJ, Todd JA, Clayton DG. Statistical independence of the colocalized association signals for type 1 diabetes and RPS26 gene expression on chromosome 12q13. Biostatistics. 2009;10(2):327-334. doi:10.1093/biostatistics/kxn039

200. Westerweel PE, van Velthoven CT, Nguyen TQ, den Ouden K, de Kleijn DP, Goumans MJ, Goldschmeding R, Verhaar MC. Modulation of TGF- $\beta$ /BMP-6 expression and increased levels of circulating smooth muscle progenitor cells in a type I diabetes mouse model. Cardiovasc Diabetol. 2010;9:55. Published 2010 Sep 21. doi:10.1186/1475-2840-9-55

201. Mikk ML, Kiviniemi M, Laine AP, Härkönen T, Veijola R, Simell O, Knip M, Ilonen J. The HLA-B*39 allele increases type 1 diabetes risk conferred by HLA-DRB1*04:04-DQB $1 * 03: 02$ and HLA-DRB1*08DQB1*04 class II haplotypes. Hum Immunol. 2014;75(1):65-70. doi:10.1016/j.humimm.2013.09.008 
202. Shalev SA, Tenenbaum-Rakover Y, Horovitz Y, Paz VP, Ye H, Carmody D, Highland HM, Boerwinkle E, Hanis CL, Muzny DM, et al. Microcephaly, epilepsy, and neonatal diabetes due to compound heterozygous mutations in IER3IP1: insights into the natural history of a rare disorder. Pediatr Diabetes. 2014;15(3):252-256. doi:10.1111/pedi.12086

203. Guo M, Zhang T, Dong X, Xiang JZ, Lei M, Evans T, Graumann J, Chen S. Using hESCs to Probe the Interaction of the Diabetes-Associated Genes CDKAL1 and MT1E. Cell Rep. 2017;19(8):1512-1521. doi:10.1016/j.celrep.2017.04.070

204. Afreh-Mensah D, Agwu JC. Coexistence of medium chain acyl-CoA dehydrogenase deficiency (MCADD) and type 1 diabetes (T1D): a management challenge. BMJ Case Rep. 2021;14(3):e239325. doi:10.1136/bcr-2020-239325

205. Blatnik M, Thorpe SR, Baynes JW. Succination of proteins by fumarate: mechanism of inactivation of glyceraldehyde-3-phosphate dehydrogenase in diabetes. Ann N Y Acad Sci. 2008;1126:272-275. doi:10.1196/annals.1433.047

206. Gao X, van der Veen JN, Zhu L, Chaba T, Ordoñez M, Lingrell S, Koonen DP, Dyck JR, Gomez-Muñoz A, Vance DE, et al. Vagus nerve contributes to the development of steatohepatitis and obesity in phosphatidylethanolamine N-methyltransferase deficient mice. J Hepatol. 2015;62(4):913-920. doi:10.1016/j.jhep.2014.11.026

207. Khan R, Raza SHA, Junjvlieke Z, Xiaoyu W, Garcia M, Elnour IE, Hongbao W, Linsen Z. Function and Transcriptional Regulation of Bovine TORC2 Gene in Adipocytes: Roles of C/EBP, XBP1, INSM1 and ZNF263. Int J Mol Sci. 2019;20(18):4338. doi:10.3390/ijms20184338

208. Senagolage MD, Sommars MA, Ramachandran K, Futtner CR, Omura Y, Allred AL, Wang J, Yang C, Procissi D, Evans RM, et al. Loss of Transcriptional Repression by BCL6 Confers Insulin Sensitivity in the Setting of Obesity. Cell Rep. 2018;25(12):3283-3298.e6. doi:10.1016/j.celrep.2018.11.074

209. Zhou Y, Hambly BD, Simmons D, McLachlan CS. RUNX1T1 rs34269950 is associated with obesity and metabolic syndrome. QJM. 2020; hcaa208. doi:10.1093/qjmed/hcaa208 
210. Galmozzi A, Kok BP, Kim AS, Montenegro-Burke JR, Lee JY, Spreafico R, Mosure S, Albert V, Cintron-Colon R, Godio C, et al. PGRMC2 is an intracellular haem chaperone critical for adipocyte function. Nature. 2019;576(7785):138-142. doi:10.1038/s41586-019-1774-2

211. Sonmez FM, Uctepe E, Gunduz M, Gormez Z, Erpolat S, Oznur M, Sagiroglu MS, Demirci H, Gunduz E. Coffin-Siris syndrome with café-aulait spots, obesity and hyperinsulinism caused by a mutation in the ARID1B gene. Intractable Rare Dis Res. 2016;5(3):222-226. doi:10.5582/irdr.2014.01040

212. Jia G, Sowers JR. Targeting CITED2 for Angiogenesis in Obesity and Insulin Resistance. Diabetes. 2016;65(12):3535-3536. doi:10.2337/dbi160052

213. Koh IU, Lee HJ, Hwang JY, Choi NH, Lee S. Obesity-related CpG Methylation (cg07814318) of Kruppel-like Factor-13 (KLF13) Gene with Childhood Obesity and its cis-Methylation Quantitative Loci. Sci Rep. 2017;7:45368. doi:10.1038/srep45368

214. Liu Y, Zhao W, Gu G, Lu L, Feng J, Guo Q, Ding Z. Palmitoylprotein thioesterase 1 (PPT1): an obesity-induced rat testicular marker of reduced fertility. Mol Reprod Dev. 2014;81(1):55-65. doi:10.1002/mrd.22281

215. Patwari P, Emilsson V, Schadt EE, Chutkow WA, Lee S, Marsili A, Zhang Y, Dobrin R, Cohen DE, Larsen PR, et al. The arrestin domaincontaining 3 protein regulates body mass and energy expenditure. Cell Metab. 2011;14(5):671-683. doi:10.1016/j.cmet.2011.08.011

216. Xiang R, Fan LL, Huang H, Chen YQ, He W, Guo S, Li JJ, Jin JY, Du R, Yan R, et al. Increased Reticulon 3 (RTN3) Leads to Obesity and Hypertriglyceridemia by Interacting With Heat Shock Protein Family A (Hsp70) Member 5 (HSPA5). Circulation. 2018;138(17):1828-1838. doi:10.1161/CIRCULATIONAHA.117.030718

217. Kim EY, Han BS, Kim WK, Lee SC, Bae KH. Acceleration of adipogenic differentiation via acetylation of malate dehydrogenase 2 . Biochem Biophys Res Commun. 2013;441(1):77-82. doi:10.1016/j.bbrc.2013.10.016

218. Ostergaard E, Weraarpachai W, Ravn K, Born AP, Jønson L, Duno M, Wibrand F, Shoubridge EA, Vissing J. Mutations in COA3 cause 
isolated complex IV deficiency associated with neuropathy, exercise intolerance, obesity, and short stature. J Med Genet. 2015;52(3):203-207. doi:10.1136/jmedgenet-2014-102914

219. Simon CM, Rauskolb S, Gunnersen JM, Holtmann B, Drepper C, Dombert B, Braga M, Wiese S, Jablonka S, Pühringer D, et al. Dysregulated IGFBP5 expression causes axon degeneration and motoneuron loss in diabetic neuropathy. Acta Neuropathol. 2015;130(3):373-387. doi:10.1007/s00401-015-1446-8

220. Zhang Q, Hu Y, Hu JE, Ding Y, Shen Y, Xu H, Chen H, Wu N. Sp1mediated upregulation of Prdx6 expression prevents podocyte injury in diabetic nephropathy via mitigation of oxidative stress and ferroptosis. Life Sci. 2021;278:119529. doi:10.1016/j.lfs.2021.119529

221. Qi W, Keenan HA, Li Q, Ishikado A, Kannt A, Sadowski T, Yorek MA, Wu IH, Lockhart S, Coppey LJ, et al. Pyruvate kinase M2 activation may protect against the progression of diabetic glomerular pathology and mitochondrial dysfunction. Nat Med. 2017;23(6):753-762. doi:10.1038/nm.4328

222. Jia C, Ke-Hong C, Fei X, Huan-Zi D, Jie Y, Li-Ming W, Xiao-Yue W, Jian-Guo Z, Ya-Ni H. Decoy receptor 2 mediation of the senescent phenotype of tubular cells by interacting with peroxiredoxin 1 presents a novel mechanism of renal fibrosis in diabetic nephropathy. Kidney Int. 2020;98(3):645-662. doi:10.1016/j.kint.2020.03.026

223. Mao R, Shen J, Hu X. BMSCs-derived exosomal microRNA-let-7a plays a protective role in diabetic nephropathy via inhibition of USP22 expression. Life Sci. 2021;268:118937. doi:10.1016/j.lfs.2020.118937

224. Durgin BG, Hahn SA, Schmidt HM, Miller MP, Hafeez N, Mathar I, Freitag D, Sandner P, Straub AC. Loss of smooth muscle CYB5R3 amplifies angiotensin II-induced hypertension by increasing sGC heme oxidation. JCI Insight. 2019;4(19):e129183. doi:10.1172/jci.insight.129183

225. Zhang L, Sun Y, Zhang X, Shan X, Li J, Yao Y, Shu Y, Lin K, Huang $\mathrm{X}$, Yang Z, et al. Three novel genetic variants in the FAM110D, CACNA1A and NLRP12 genes are associated with susceptibility to hypertension among Dai people. Am J Hypertens. 2021; hpab040. doi:10.1093/ajh/hpab040

226. Hamada AM, Yamamoto I, Nakada Y, Kobayashi A, Koike Y, Miki J, Yamada H, Tanno Y, Ohkido I, Tsuboi N, et al. Association Between 
GLCCI1 Promoter Polymorphism (Rs37972) and Post-Transplant Hypertension in Renal Transplant Recipients. Kidney Blood Press Res. 2017;42(6):1155-1163. doi:10.1159/000485862

227. Gong Y, Yu M, Yang J, Gonzales E, Perez R, Hou M, Tripathi P, Hering-Smith KS, Hamm LL, Hou J. The Cap1-claudin-4 regulatory pathway is important for renal chloride reabsorption and blood pressure regulation. Proc Natl Acad Sci U S A. 2014;111(36):E3766-E3774. doi:10.1073/pnas.1406741111

228. Li M, Mulkey F, Jiang C, O'Neil BH, Schneider BP, Shen F, Friedman PN, Momozawa Y, Kubo M, Niedzwiecki D, et al. Identification of a Genomic Region between SLC29A1 and HSP90AB1 Associated with Risk of Bevacizumab-Induced Hypertension: CALGB 80405 (Alliance). Clin Cancer Res. 2018;24(19):4734-4744. doi:10.1158/1078-0432.CCR-171523

229. Lin R, Wang $\mathrm{X}$, Zhou W, Fu W, Wang Y, Huang W, Jin L. Association of a BLVRA common polymorphism with essential hypertension and blood pressure in Kazaks. Clin Exp Hypertens. 2011;33(5):294-298. doi:10.3109/10641963.2010.531854

230. Schweigert O, Adler J, Längst N, Aïssi D, Duque Escobar J, Tong T, Müller C, Trégouët DA, Lukowski R, Zeller T. CRIP1 expression in monocytes related to hypertension. Clin Sci (Lond). 2021;135(7):911-924. doi:10.1042/CS20201372

231. Collares CV, Evangelista AF, Xavier DJ, Rassi DM, Arns T, FossFreitas MC, Foss MC, Puthier D, Sakamoto-Hojo ET, Passos GA, et al. Identifying common and specific microRNAs expressed in peripheral blood mononuclear cell of type 1, type 2, and gestational diabetes mellitus patients. BMC Res Notes. 2013;6:491. doi:10.1186/1756-0500-6-491

232. Catanzaro G, Besharat ZM, Chiacchiarini M, Abballe L, Sabato C, Vacca A, Borgiani P, Dotta F, Tesauro M, Po A, et al. Circulating MicroRNAs in Elderly Type 2 Diabetic Patients. Int J Endocrinol. 2018;2018:6872635. doi:10.1155/2018/6872635

233. Sawaf ES, Saleh S, Abdallah DM, Ahmed KA, El-Abhar HS. Vitamin $\mathrm{D}$ and rosuvastatin obliterate peripheral neuropathy in a type-2 diabetes model through modulating Notch1, Wnt-10 $\alpha$, TGF- $\beta$ and NRF-1 crosstalk. Life Sci. 2021;279:119697. doi:10.1016/j.lfs.2021.119697 
234. Villegas R, Williams S, Gao Y, Cai Q, Li H, Elasy T, Cai H, Edwards T, Xiang YB, Zheng W, et al. Peroxisome proliferator-activated receptor delta (PPARD) genetic variation and type 2 diabetes in middle-aged Chinese women. Ann Hum Genet. 2011;75(5):621-629. doi:10.1111/j.14691809.2011.00669.X

235. Huang Y, Jin L, Yu H, Jiang G, Tam CHT, Jiang S, Zheng C, Jiang F, Zhang R, Zhang $\mathrm{H}$, et al. al. SNPs in PRKCA-HIF1A-GLUT1 are associated with diabetic kidney disease in a Chinese Han population with type 2 diabetes. Eur J Clin Invest. 2020;50(9):e13264. doi:10.1111/eci.13264

236. Zhang G, Li H, Zhao W, Li M, Tian L, Ju W, Li X. miR-205 regulates bone turnover in elderly female patients with type 2 diabetes mellitus through targeted inhibition of Runx2. Exp Ther Med. 2020;20(2):1557-1565. doi:10.3892/etm.2020.8867

237. Ali Beg MM, Verma AK, Saleem M, Saud Alreshidi F, Alenazi F, Ahmad H, Joshi PC. Role and Significance of Circulating Biomarkers: miRNA and E2F1 mRNA Expression and Their Association with Type-2 Diabetic Complications. Int J Endocrinol. 2020;2020:6279168. doi:10.1155/2020/6279168

238. Tesovnik T, Kovač J, Pohar K, Hudoklin S, Dovč K, Bratina N, Trebušak Podkrajšek K, Debeljak M, Veranič P, Bosi E, et al. Extracellular Vesicles Derived Human-miRNAs Modulate the Immune System in Type 1 Diabetes. Front Cell Dev Biol. 2020;8:202. doi:10.3389/fcell.2020.00202

239. Assmann TS, Recamonde-Mendoza M, Puñales M, Tschiedel B, Canani LH, Crispim D. MicroRNA expression profile in plasma from type 1 diabetic patients: Case-control study and bioinformatic analysis. Diabetes Res Clin Pract. 2018;141:35-46. doi:10.1016/j.diabres.2018.03.044

240. Groen K, Maltby VE, Lea RA, Sanders KA, Fink JL, Scott RJ, Tajouri L, Lechner-Scott J. Erythrocyte microRNA sequencing reveals differential expression in relapsing-remitting multiple sclerosis. BMC Med Genomics. 2018;11(1):48. doi:10.1186/s12920-018-0365-7

241. Chen Y, Zhang Y, Ye G, Sheng C, Kong L, Yuan L. Knockdown of lncRNA PCAI protects against cognitive decline induced by hippocampal neuroinflammation via regulating SUZ12. Life Sci. 2020;253:117626. doi:10.1016/j.lfs.2020.117626 
242. Sun W, Zhao J, Li C. Dexmedetomidine Provides Protection Against Hippocampal Neuron Apoptosis and Cognitive Impairment in Mice with Alzheimer's Disease by Mediating the miR-129/YAP1/JAG1 Axis. Mol Neurobiol. 2020;57(12):5044-5055. doi:10.1007/s12035-020-02069-Z

243. Wang P, Zhang C, Li J, Luo L, Zhang S, Dong F, Tang Z, Ni S. Adipose-derived mesenchymal stromal cells improve hemodynamic function in pulmonary arterial hypertension: identification of microRNAs implicated in modulating endothelial function. Cytotherapy. 2019;21(4):416-427. doi:10.1016/j.jcyt.2019.02.011

244. Ma H, He Y, Bai M, Zhu L, He X, Wang L, Jin T. The genetic polymorphisms of ZC3HC1 and SMARCA4 are associated with hypertension risk. Mol Genet Genomic Med. 2019;7(11):e942. doi: $10.1002 / \mathrm{mgg} 3.942$ 
Tables

Table 1 The statistical metrics for key differentially expressed genes (DEGs)

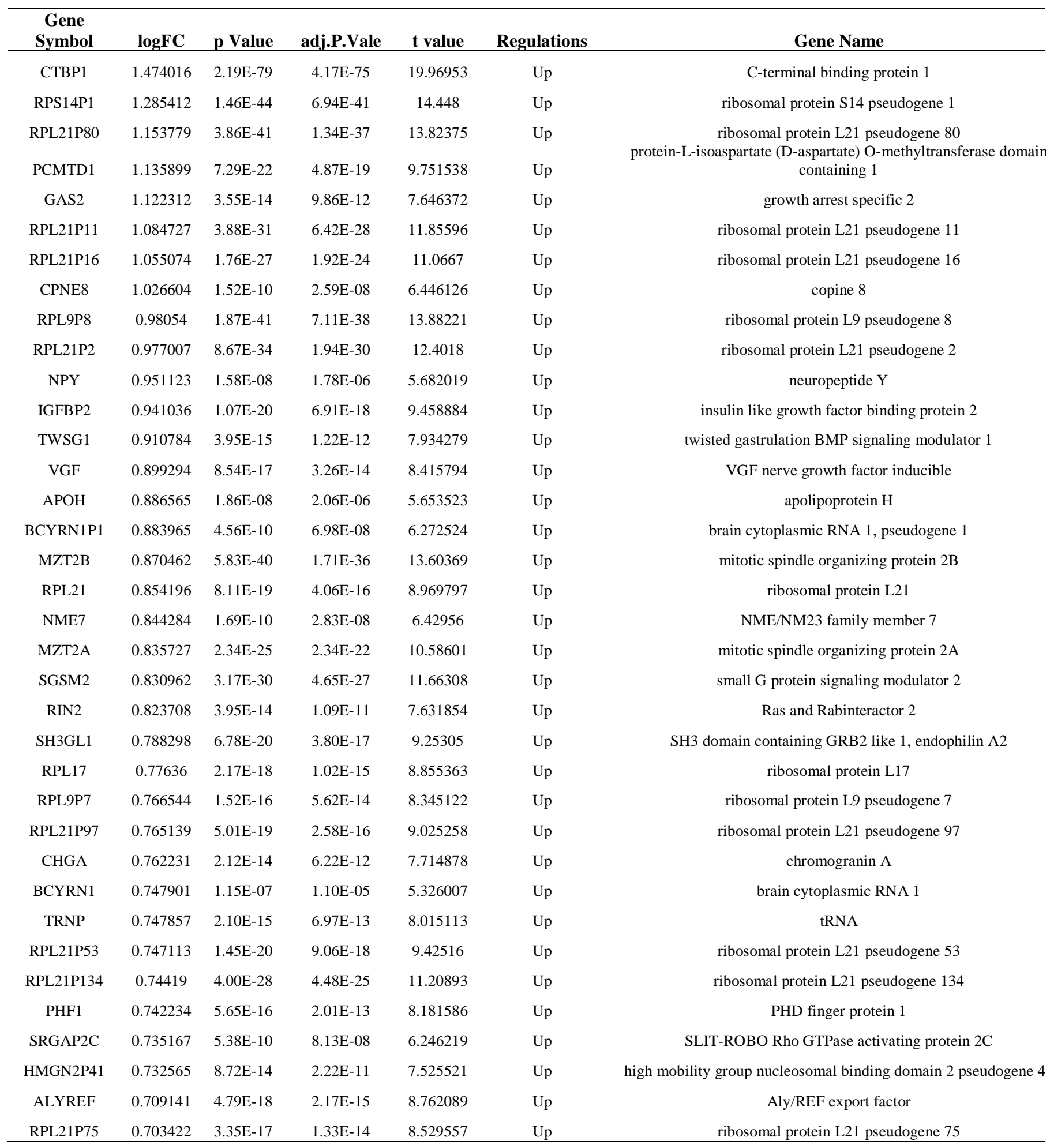




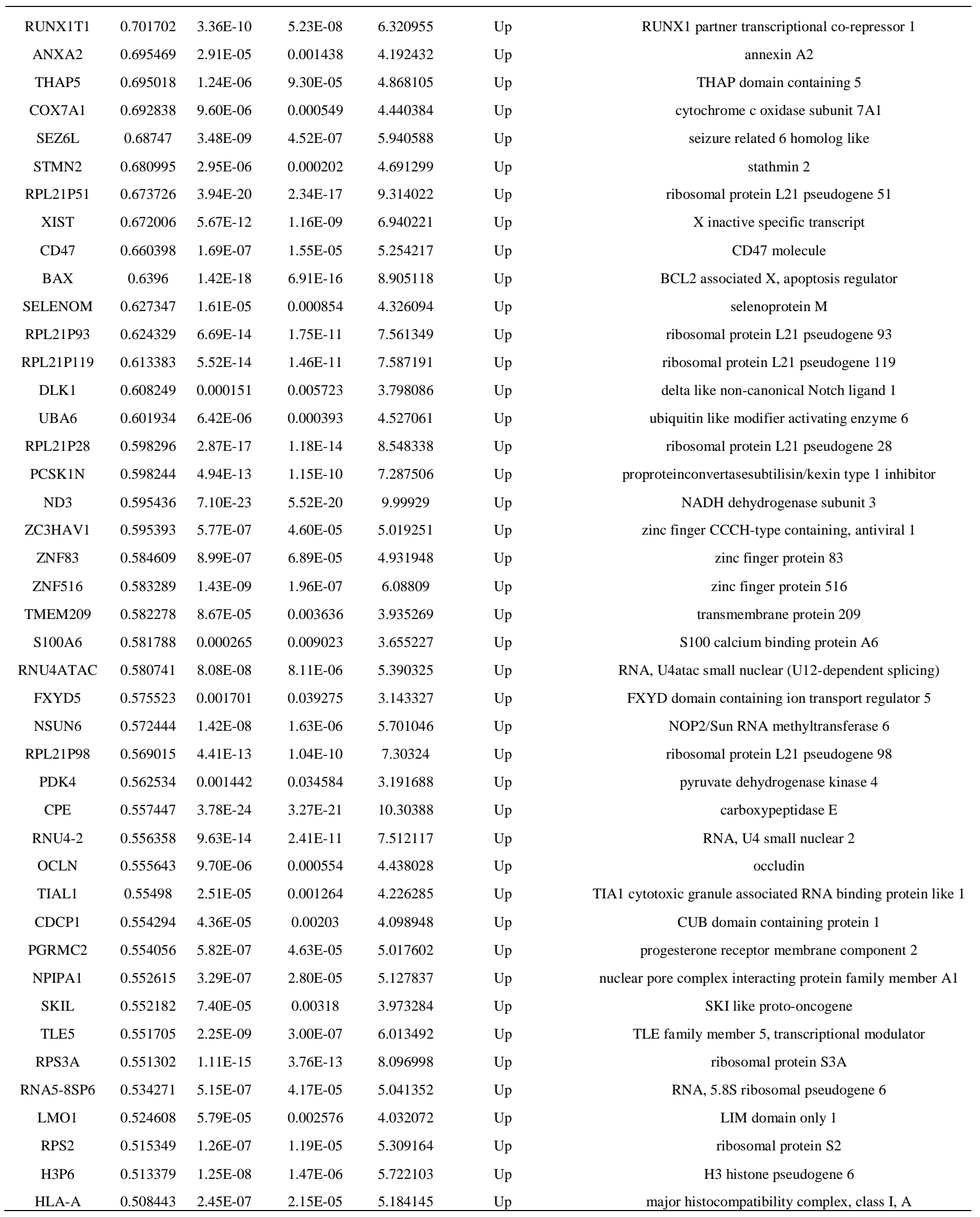




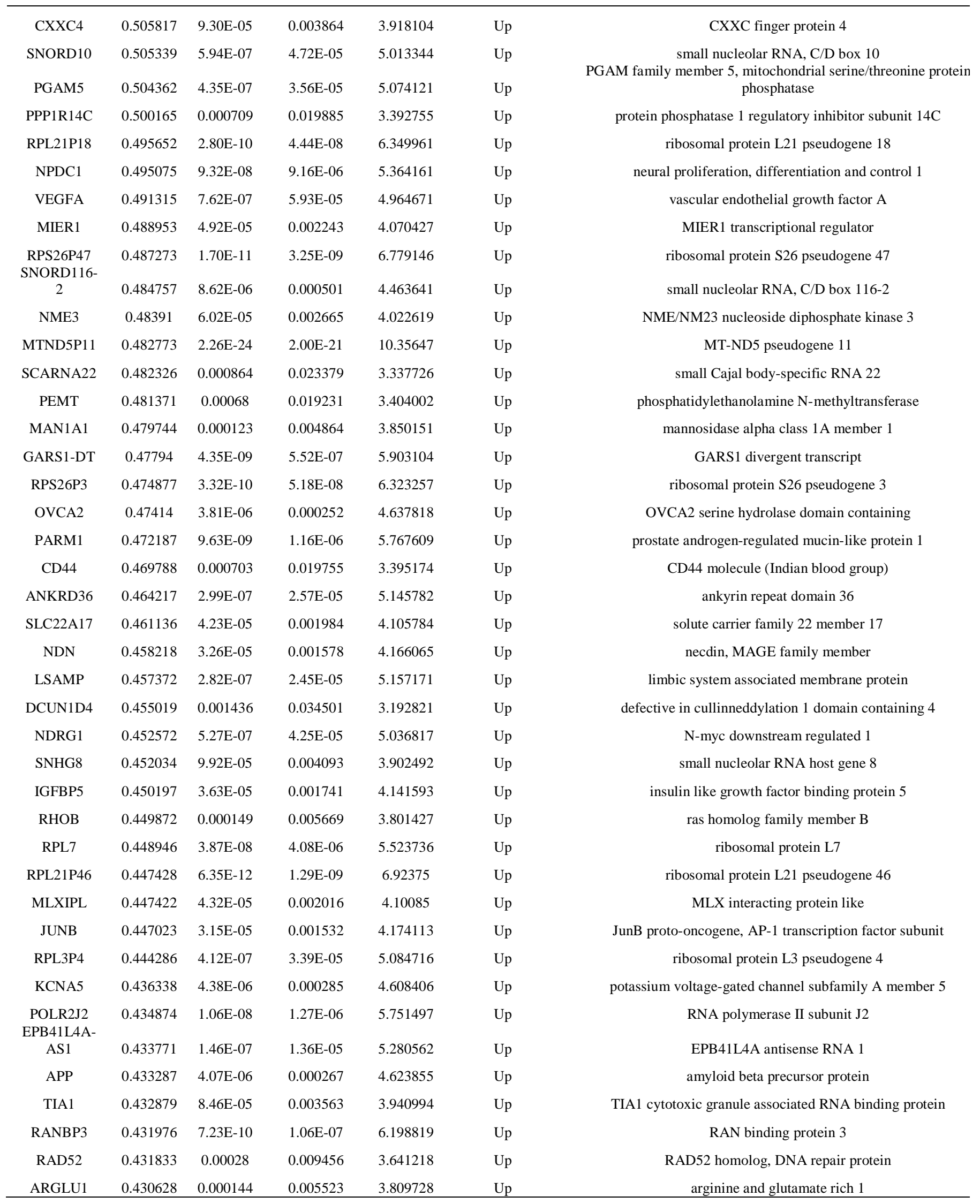




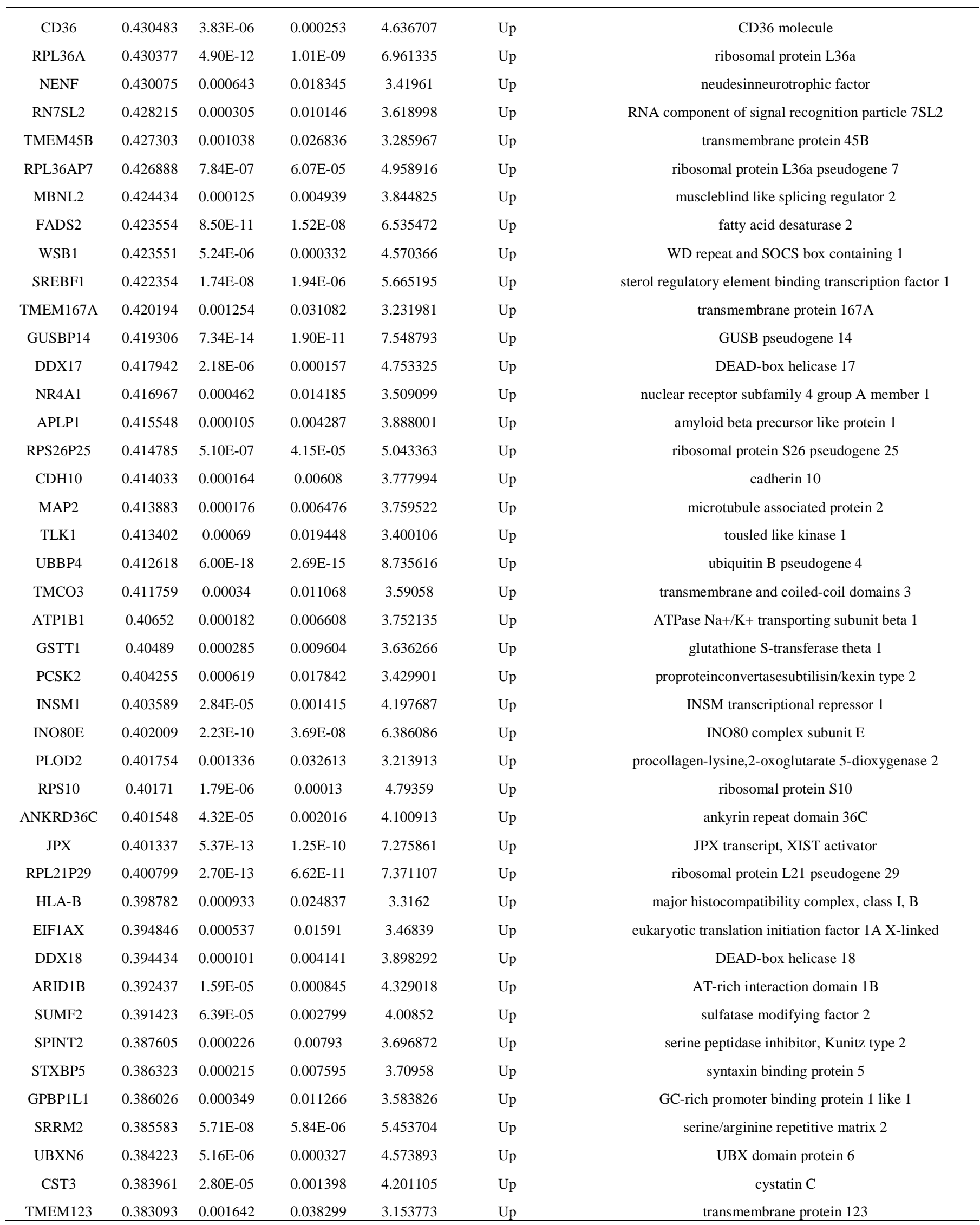




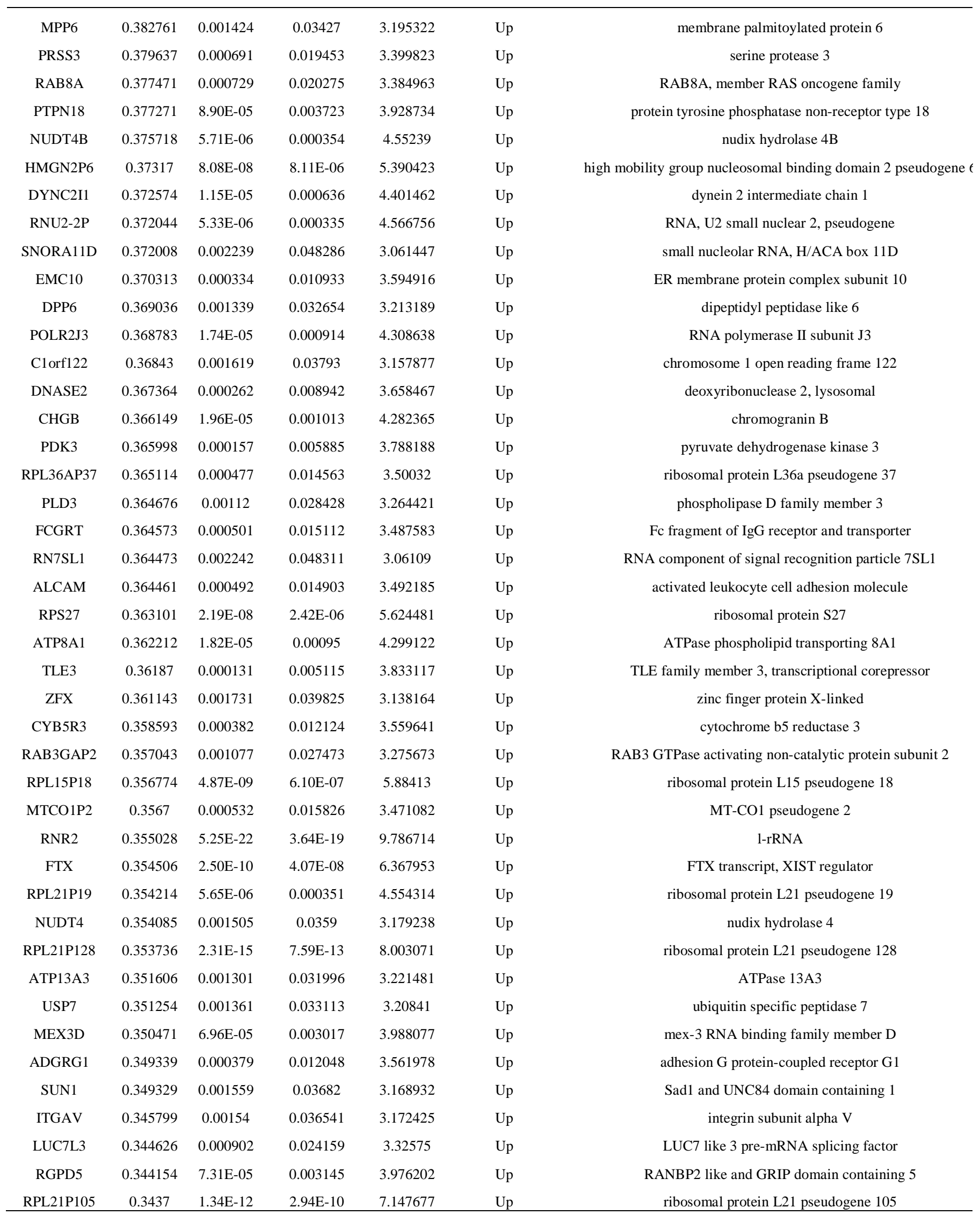




\begin{tabular}{|c|c|c|c|c|c|c|}
\hline SEZ6L2 & 0.343462 & $8.70 \mathrm{E}-05$ & 0.003644 & 3.934455 & Up & seizure related 6 homolog like 2 \\
\hline RPL21P7 & 0.340677 & $8.78 \mathrm{E}-13$ & $1.99 \mathrm{E}-10$ & 7.20703 & Up & ribosomal protein L21 pseudogene 7 \\
\hline ELF2 & 0.340647 & 0.000111 & 0.004458 & 3.875783 & Up & E74 like ETS transcription factor 2 \\
\hline ARL4C & 0.339133 & $6.31 \mathrm{E}-05$ & 0.002772 & 4.011638 & Up & ADP ribosylation factor like GTPase $4 \mathrm{C}$ \\
\hline MXRA7P1 & 0.338508 & $6.96 \mathrm{E}-06$ & 0.000419 & 4.509836 & Up & MXRA7 pseudogene 1 \\
\hline ATAD3C & 0.338127 & $7.90 \mathrm{E}-06$ & 0.000464 & 4.482682 & Up & ATPase family AAA domain containing $3 \mathrm{C}$ \\
\hline RPL9P25 & 0.337992 & $5.00 \mathrm{E}-06$ & 0.000319 & 4.580412 & Up & ribosomal protein L9 pseudogene 25 \\
\hline ELL2P1 & 0.337472 & $2.16 \mathrm{E}-18$ & $1.02 \mathrm{E}-15$ & 8.855545 & Up & elongation factor for RNA polymerase II 2 pseudogene 1 \\
\hline FAM102A & 0.334028 & 0.000615 & 0.017752 & 3.431681 & $\mathrm{Up}$ & family with sequence similarity 102 member A \\
\hline RPS26P15 & 0.331872 & $1.27 \mathrm{E}-07$ & $1.20 \mathrm{E}-05$ & 5.306605 & $\mathrm{Up}$ & ribosomal protein S26 pseudogene 15 \\
\hline SAMD12 & 0.33076 & 0.000197 & 0.007041 & 3.731463 & Up & sterile alpha motif domain containing 12 \\
\hline UPK3BL1 & 0.328408 & 0.00018 & 0.006558 & 3.754786 & Up & uroplakin 3B like 1 \\
\hline PAFAH1B1 & 0.328304 & 0.002178 & 0.047368 & 3.069839 & Up & platelet activating factor acetylhydrolase $1 \mathrm{~b}$ regulatory subunit 1 \\
\hline MCTS1 & 0.325819 & 0.000449 & 0.013864 & 3.516522 & Up & MCTS1 re-initiation and release factor \\
\hline FGF7P3 & 0.325584 & $2.35 \mathrm{E}-16$ & $8.61 \mathrm{E}-14$ & 8.291084 & Up & fibroblast growth factor 7 pseudogene 3 \\
\hline TNRC6B & 0.324738 & $4.14 \mathrm{E}-06$ & 0.000271 & 4.620155 & $\mathrm{Up}$ & trinucleotide repeat containing adaptor $6 \mathrm{~B}$ \\
\hline RREB1 & 0.324583 & 2.67E-05 & 0.00134 & 4.211896 & Up & ras responsive element binding protein 1 \\
\hline KRT10 & 0.319788 & 0.000664 & 0.018862 & 3.410766 & Up & keratin 10 \\
\hline UNC80 & 0.3189 & 0.000572 & 0.016763 & 3.45169 & Up & unc-80 homolog, NALCN channel complex subunit \\
\hline DPH1 & 0.317036 & 0.00015 & 0.005669 & 3.800712 & Up & diphthamide biosynthesis 1 \\
\hline NRP1 & 0.316879 & 0.001596 & 0.037518 & 3.161974 & Up & neuropilin 1 \\
\hline DDR1 & 0.315885 & 0.002139 & 0.046761 & 3.075171 & Up & discoidin domain receptor tyrosine kinase 1 \\
\hline PAK3 & 0.315642 & 0.001233 & 0.03073 & 3.23684 & Up & p21 (RAC1) activated kinase 3 \\
\hline HNRNPAB & 0.31556 & 0.000624 & 0.01796 & 3.42761 & Up & heterogeneous nuclear ribonucleoprotein A/B \\
\hline RPS26P8 & 0.314553 & 7.05E-05 & 0.003047 & 3.985203 & Up & ribosomal protein S26 pseudogene 8 \\
\hline EGFEM1P & 0.314407 & 4.78E-09 & $6.01 \mathrm{E}-07$ & 5.887039 & Up & EGF like and EMI domain containing 1, pseudogene \\
\hline OTUD4 & 0.314026 & 0.00016 & 0.005946 & 3.784815 & Up & OTU deubiquitinase 4 \\
\hline LSR & 0.313715 & $1.02 \mathrm{E}-05$ & 0.000576 & 4.427448 & Up & lipolysis stimulated lipoprotein receptor \\
\hline SNORD3B-2 & 0.313053 & $1.77 \mathrm{E}-06$ & 0.000129 & 4.796 & Up & small nucleolar RNA, C/D box 3B-2 \\
\hline FOSB & 0.311504 & $9.77 \mathrm{E}-05$ & 0.00405 & 3.906109 & Up & FosB proto-oncogene, AP-1 transcription factor subunit \\
\hline CPT1A & 0.31039 & 0.000325 & 0.010699 & 3.60217 & Up & carnitinepalmitoyltransferase $1 \mathrm{~A}$ \\
\hline ILF3 & 0.309346 & 0.000348 & 0.011264 & 3.584385 & Up & interleukin enhancer binding factor 3 \\
\hline
\end{tabular}




\begin{tabular}{|c|c|c|c|c|c|c|}
\hline DOC2A & 0.308827 & $3.24 \mathrm{E}-11$ & $6.05 \mathrm{E}-09$ & 6.68232 & Up & double $\mathrm{C} 2$ domain alpha \\
\hline TRNQ & 0.306615 & 0.000182 & 0.006628 & 3.751111 & Up & tRNA \\
\hline FAR2P2 & 0.306113 & 0.000181 & 0.006584 & 3.753265 & Up & fatty acyl-CoA reductase 2 pseudogene 2 \\
\hline A1BG & 0.304071 & 0.000207 & 0.007341 & 3.718944 & Up & alpha-1-B glycoprotein \\
\hline KMT2E & 0.300576 & 0.002329 & 0.0497 & 3.049652 & Up & lysine methyltransferase $2 \mathrm{E}$ (inactive) \\
\hline ZNF189 & 0.300182 & 0.001066 & 0.027328 & 3.278513 & Up & zinc finger protein 189 \\
\hline PDCD2 & 0.299528 & 0.000573 & 0.016784 & 3.451149 & Up & programmed cell death 2 \\
\hline BMS1P20 & 0.299317 & 4.94E-05 & 0.002249 & 4.069544 & Up & BMS1 pseudogene 20 \\
\hline ITSN2 & 0.298834 & 0.000337 & 0.011014 & 3.59254 & Up & intersectin 2 \\
\hline $\mathrm{ABCA} 1$ & 0.293634 & 0.000881 & 0.023681 & 3.332327 & Up & ATP binding cassette subfamily A member 1 \\
\hline PI4KA & 0.293606 & 0.000441 & 0.01367 & 3.521384 & Up & phosphatidylinositol 4-kinase alpha \\
\hline PNISR & 0.29356 & 0.000949 & 0.025072 & 3.311392 & Up & PNN interacting serine and arginine rich protein \\
\hline VWA1 & 0.293559 & $1.21 \mathrm{E}-05$ & 0.000663 & 4.390089 & Up & von Willebrand factor A domain containing 1 \\
\hline SLF2 & 0.293105 & 0.001924 & 0.043325 & 3.106845 & Up & SMC5-SMC6 complex localization factor 2 \\
\hline RPS26 & 0.291732 & 0.001731 & 0.039825 & 3.138254 & Up & ribosomal protein S26 \\
\hline GNAO1 & 0.291484 & $9.75 \mathrm{E}-05$ & 0.004047 & 3.906537 & $\mathrm{Up}$ & G protein subunit alpha o1 \\
\hline FRG1BP & 0.29043 & $1.62 \mathrm{E}-06$ & 0.000118 & 4.814235 & Up & FSHD region gene 1 family member $\mathrm{B}$, pseudogene \\
\hline CSKMT & 0.282948 & $6.71 \mathrm{E}-10$ & 9.95E-08 & 6.210615 & Up & citrate synthase lysine methyltransferase \\
\hline TOP1 & 0.282915 & 0.001545 & 0.036592 & 3.171551 & Up & DNA topoisomerase I \\
\hline HMGN2P1 & 0.282831 & 7.51E-08 & 7.59E-06 & 5.403866 & Up & high mobility group nucleosomal binding domain 2 pseudogene 1 \\
\hline ITGB1P1 & 0.282659 & $3.68 \mathrm{E}-05$ & 0.001762 & 4.138566 & Up & integrin subunit beta 1 pseudogene 1 \\
\hline MYH9 & 0.282628 & 0.000727 & 0.020233 & 3.385935 & Up & myosin heavy chain 9 \\
\hline SYNPO & 0.282591 & 0.000189 & 0.006834 & 3.742144 & Up & synaptopodin \\
\hline ATP2A2 & 0.281957 & 0.000268 & 0.009104 & 3.652678 & Up & ATPase sarcoplasmic/endoplasmic reticulum $\mathrm{Ca} 2+$ transporting 2 \\
\hline GAA & 0.281659 & 0.000639 & 0.018255 & 3.421382 & Up & glucosidase alpha, acid \\
\hline RPL41P3 & 0.27995 & 8.82E-05 & 0.003691 & 3.931082 & Up & ribosomal protein $\mathrm{L} 41$ pseudogene 3 \\
\hline TRA2A & 0.277281 & 0.001453 & 0.034801 & 3.189385 & Up & transformer 2 alpha homolog \\
\hline LENG8 & 0.276588 & $2.02 \mathrm{E}-07$ & $1.81 \mathrm{E}-05$ & 5.220641 & Up & leukocyte receptor cluster member 8 \\
\hline RPL41P5 & 0.275765 & $6.84 \mathrm{E}-05$ & 0.002971 & 3.992301 & Up & ribosomal protein L41 pseudogene 5 \\
\hline SFTPA1 & 0.275626 & 8.75E-06 & 0.000507 & 4.460364 & Up & surfactant protein A1 \\
\hline PIKFYVE & 0.274637 & 0.000963 & 0.025335 & 3.307282 & $\mathrm{Up}$ & phosphoinositide kinase, FYVE-type zinc finger containing \\
\hline CCDC18- & 0.274441 & 0.000116 & 0.004629 & 3.864689 & Up & CCDC18 antisense RNA 1 \\
\hline
\end{tabular}




\begin{tabular}{|c|c|c|c|c|c|c|}
\hline AS1 & & & & & & \\
\hline $\begin{array}{l}\text { PDXDC2P- } \\
\text { NPIPB14P }\end{array}$ & 0.273908 & $7.52 \mathrm{E}-10$ & $1.10 \mathrm{E}-07$ & 6.192371 & Up & nuclear pore complex-interacting protein \\
\hline RPS25P2 & 0.270903 & 0.000144 & 0.005501 & 3.811211 & Up & ribosomal protein S25 pseudogene 2 \\
\hline MAFG & 0.270117 & $8.41 \mathrm{E}-05$ & 0.00355 & 3.942689 & Up & MAF bZIP transcription factor $\mathrm{G}$ \\
\hline $\mathrm{U} 2 \mathrm{AF} 2$ & 0.269571 & 4.77E-06 & 0.000306 & 4.590367 & Up & U2 small nuclear RNA auxiliary factor 2 \\
\hline ST14 & 0.268932 & 0.000611 & 0.017676 & 3.4335 & Up & ST14 transmembrane serine protease matriptase \\
\hline MIDN & 0.268354 & 0.001768 & 0.040546 & 3.131976 & Up & midnolin \\
\hline $\begin{array}{l}\text { HOOK3 } \\
\text { SLMO2- }\end{array}$ & 0.267489 & 0.000813 & 0.022273 & 3.3547 & Up & hook microtubule tethering protein 3 \\
\hline CHCHD2P2 & 0.266572 & 0.000125 & 0.004922 & 3.845946 & Up & coiled-coil-helix-coiled-coil-helix domain containing 2 pseudogent \\
\hline TNRC6A & 0.265649 & 0.001947 & 0.043688 & 3.103305 & Up & trinucleotide repeat containing adaptor $6 \mathrm{~A}$ \\
\hline TCTN2 & 0.26518 & 0.001087 & 0.027652 & 3.273064 & Up & tectonic family member 2 \\
\hline SSTR3 & 0.265012 & 0.000713 & 0.019968 & 3.391203 & Up & somatostatin receptor 3 \\
\hline ZSWIM1 & 0.263879 & 0.000741 & 0.02051 & 3.380431 & Up & zinc finger SWIM-type containing 1 \\
\hline FRG1JP & 0.263268 & $2.50 \mathrm{E}-06$ & 0.000176 & 4.725601 & Up & FSHD region gene 1 family member $J$, pseudogene \\
\hline WDR17 & 0.261331 & $4.58 \mathrm{E}-05$ & 0.002116 & 4.087257 & Up & WD repeat domain 17 \\
\hline LENG9 & 0.260459 & $3.41 \mathrm{E}-07$ & $2.88 \mathrm{E}-05$ & 5.120644 & Up & leukocyte receptor cluster member 9 \\
\hline $\begin{array}{c}\text { NPIPA5 } \\
\text { NUTM2B- }\end{array}$ & 0.259831 & 0.002296 & 0.049117 & 3.053895 & Up & nuclear pore complex interacting protein family member A5 \\
\hline ZXDC & 0.256259 & 0.001081 & 0.027566 & 3.274523 & Up & ZXD family zinc finger $\mathrm{C}$ \\
\hline MAN2B2 & 0.255435 & 0.001141 & 0.028914 & 3.259015 & Up & mannosidase alpha class $2 \mathrm{~B}$ member 2 \\
\hline $\begin{array}{l}\text { PPP1R37 } \\
\text { BCL2L2- } \\
\text { PABPN1 }\end{array}$ & 0.255146 & 5.04E-08 & $5.24 \mathrm{E}-06$ & 5.476299 & Up & protein phosphatase 1 regulatory subunit 37 \\
\hline TSIX & 0.254558 & $2.66 \mathrm{E}-06$ & 0.000185 & 4.71253 & Up & TSIX transcript, XIST antisense RNA \\
\hline MAPT & 0.254238 & $6.82 \mathrm{E}-05$ & 0.002968 & 3.992839 & Up & microtubule associated protein tau \\
\hline $\mathrm{ZCCHC} 3$ & 0.254221 & 0.002036 & 0.045181 & 3.089951 & Up & zinc finger CCHC-type containing 3 \\
\hline GANAB & 0.25409 & 0.002052 & 0.045422 & 3.087678 & Up & glucosidase II alpha subunit \\
\hline RPL41 & 0.254 & 0.000141 & 0.005454 & 3.815092 & Up & ribosomal protein $\mathrm{L} 41$ \\
\hline PABPN1 & 0.253521 & 0.000414 & 0.012957 & 3.538721 & Up & poly(A) binding protein nuclear 1 \\
\hline NAA40 & 0.252484 & 0.001374 & 0.033347 & 3.205632 & Up & $\mathrm{N}$-alpha-acetyltransferase 40 , NatD catalytic subunit \\
\hline B4GALT5 & 0.25192 & 0.000256 & 0.00877 & 3.66459 & Up & beta-1,4-galactosyltransferase 5 \\
\hline FGF7P8 & 0.251644 & $1.99 \mathrm{E}-07$ & $1.80 \mathrm{E}-05$ & 5.223331 & Up & fibroblast growth factor 7 pseudogene 8 \\
\hline CELF3 & 0.250908 & $1.31 \mathrm{E}-06$ & $9.78 \mathrm{E}-05$ & 4.857361 & Up & CUGBP Elav-like family member 3 \\
\hline PRKDC & 0.250799 & 0.002059 & 0.045525 & 3.086656 & Up & protein kinase, DNA-activated, catalytic subunit \\
\hline
\end{tabular}




\begin{tabular}{|c|c|c|c|c|c|c|}
\hline HIVEP1 & 0.250042 & 0.000272 & 0.009236 & 3.64849 & Up & HIVEP zinc finger 1 \\
\hline KIAA0895L & 0.248637 & 0.000488 & 0.014793 & 3.494615 & Up & KIAA0895 like \\
\hline HSPA8P8 & 0.24862 & $1.86 \mathrm{E}-06$ & 0.000135 & 4.785835 & Up & heat shock protein family A (Hsp70) member 8 pseudogene 8 \\
\hline NOL3 & 0.24829 & 0.000537 & 0.01591 & 3.468422 & Up & nucleolar protein 3 \\
\hline UBN2 & 0.248245 & 0.000515 & 0.015407 & 3.480027 & Up & ubinuclein 2 \\
\hline SNRNP70 & 0.247862 & 0.000273 & 0.009258 & 3.647639 & Up & small nuclear ribonucleoprotein $\mathrm{U} 1$ subunit 70 \\
\hline TMEM159 & 0.247826 & 0.001581 & 0.037269 & 3.164836 & Up & transmembrane protein 159 \\
\hline RBM33 & 0.247317 & 0.00054 & 0.015947 & 3.467331 & Up & $\begin{array}{c}\text { RNA binding motif protein } 33 \\
\text { membrane associated guanylate kinase, } \mathrm{WW} \text { and PDZ domain }\end{array}$ \\
\hline MAGI1 & 0.247238 & 0.000332 & 0.010852 & 3.597094 & Up & containing 1 \\
\hline WIPF2 & 0.244272 & 0.001598 & 0.037518 & 3.161708 & Up & WAS/WASL interacting protein family member 2 \\
\hline CEBPZOS & 0.243736 & $8.63 \mathrm{E}-05$ & 0.003624 & 3.936351 & Up & CEBPZ opposite strand \\
\hline UMAD1 & 0.243619 & 7.15E-09 & $8.79 \mathrm{E}-07$ & 5.818704 & Up & UBAP1-MVB12-associated (UMA) domain containing 1 \\
\hline SNORD3A & 0.242038 & 0.001401 & 0.033856 & 3.20012 & Up & small nucleolar RNA, C/D box $3 \mathrm{~A}$ \\
\hline RPL41P1 & 0.241074 & 0.000709 & 0.019887 & 3.392522 & Up & ribosomal protein $\mathrm{L} 41$ pseudogene 1 \\
\hline HNRNPL & 0.238866 & 0.002335 & 0.049809 & 3.048821 & Up & heterogeneous nuclear ribonucleoprotein $\mathrm{L}$ \\
\hline RCN1P2 & 0.238833 & $2.78 \mathrm{E}-08$ & 3.03E-06 & 5.582827 & Up & reticulocalbin 1 pseudogene 2 \\
\hline MCPH1 & 0.23857 & 0.001404 & 0.03387 & 3.199463 & Up & microcephalin 1 \\
\hline SYT7 & 0.235793 & 0.001196 & 0.030041 & 3.245613 & Up & synaptotagmin 7 \\
\hline RNU4-1 & 0.235414 & $1.45 \mathrm{E}-07$ & $1.35 \mathrm{E}-05$ & 5.282363 & Up & RNA, U4 small nuclear 1 \\
\hline GGCX & 0.235237 & 0.00057 & 0.016729 & 3.452462 & Up & gamma-glutamyl carboxylase \\
\hline SLC35E2A & 0.235195 & $4.42 \mathrm{E}-06$ & 0.000287 & 4.606706 & Up & solute carrier family 35 member E2A \\
\hline RPL28 & 0.235141 & 0.001052 & 0.027103 & 3.282203 & Up & ribosomal protein $\mathrm{L} 28$ \\
\hline TFAP4 & 0.233953 & 4.92E-07 & 4.01E-05 & 5.050106 & Up & transcription factor $\mathrm{AP}-4$ \\
\hline RGL2 & 0.233729 & 0.000372 & 0.011906 & 3.566824 & Up & ral guanine nucleotide dissociation stimulator like 2 \\
\hline RPS10P28 & 0.233253 & $5.25 \mathrm{E}-05$ & 0.002371 & 4.05504 & Up & ribosomal protein S10 pseudogene 28 \\
\hline HIF1A-AS2 & 0.232811 & 0.002133 & 0.046648 & 3.076073 & Up & HIF1A antisense RNA 2 \\
\hline SDK1 & 0.232184 & 7.32E-06 & 0.000438 & 4.498972 & Up & sidekick cell adhesion molecule 1 \\
\hline SACS & 0.231787 & $1.24 \mathrm{E}-05$ & 0.000676 & 4.384897 & Up & sacsin molecular chaperone \\
\hline ANKRD18A & 0.231539 & 0.000601 & 0.017471 & 3.438099 & Up & $\begin{array}{c}\text { ankyrin repeat domain } 18 \mathrm{~A} \\
\text { and }\end{array}$ \\
\hline CITED2 & 0.230839 & 0.000156 & 0.005865 & 3.790214 & Up & $\begin{array}{l}\mathrm{Cbp} / \mathrm{p} 300 \text { interacting transactivator with Glu/Asp rich carboxy- } \\
\text { terminal domain } 2\end{array}$ \\
\hline NFASC & 0.230788 & 0.001249 & 0.031048 & 3.233128 & Up & neurofascin \\
\hline PTMAP2 & 0.229398 & $6.89 \mathrm{E}-05$ & 0.002988 & 3.990659 & Up & prothymosin alpha pseudogene 2 \\
\hline
\end{tabular}




\begin{tabular}{|c|c|c|c|c|c|c|}
\hline B2M & 0.229397 & 0.00011 & 0.004435 & 3.877282 & Up & beta-2-microglobulin \\
\hline SON & 0.226282 & 0.00067 & 0.019007 & 3.408244 & Up & SON DNA and RNA binding protein \\
\hline GRAMD4 & 0.225983 & $1.02 \mathrm{E}-05$ & 0.000579 & 4.426313 & Up & GRAM domain containing 4 \\
\hline RPL7P26 & 0.225397 & 0.001237 & 0.0308 & 3.235995 & Up & ribosomal protein L7 pseudogene 26 \\
\hline NAIPP4 & 0.225183 & $1.25 \mathrm{E}-05$ & 0.00068 & 4.383041 & Up & NAIP pseudogene 4 \\
\hline SLC18A2 & 0.224659 & 0.000375 & 0.011987 & 3.564422 & $\mathrm{Up}$ & solute carrier family 18 member A2 \\
\hline RMST & 0.222931 & 7.01E-05 & 0.003035 & 3.986416 & Up & rhabdomyosarcoma 2 associated transcript \\
\hline RGL3 & 0.222739 & 0.002037 & 0.045181 & 3.089792 & Up & ral guanine nucleotide dissociation stimulator like 3 \\
\hline GLCCI1 & 0.222701 & 0.001726 & 0.039764 & 3.138972 & Up & glucocorticoid induced 1 \\
\hline CAPN12 & 0.221658 & $6.64 \mathrm{E}-06$ & 0.000403 & 4.520024 & $\mathrm{Up}$ & calpain 12 \\
\hline PRH1-PRR4 & 0.220566 & $1.06 \mathrm{E}-06$ & 8.03E-05 & 4.898714 & Up & PRH1-PRR4 readthrough \\
\hline SEC22B3P & 0.22003 & 0.000741 & 0.02051 & 3.3805 & Up & SEC22 homolog B3, pseudogene \\
\hline CSNK1G2 & 0.219891 & $1.66 \mathrm{E}-05$ & 0.000873 & 4.320137 & Up & casein kinase 1 gamma 2 \\
\hline TOP1P1 & 0.219441 & $8.76 \mathrm{E}-08$ & $8.69 \mathrm{E}-06$ & 5.375711 & Up & DNA topoisomerase I pseudogene 1 \\
\hline FAR2P3 & 0.219075 & 0.000193 & 0.006941 & 3.736292 & Up & fatty acyl-CoA reductase 2 pseudogene 3 \\
\hline SNORD81 & 0.217346 & $4.69 \mathrm{E}-07$ & 3.84E-05 & 5.059332 & Up & small nucleolar RNA, C/D box 81 \\
\hline SSBP4 & 0.215959 & 0.000126 & 0.004952 & 3.843425 & $\mathrm{Up}$ & single stranded DNA binding protein 4 \\
\hline GUSBP1 & 0.213084 & 0.000158 & 0.005904 & 3.787054 & Up & GUSB pseudogene 1 \\
\hline SKP1P1 & 0.211385 & 0.002069 & 0.045704 & 3.085136 & Up & S-phase kinase associated protein 1 pseudogene 1 \\
\hline SLC6A17 & 0.211288 & 0.00018 & 0.006557 & 3.755057 & Up & solute carrier family 6 member 17 \\
\hline NBPF20 & 0.211211 & $5.11 \mathrm{E}-06$ & 0.000325 & 4.575956 & Up & NBPF member 20 \\
\hline MPRIP & 0.210727 & 0.000137 & 0.005318 & 3.82214 & Up & myosin phosphatase Rho interacting protein \\
\hline GUSBP15 & 0.208689 & 4.07E-06 & 0.000267 & 4.623875 & Up & GUSB pseudogene 15 \\
\hline FAM3C $2 P$ & 0.208395 & 0.000153 & 0.005784 & 3.794913 & Up & FAM3C pseudogene \\
\hline BCL6 & 0.208367 & 0.000947 & 0.02506 & 3.312116 & Up & BCL6 transcription repressor \\
\hline PCDHB@ & 0.208149 & $5.35 \mathrm{E}-08$ & $5.55 \mathrm{E}-06$ & 5.465433 & Up & protocadherin beta cluster \\
\hline RAI1 & 0.208006 & $2.11 \mathrm{E}-05$ & 0.00108 & 4.265645 & Up & retinoic acid induced 1 \\
\hline SSR4 & 0.207945 & $1.34 \mathrm{E}-05$ & 0.000725 & 4.36696 & Up & signal sequence receptor subunit 4 \\
\hline RPL17P27 & 0.20794 & $1.52 \mathrm{E}-05$ & 0.000812 & 4.339099 & Up & ribosomal protein L17 pseudogene 27 \\
\hline AHDC1 & 0.207521 & 4.72E- 05 & 0.002166 & 4.08009 & Up & AT-hook DNA binding motif containing 1 \\
\hline TAOK2 & 0.207402 & $8.16 \mathrm{E}-09$ & $9.90 \mathrm{E}-07$ & 5.796083 & Up & TAO kinase 2 \\
\hline SEMA6A & 0.207007 & 0.000529 & 0.015773 & 3.472621 & Up & semaphorin 6A \\
\hline
\end{tabular}




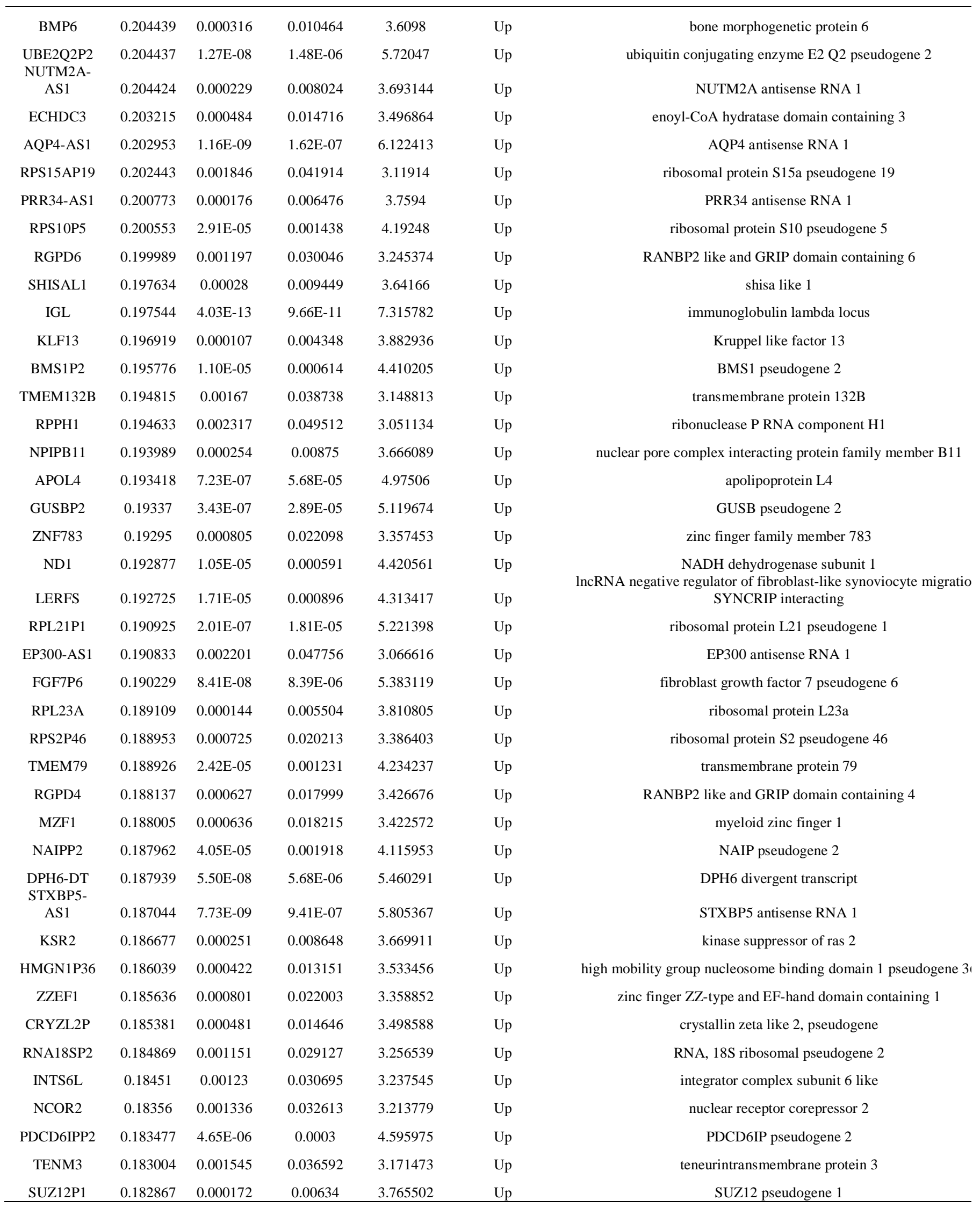




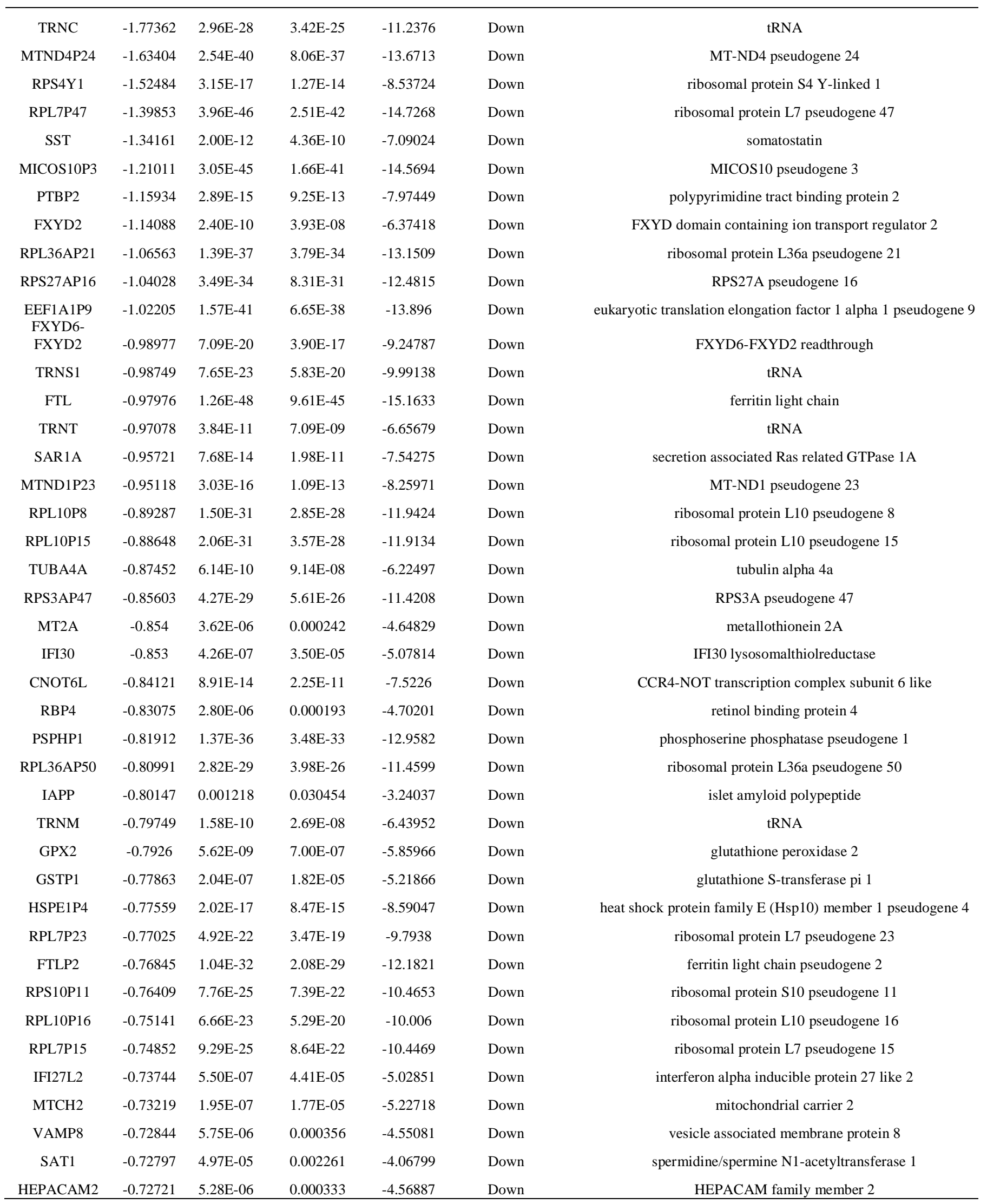




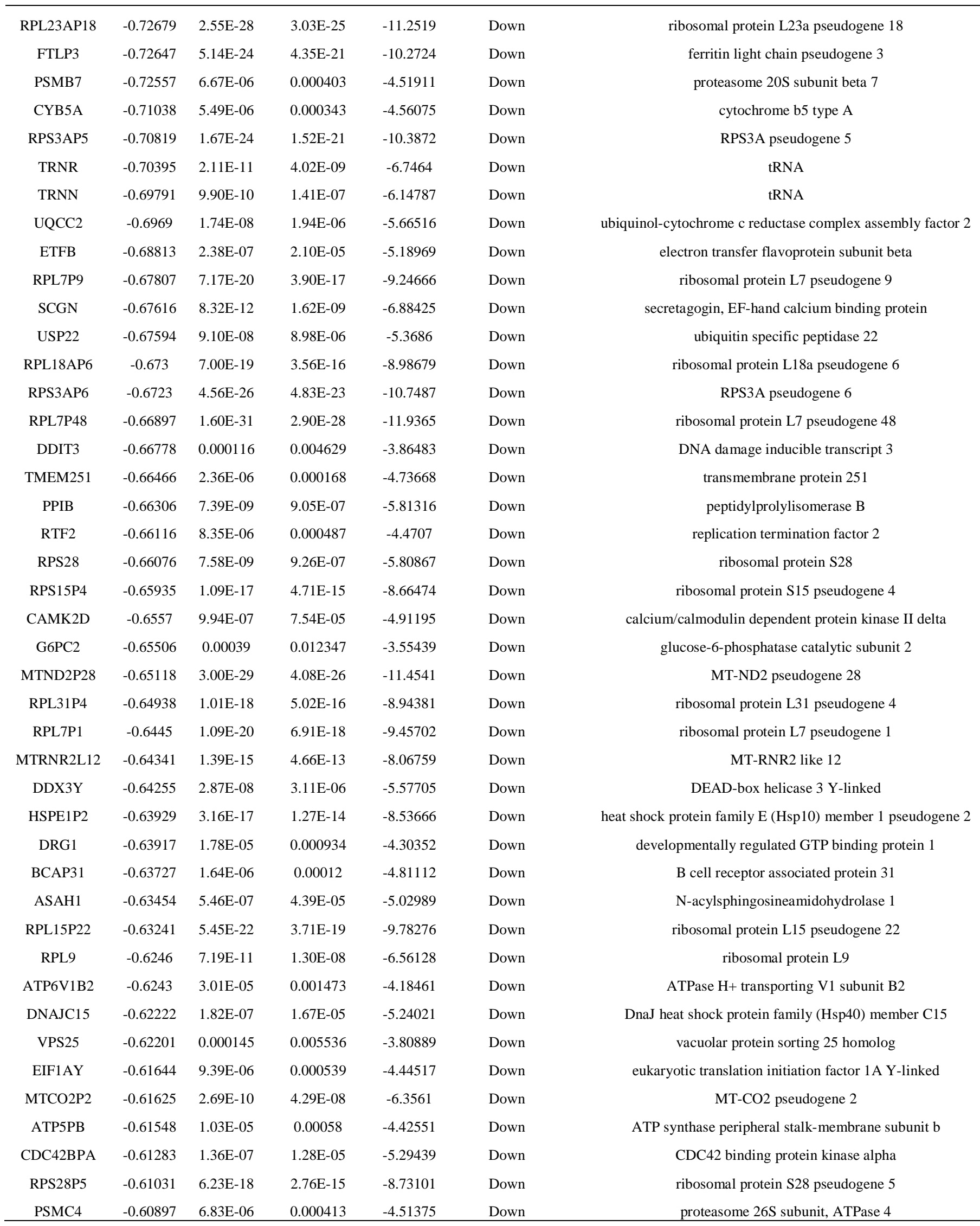




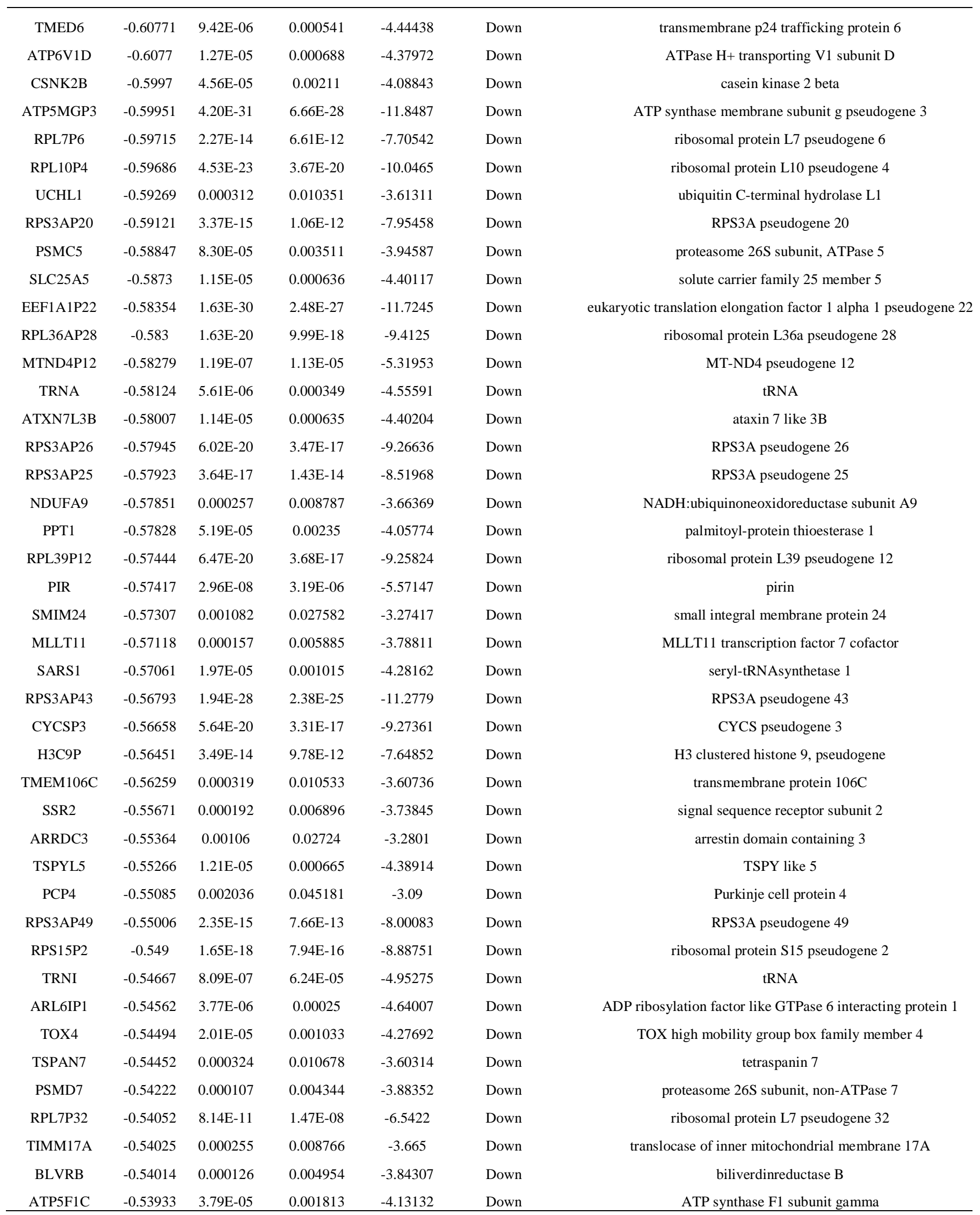




\begin{tabular}{|c|c|c|c|c|c|c|}
\hline RPS3AP21 & -0.53899 & $8.90 \mathrm{E}-16$ & $3.06 \mathrm{E}-13$ & -8.12441 & Down & RPS3A pseudogene 21 \\
\hline SH3BGRL3 & -0.53822 & 0.00021 & 0.007439 & -3.7151 & Down & SH3 domain binding glutamate rich protein like 3 \\
\hline PRPS2 & -0.53753 & $1.61 \mathrm{E}-05$ & 0.000854 & -4.32634 & Down & phosphoribosyl pyrophosphate synthetase 2 \\
\hline MRPL54 & -0.53538 & 7.10E-05 & 0.003065 & -3.98335 & Down & mitochondrial ribosomal protein L54 \\
\hline RPS27P17 & -0.53464 & $5.03 \mathrm{E}-10$ & 7.64E-08 & -6.25691 & Down & ribosomal protein S27 pseudogene 17 \\
\hline NDUFA12 & -0.53433 & 0.000142 & 0.005463 & -3.81407 & Down & NADH:ubiquinoneoxidoreductase subunit A12 \\
\hline ATP6V1E1 & -0.53365 & $4.65 \mathrm{E}-05$ & 0.002136 & -4.08386 & Down & ATPase $\mathrm{H}+$ transporting V1 subunit $\mathrm{E} 1$ \\
\hline GRAMD2B & -0.53356 & $6.07 \mathrm{E}-06$ & 0.000373 & -4.53906 & Down & GRAM domain containing $2 \mathrm{~B}$ \\
\hline EEF1A1P12 & -0.53355 & $1.28 \mathrm{E}-16$ & $4.78 \mathrm{E}-14$ & -8.36634 & Down & eukaryotic translation elongation factor 1 alpha 1 pseudogene 12 \\
\hline RAB21 & -0.53177 & 0.000551 & 0.016223 & -3.46142 & Down & RAB21, member RAS oncogene family \\
\hline PRDX1 & -0.53131 & 0.000179 & 0.006553 & -3.7557 & Down & peroxiredoxin 1 \\
\hline CTSA & -0.53115 & 0.000232 & 0.008132 & -3.68947 & Down & cathepsin A \\
\hline NIT2 & -0.5293 & 0.000342 & 0.011123 & -3.58859 & Down & nitrilase family member 2 \\
\hline BUD23 & -0.52874 & 0.000609 & 0.017618 & -3.4346 & Down & BUD23 rRNAmethyltransferase and ribosome maturation factor \\
\hline ATP5MC1 & -0.52481 & 0.000345 & 0.011201 & -3.58632 & Down & ATP synthase membrane subunit $\mathrm{c}$ locus 1 \\
\hline LCLAT1 & -0.5244 & 0.000507 & 0.015249 & -3.48434 & Down & lysocardiolipinacyltransferase 1 \\
\hline UBE2L5 & -0.52356 & 7.34E-25 & 7.17E-22 & -10.4708 & Down & ubiquitin conjugating enzyme E2 L5 \\
\hline MPC1 & -0.52344 & 0.00043 & 0.013381 & -3.52817 & Down & mitochondrial pyruvate carrier 1 \\
\hline PSMD6 & -0.52003 & 0.000256 & 0.00877 & -3.66442 & Down & proteasome $26 \mathrm{~S}$ subunit, non-ATPase 6 \\
\hline CLIC1 & -0.51993 & 0.000285 & 0.009599 & -3.63672 & Down & chloride intracellular channel 1 \\
\hline THYN1 & -0.51925 & 0.000518 & 0.015496 & -3.47825 & Down & thymocyte nuclear protein 1 \\
\hline GBA & -0.5191 & $5.82 \mathrm{E}-05$ & 0.002587 & -4.03081 & Down & glucosylceramidase beta \\
\hline ENO1 & -0.51877 & 5.03E-05 & 0.002282 & -4.06521 & Down & enolase 1 \\
\hline ESD & -0.51809 & 0.000908 & 0.024302 & -3.3237 & Down & esterase D \\
\hline REEP5 & -0.51715 & 5.99E-05 & 0.002652 & -4.02406 & Down & receptor accessory protein 5 \\
\hline FDPS & -0.517 & 0.001077 & 0.027473 & -3.27569 & Down & farnesyldiphosphate synthase \\
\hline IDH1 & -0.51672 & 0.000105 & 0.004267 & -3.88938 & Down & isocitrate dehydrogenase $(\mathrm{NADP}(+)) 1$ \\
\hline HOPX & -0.51644 & 0.000233 & 0.008144 & -3.68887 & Down & HOP homeobox \\
\hline PSMB5 & -0.51427 & $1.91 \mathrm{E}-05$ & 0.000988 & -4.28861 & Down & proteasome $20 \mathrm{~S}$ subunit beta 5 \\
\hline RPS24P8 & -0.514 & $4.58 \mathrm{E}-14$ & $1.23 \mathrm{E}-11$ & -7.61222 & Down & ribosomal protein S24 pseudogene 8 \\
\hline MRPS35 & -0.51317 & 0.000385 & 0.012208 & -3.55761 & Down & mitochondrial ribosomal protein S35 \\
\hline XRCC6 & -0.51246 & 0.000184 & 0.006687 & -3.74862 & Down & $\mathrm{X}$-ray repair cross complementing 6 \\
\hline PSMB3 & -0.51184 & 0.000277 & 0.009386 & -3.64385 & Down & proteasome $20 \mathrm{~S}$ subunit beta 3 \\
\hline PRDX6 & -0.50942 & 0.000566 & 0.016615 & -3.45453 & Down & peroxiredoxin 6 \\
\hline ZNF165 & -0.50861 & $7.86 \mathrm{E}-05$ & 0.00335 & -3.95886 & Down & zinc finger protein 165 \\
\hline NDUFV3 & -0.50647 & $9.19 \mathrm{E}-06$ & 0.00053 & -4.44984 & Down & NADH:ubiquinoneoxidoreductase subunit V3 \\
\hline CLU & -0.50421 & $6.46 \mathrm{E}-06$ & 0.000395 & -4.5257 & Down & clusterin \\
\hline RPL36AP13 & -0.50417 & $1.36 \mathrm{E}-08$ & $1.57 \mathrm{E}-06$ & -5.70845 & Down & ribosomal protein L36a pseudogene 13 \\
\hline CDV3 & -0.50276 & 0.000495 & 0.014945 & -3.49079 & Down & CDV3 homolog \\
\hline GLMP & -0.50089 & $9.28 \mathrm{E}-06$ & 0.000534 & -4.44771 & Down & glycosylated lysosomal membrane protein \\
\hline PLEKHB2 & -0.49916 & 0.000221 & 0.007817 & -3.70172 & Down & pleckstrin homology domain containing B2 \\
\hline $\mathrm{MDH} 2$ & -0.4975 & 0.000106 & 0.004325 & -3.88529 & Down & malate dehydrogenase 2 \\
\hline EIF3K & -0.49682 & 0.000537 & 0.015906 & -3.46886 & Down & eukaryotic translation initiation factor 3 subunit $\mathrm{K}$ \\
\hline
\end{tabular}




\begin{tabular}{|c|c|c|c|c|c|c|}
\hline TTR & -0.49514 & 0.000355 & 0.011452 & -3.57891 & Down & transthyretin \\
\hline PTGR2 & -0.49288 & 4.28E-05 & 0.001999 & -4.10344 & Down & prostaglandin reductase 2 \\
\hline NME2P1 & -0.49286 & $2.14 \mathrm{E}-11$ & 4.05E-09 & -6.74477 & Down & NME2 pseudogene 1 \\
\hline GNPDA1 & -0.49283 & 0.00027 & 0.009154 & -3.65102 & Down & glucosamine-6-phosphate deaminase 1 \\
\hline GHITM & -0.49196 & 0.000345 & 0.011198 & -3.58661 & Down & growth hormone inducible transmembrane protein \\
\hline GRB2 & -0.48936 & 0.000667 & 0.018939 & -3.40943 & Down & growth factor receptor bound protein 2 \\
\hline RPL10P9 & -0.48309 & $4.59 \mathrm{E}-14$ & $1.23 \mathrm{E}-11$ & -7.61179 & Down & ribosomal protein L10 pseudogene 9 \\
\hline EEF1A1P16 & -0.47667 & 2.13E-20 & $1.29 \mathrm{E}-17$ & -9.38232 & Down & eukaryotic translation elongation factor 1 alpha 1 pseudogene 16 \\
\hline MT1E & -0.47613 & 0.001443 & 0.034584 & -3.19157 & Down & metallothionein $1 \mathrm{E}$ \\
\hline MDH1 & -0.47432 & $7.70 \mathrm{E}-05$ & 0.0033 & -3.9638 & Down & malate dehydrogenase 1 \\
\hline RPL34P18 & -0.47406 & $8.45 \mathrm{E}-10$ & $1.22 \mathrm{E}-07$ & -6.17359 & Down & ribosomal protein L34 pseudogene 18 \\
\hline ATP5PO & -0.4708 & 0.000403 & 0.012677 & -3.54563 & Down & ATP synthase peripheral stalk subunit OSCP \\
\hline POLR3K & -0.47059 & 0.000999 & 0.025998 & -3.29689 & Down & RNA polymerase III subunit $\mathrm{K}$ \\
\hline UBE2L6 & -0.47009 & 0.00024 & 0.008347 & -3.68111 & Down & ubiquitin conjugating enzyme E2 L6 \\
\hline CYSTM1 & -0.46993 & 7.92E-06 & 0.000464 & -4.48191 & Down & cysteine rich transmembrane module containing 1 \\
\hline C11 orf54 & -0.46706 & $4.56 \mathrm{E}-05$ & 0.002111 & -4.08812 & Down & chromosome 11 open reading frame 54 \\
\hline TRAPPC2L & -0.46693 & 0.000315 & 0.01046 & -3.61013 & Down & trafficking protein particle complex 2 like \\
\hline PIGP & -0.46187 & 0.001669 & 0.038738 & -3.14901 & Down & phosphatidylinositol glycan anchor biosynthesis class $\mathrm{P}$ \\
\hline SUCLG1 & -0.46129 & 0.002025 & 0.045059 & -3.09164 & Down & succinate-CoA ligase GDP/ADP-forming subunit alpha \\
\hline NAPA & -0.46093 & 0.000225 & 0.007921 & -3.69787 & Down & NSF attachment protein alpha \\
\hline RPL31P17 & -0.46077 & 7.57E-17 & $2.94 \mathrm{E}-14$ & -8.43059 & Down & ribosomal protein L31 pseudogene 17 \\
\hline VAT1 & -0.45987 & 0.000289 & 0.009676 & -3.63335 & Down & vesicle amine transport 1 \\
\hline TXN2 & -0.45817 & 0.001775 & 0.040657 & -3.13085 & Down & thioredoxin 2 \\
\hline HSPE1P3 & -0.45727 & $5.89 \mathrm{E}-08$ & $6.02 \mathrm{E}-06$ & -5.44795 & Down & heat shock protein family E (Hsp10) member 1 pseudogene 3 \\
\hline GAPDHP65 & -0.4563 & $2.40 \mathrm{E}-23$ & $1.99 \mathrm{E}-20$ & -10.1128 & Down & glyceraldehyde 3 phosphate dehydrogenase pseudogene 65 \\
\hline NTPCR & -0.45604 & 0.001094 & 0.027791 & -3.27126 & Down & nucleoside-triphosphatase, cancer-related \\
\hline UBE2B & -0.45399 & 0.000398 & 0.012573 & -3.54868 & Down & ubiquitin conjugating enzyme E2 B \\
\hline PRXL2A & -0.45369 & 0.000318 & 0.010512 & -3.60839 & Down & peroxiredoxin like $2 \mathrm{~A}$ \\
\hline CUTA & -0.45315 & 7.51E-06 & 0.000446 & -4.49344 & Down & cutA divalent cation tolerance homolog \\
\hline HMGB1P37 & -0.45312 & $7.75 \mathrm{E}-16$ & $2.71 \mathrm{E}-13$ & -8.14189 & Down & high mobility group box 1 pseudogene 37 \\
\hline RPS28P9 & -0.45125 & $5.57 \mathrm{E}-11$ & $1.03 \mathrm{E}-08$ & -6.60005 & Down & ribosomal protein S28 pseudogene 9 \\
\hline GTF2A2 & -0.45055 & 0.001522 & 0.036218 & -3.17589 & Down & general transcription factor IIA subunit 2 \\
\hline
\end{tabular}




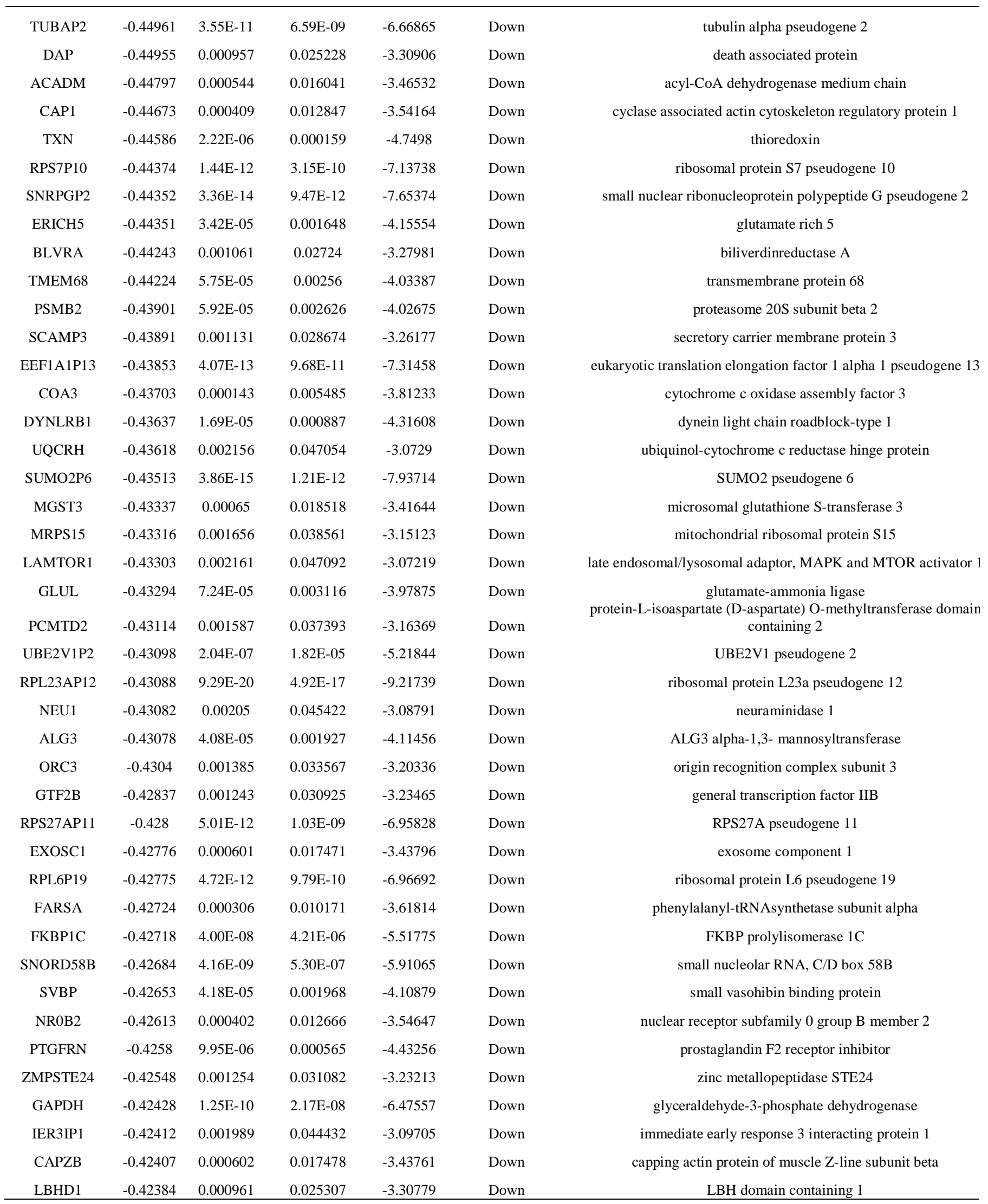




\begin{tabular}{|c|c|c|c|c|c|c|}
\hline FTH1 & -0.42333 & $5.29 \mathrm{E}-06$ & 0.000333 & -4.56862 & Down & ferritin heavy chain 1 \\
\hline RPL15P14 & -0.42247 & $1.50 \mathrm{E}-17$ & $6.36 \mathrm{E}-15$ & -8.62629 & Down & ribosomal protein L15 pseudogene 14 \\
\hline PPIL1 & -0.42158 & $2.54 \mathrm{E}-05$ & 0.001278 & -4.22338 & Down & peptidylprolylisomerase like 1 \\
\hline EEF1A1P8 & -0.42156 & $2.72 \mathrm{E}-16$ & $9.85 \mathrm{E}-14$ & -8.27318 & Down & eukaryotic translation elongation factor 1 alpha 1 pseudogene 8 \\
\hline PSMD12 & -0.42077 & 0.00198 & 0.044344 & -3.09834 & Down & proteasome $26 \mathrm{~S}$ subunit, non-ATPase 12 \\
\hline COX6B1 & -0.41892 & $8.34 \mathrm{E}-05$ & 0.003528 & -3.94445 & Down & cytochrome c oxidase subunit $6 \mathrm{~B} 1$ \\
\hline RPL7P2 & -0.41268 & $9.98 \mathrm{E}-12$ & $1.92 \mathrm{E}-09$ & -6.85757 & Down & ribosomal protein $\mathrm{L} 7$ pseudogene 2 \\
\hline NDUFB7 & -0.41261 & 0.002 & 0.044641 & -3.0953 & Down & NADH:ubiquinoneoxidoreductase subunit B7 \\
\hline IBTK & -0.41138 & 0.000948 & 0.02507 & -3.31181 & Down & inhibitor of Bruton tyrosine kinase \\
\hline ARG2 & -0.40998 & 0.002075 & 0.045802 & -3.08432 & Down & arginase 2 \\
\hline FKBP2 & -0.40995 & $6.17 \mathrm{E}-05$ & 0.002718 & -4.0171 & Down & FKBP prolylisomerase 2 \\
\hline RNR1 & -0.40959 & $1.18 \mathrm{E}-15$ & $3.98 \mathrm{E}-13$ & -8.08859 & Down & s-rRNA \\
\hline SUMO2P17 & -0.40806 & $1.06 \mathrm{E}-09$ & $1.51 \mathrm{E}-07$ & -6.13613 & Down & SUMO2 pseudogene 17 \\
\hline MORF4L2 & -0.40779 & 0.00078 & 0.021497 & -3.36633 & Down & mortality factor 4 like 2 \\
\hline DHDDS & -0.4037 & 0.000531 & 0.015816 & -3.47167 & Down & dehydrodolichyldiphosphate synthase subunit \\
\hline ARCN1 & -0.40218 & 0.001721 & 0.039674 & -3.13981 & Down & archain 1 \\
\hline RPS3AP36 & -0.40086 & $8.34 \mathrm{E}-20$ & 4.47E-17 & -9.22964 & Down & RPS3A pseudogene 36 \\
\hline RPS28P4 & -0.39301 & $1.57 \mathrm{E}-08$ & $1.78 \mathrm{E}-06$ & -5.68274 & Down & ribosomal protein S28 pseudogene 4 \\
\hline CYCSP24 & -0.39294 & $2.10 \mathrm{E}-14$ & $6.22 \mathrm{E}-12$ & -7.71604 & Down & CYCS pseudogene 24 \\
\hline COTL1 & -0.39288 & 0.001598 & 0.037518 & -3.16162 & Down & coactosin like F-actin binding protein 1 \\
\hline RPS3AP44 & -0.39056 & $3.54 \mathrm{E}-18$ & $1.62 \mathrm{E}-15$ & -8.79783 & Down & RPS3A pseudogene 44 \\
\hline MPP1 & -0.38941 & 0.000175 & 0.006423 & -3.76195 & Down & membrane palmitoylated protein 1 \\
\hline NSMCE2 & -0.38873 & 0.000263 & 0.00896 & -3.65726 & Down & NSE2 (MMS21) homolog, SMC5-SMC6 complex SUMO ligase \\
\hline HMGN2P21 & -0.38828 & $2.65 \mathrm{E}-12$ & $5.65 \mathrm{E}-10$ & -7.04986 & Down & high mobility group nucleosomal binding domain 2 pseudogene 2 \\
\hline MTRNR2L1 & -0.38658 & 3.61E-08 & $3.86 \mathrm{E}-06$ & -5.53609 & Down & MT-RNR2 like 1 \\
\hline PEF1 & -0.3863 & 0.00226 & 0.04858 & -3.05874 & Down & penta-EF-hand domain containing 1 \\
\hline RPL10P6 & -0.38617 & 2.63E-09 & $3.50 \mathrm{E}-07$ & -5.98699 & Down & ribosomal protein L10 pseudogene 6 \\
\hline RPS3AP7 & -0.38579 & $2.94 \mathrm{E}-12$ & $6.18 \mathrm{E}-10$ & -7.03537 & Down & RPS3A pseudogene 7 \\
\hline ATP5MFP2 & -0.3854 & $2.47 \mathrm{E}-22$ & $1.77 \mathrm{E}-19$ & -9.86745 & Down & ATP synthase membrane subunit $\mathrm{f}$ pseudogene 2 \\
\hline MBIP & -0.38484 & 0.000522 & 0.015597 & -3.47608 & Down & MAP3K12 binding inhibitory protein 1 \\
\hline TATDN3 & -0.38481 & 0.001356 & 0.033022 & -3.20958 & Down & TatDDNase domain containing 3 \\
\hline RPS10P17 & -0.38179 & $3.26 \mathrm{E}-08$ & $3.50 \mathrm{E}-06$ & -5.55428 & Down & ribosomal protein S10 pseudogene 17 \\
\hline
\end{tabular}




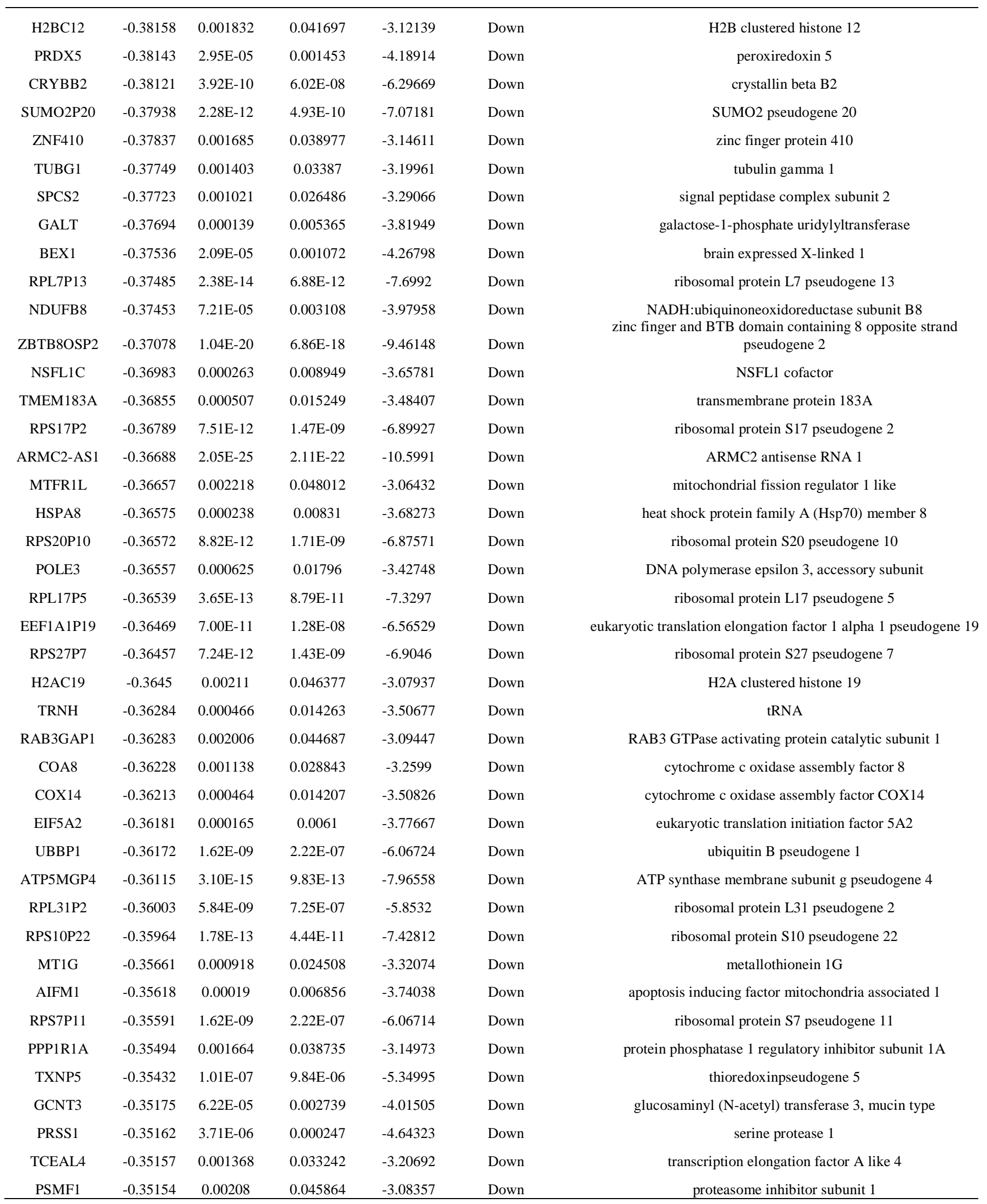




\begin{tabular}{|c|c|c|c|c|c|c|}
\hline TRNY & -0.35146 & 0.001577 & 0.037208 & -3.1655 & Down & tRNA \\
\hline HMGN2P19 & -0.35078 & $2.31 \mathrm{E}-10$ & 3.81E-08 & -6.38038 & Down & high mobility group nucleosomal binding domain 2 pseudogene 1 \\
\hline CCDC28B & -0.35008 & 0.002068 & 0.045694 & -3.08537 & Down & coiled-coil domain containing 28B \\
\hline RPL35P1 & -0.34973 & $2.03 \mathrm{E}-09$ & 2.75E-07 & -6.02984 & Down & ribosomal protein L35 pseudogene 1 \\
\hline CYCSP39 & -0.34969 & $2.71 \mathrm{E}-13$ & $6.62 \mathrm{E}-11$ & -7.37069 & Down & CYCS pseudogene 39 \\
\hline USP9Y & -0.34852 & $1.12 \mathrm{E}-05$ & 0.000626 & -4.40562 & Down & ubiquitin specific peptidase 9 Y-linked \\
\hline PKM & -0.34839 & 0.000103 & 0.004198 & -3.89425 & Down & pyruvate kinase $\mathrm{M} 1 / 2$ \\
\hline RPL7P50 & -0.34813 & 7.93E-18 & $3.47 \mathrm{E}-15$ & -8.70243 & Down & ribosomal protein L7 pseudogene 50 \\
\hline RPL28P3 & -0.34505 & 3.60E-09 & 4.67E-07 & -5.93477 & Down & ribosomal protein L28 pseudogene 3 \\
\hline CANX & -0.34183 & 0.000446 & 0.013793 & -3.51834 & Down & calnexin \\
\hline SPINK4 & -0.34142 & 0.001734 & 0.039855 & -3.13776 & Down & serine peptidase inhibitor Kazal type 4 \\
\hline SLC25A6P2 & -0.33937 & $1.36 \mathrm{E}-17$ & $5.83 \mathrm{E}-15$ & -8.63792 & Down & solute carrier family 25 member 6 pseudogene 2 \\
\hline NDUFA4P1 & -0.33899 & $7.21 \mathrm{E}-12$ & $1.43 \mathrm{E}-09$ & -6.90516 & Down & NDUFA4 pseudogene 1 \\
\hline UBE2L4 & -0.33748 & $8.82 \mathrm{E}-10$ & $1.26 \mathrm{E}-07$ & -6.16659 & Down & ubiquitin conjugating enzyme E2 L4 (pseudogene) \\
\hline RPLP0P9 & -0.33611 & $4.30 \mathrm{E}-06$ & 0.00028 & -4.61241 & Down & ribosomal protein lateral stalk subunit $\mathrm{P} 0$ pseudogene \\
\hline NQO1 & -0.33534 & 7.91E-06 & 0.000464 & -4.4824 & Down & $\mathrm{NAD}(\mathrm{P}) \mathrm{H}$ quinone dehydrogenase 1 \\
\hline CTNNAL1 & -0.33523 & 0.000131 & 0.005101 & -3.83429 & Down & catenin alpha like 1 \\
\hline RPL39P27 & -0.32699 & $3.42 \mathrm{E}-10$ & 5.29E-08 & -6.31839 & Down & ribosomal protein L39 pseudogene 27 \\
\hline HMGN2P18 & -0.32623 & $1.69 \mathrm{E}-14$ & $5.15 \mathrm{E}-12$ & -7.74457 & Down & high mobility group nucleosomal binding domain 2 pseudogene 1 \\
\hline CRIP1 & -0.32531 & 0.000709 & 0.019885 & -3.39276 & Down & cysteine rich protein 1 \\
\hline RPL37AP1 & -0.32523 & 4.73E-12 & $9.79 \mathrm{E}-10$ & -6.96667 & Down & ribosomal protein L37a pseudogene 1 \\
\hline UFD1 & -0.3246 & 0.000986 & 0.025803 & -3.30056 & Down & ubiquitin recognition factor in ER associated degradation 1 \\
\hline PXK & -0.32391 & 0.001856 & 0.042076 & -3.11764 & Down & PX domain containing serine/threonine kinase like \\
\hline ZNF326 & -0.3234 & 0.00083 & 0.022591 & -3.3491 & Down & zinc finger protein 326 \\
\hline RPL39P32 & -0.32252 & $7.80 \mathrm{E}-07$ & $6.05 \mathrm{E}-05$ & -4.96006 & Down & ribosomal protein L39 pseudogene 32 \\
\hline SNRPEP4 & -0.32224 & 4.61E-05 & 0.002121 & -4.08577 & Down & SNRPE pseudogene 4 \\
\hline RPL17P36 & -0.32176 & $3.69 \mathrm{E}-06$ & 0.000246 & -4.64418 & Down & ribosomal protein L17 pseudogene 36 \\
\hline RPL41P4 & -0.32162 & $1.22 \mathrm{E}-08$ & $1.44 \mathrm{E}-06$ & -5.7269 & Down & ribosomal protein L41 pseudogene 4 \\
\hline TUBA1C & -0.32135 & 0.002099 & 0.046178 & -3.08083 & Down & tubulin alpha $1 \mathrm{c}$ \\
\hline MTRNR2L8 & -0.32104 & $6.50 \mathrm{E}-06$ & 0.000396 & -4.52457 & Down & MT-RNR2 like 8 \\
\hline RPL24P4 & -0.32073 & $2.88 \mathrm{E}-07$ & $2.49 \mathrm{E}-05$ & -5.15335 & Down & RPL24 pseudogene 4 \\
\hline RPL26P30 & -0.32051 & $5.20 \mathrm{E}-07$ & 4.21E-05 & -5.03928 & Down & ribosomal protein L26 pseudogene 30 \\
\hline
\end{tabular}




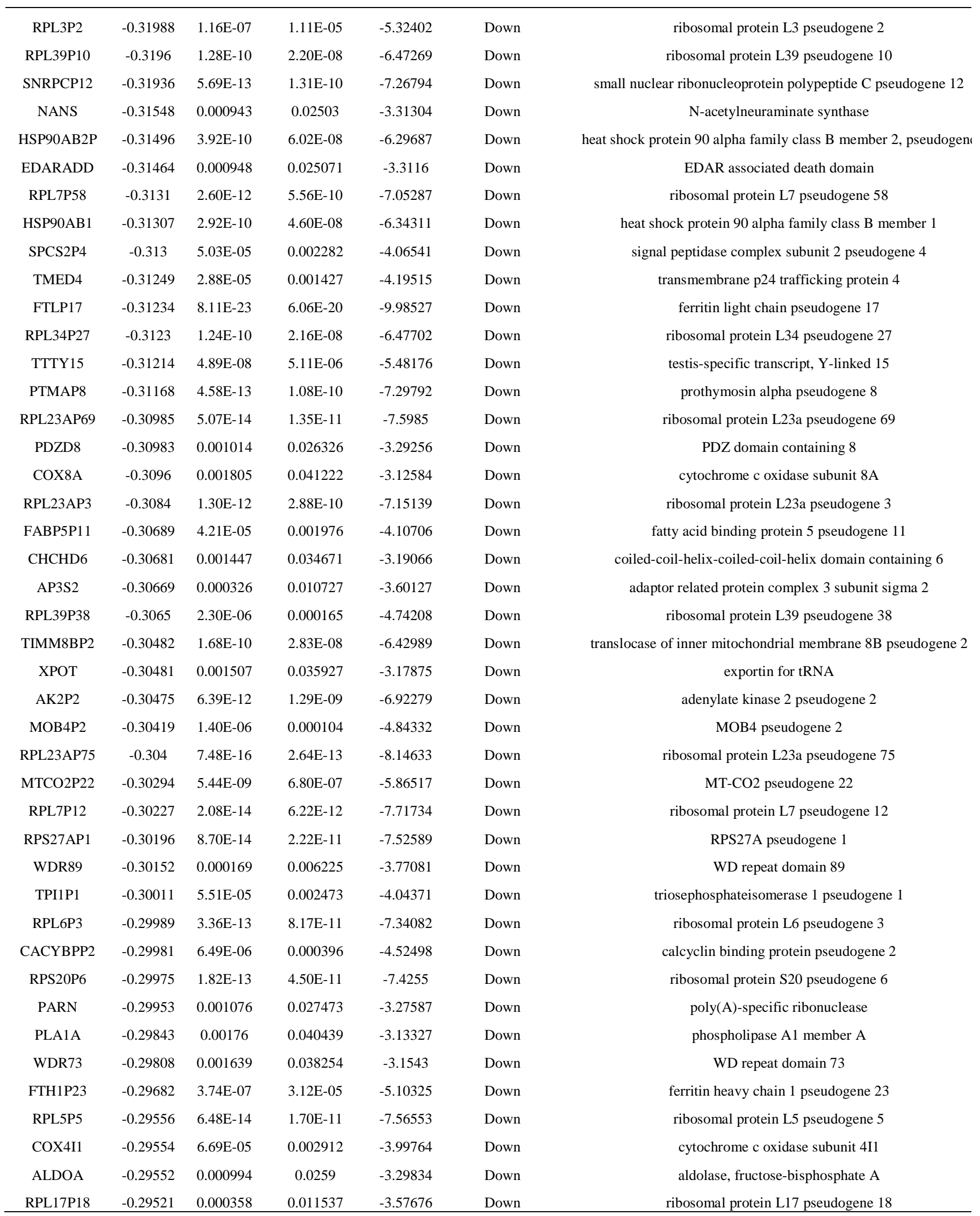




\begin{tabular}{|c|c|c|c|c|c|c|}
\hline TMEM45A & -0.29497 & 0.000507 & 0.015249 & -3.48414 & Down & transmembrane protein $45 \mathrm{~A}$ \\
\hline $\mathrm{AK} 2 \mathrm{P} 1$ & -0.29357 & 8.72E-06 & 0.000507 & -4.46113 & Down & adenylate kinase 2 pseudogene 1 \\
\hline RPL17P8 & -0.29299 & $2.71 \mathrm{E}-12$ & $5.73 \mathrm{E}-10$ & -7.04707 & Down & ribosomal protein L17 pseudogene 8 \\
\hline MTRNR2L10 & -0.29272 & $1.23 \mathrm{E}-10$ & 2.15E-08 & -6.47884 & Down & MT-RNR2 like 10 \\
\hline RPL22P2 & -0.2924 & $1.26 \mathrm{E}-05$ & 0.000687 & -4.38018 & Down & ribosomal protein L22 pseudogene 2 \\
\hline RPL36AP45 & -0.2914 & $2.35 \mathrm{E}-06$ & 0.000168 & -4.73774 & Down & ribosomal protein L36a pseudogene 45 \\
\hline ATP5MDP1 & -0.29073 & $8.75 \mathrm{E}-06$ & 0.000507 & -4.46052 & Down & ATP synthase membrane subunit DAPIT pseudogene 1 \\
\hline RPL39P19 & -0.28815 & 4.20E-07 & $3.45 \mathrm{E}-05$ & -5.08096 & Down & ribosomal protein L39 pseudogene 19 \\
\hline RPL26P6 & -0.28765 & 0.001911 & 0.043097 & -3.10897 & Down & ribosomal protein L26 pseudogene 6 \\
\hline SNRPGP10 & -0.2849 & 2.43E-07 & 2.14E-05 & -5.18542 & Down & small nuclear ribonucleoprotein polypeptide G pseudogene 10 \\
\hline EEF1B2P6 & -0.2846 & $1.33 \mathrm{E}-05$ & 0.00072 & -4.36856 & Down & eukaryotic translation elongation factor 1 beta 2 pseudogene 6 \\
\hline NQO2 & -0.28447 & 0.001315 & 0.032295 & -3.21842 & Down & N-ribosyldihydronicotinamide:quinonereductase 2 \\
\hline RPL23AP65 & -0.28402 & $2.51 \mathrm{E}-05$ & 0.001264 & -4.22608 & Down & ribosomal protein L23a pseudogene 65 \\
\hline RPL7P11 & -0.28298 & $4.22 \mathrm{E}-14$ & $1.15 \mathrm{E}-11$ & -7.62331 & Down & ribosomal protein L7 pseudogene 11 \\
\hline CD63 & -0.28254 & $5.62 \mathrm{E}-07$ & $4.48 \mathrm{E}-05$ & -5.02445 & Down & CD63 molecule \\
\hline RPS15AP12 & -0.2825 & $1.17 \mathrm{E}-08$ & $1.38 \mathrm{E}-06$ & -5.73422 & Down & ribosomal protein S15a pseudogene 12 \\
\hline RPL14 & -0.28079 & $5.42 \mathrm{E}-05$ & 0.002436 & -4.04785 & Down & ribosomal protein L14 \\
\hline UQCRHL & -0.27518 & $1.61 \mathrm{E}-07$ & $1.49 \mathrm{E}-05$ & -5.2628 & Down & ubiquinol-cytochrome $\mathrm{c}$ reductase hinge protein like \\
\hline CORO1C & -0.27502 & 0.001554 & 0.036725 & -3.16987 & Down & coronin 1C \\
\hline RPL15P20 & -0.27449 & $1.36 \mathrm{E}-09$ & $1.88 \mathrm{E}-07$ & -6.09611 & Down & ribosomal protein L15 pseudogene 20 \\
\hline DNAJC19P9 & -0.274 & 0.000114 & 0.00458 & -3.8681 & Down & DnaJ heat shock protein family (Hsp40) member C19 pseudogene \\
\hline HIGD1AP14 & -0.27375 & $6.93 \mathrm{E}-10$ & 1.02E-07 & -6.20549 & Down & HIG1 hypoxia inducible domain family member $1 \mathrm{~A}$ pseudogene 1 \\
\hline FABP5P8 & -0.27319 & $4.75 \mathrm{E}-09$ & $5.99 \mathrm{E}-07$ & -5.88828 & Down & fatty acid binding protein 5 pseudogene 8 \\
\hline HMBS & -0.27266 & 0.000468 & 0.014321 & -3.50546 & Down & hydroxymethylbilane synthase \\
\hline RPSAP17 & -0.27253 & $1.27 \mathrm{E}-08$ & 1.49E-06 & -5.71973 & Down & ribosomal protein SA pseudogene 17 \\
\hline PPP2CBP1 & -0.27127 & $1.19 \mathrm{E}-12$ & $2.65 \mathrm{E}-10$ & -7.16403 & Down & protein phosphatase 2 catalytic subunit beta pseudogene 1 \\
\hline RPL24P8 & -0.27089 & $1.51 \mathrm{E}-08$ & $1.72 \mathrm{E}-06$ & -5.68998 & Down & RPL24 pseudogene 8 \\
\hline ETV5 & -0.27005 & 0.001333 & 0.032586 & -3.21453 & Down & ETS variant transcription factor 5 \\
\hline
\end{tabular}


bioRxiv preprint doi: https://doi.org/10.1101/2021.08.12.456106; this version posted August 17, 2021. The copyright holder for this preprint (which was not certified by peer review) is the author/funder. All rights reserved. No reuse allowed without permission.

Table 2 The enriched GO terms of the up and down regulated differentially expressed genes

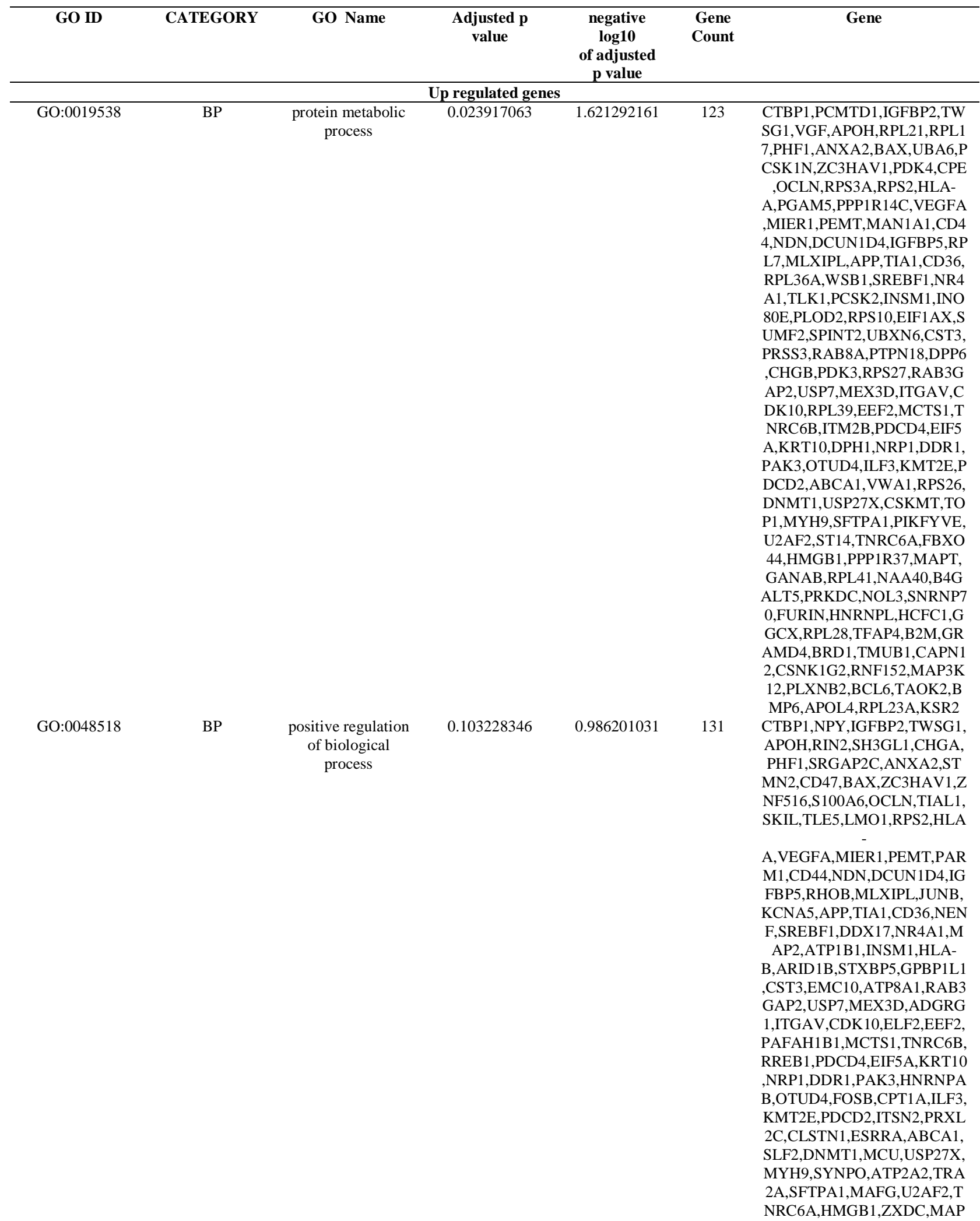


bioRxiv preprint doi: https://doi.org/10.1101/2021.08.12.456106; this version posted August 17, 2021. The copyright holder for this preprint (which was not certified by peer review) is the author/funder. All rights reserved. No reuse allowed without permission.

GO:0005622

CC

intracellular

anatomical

structure
T,ZCCHC3,B4GALT5,CELF3, PRKDC,HIVEP1,SNRNP70,M AGI1,FURIN,WIPF2,HCFC1, SYT7,TFAP4,RGL2,CITED2, B2M,GRAMD4,BRD1,CSNK1 G2,SSBP4,RNF152,MAP3K12 ,PLXNB2,BCL6,TAOK2,SEM A6A,BMP6,ECHDC3,KLF13, TMEM79,MZF1,KSR2,NCOR 2,TENM3

4.57833E-06 $\quad 5.339293274$

267

CTBP1,PCMTD1,GAS2,NPY,I GFBP2,VGF,APOH,MZT2B,R PL21,NME7,MZT2A,SGSM2, RIN2,SH3GL1,RPL17,CHGA, PHF1,SRGAP2C,ALYREF,RU NX1T1,ANXA2,THAP5,COX 7A1,SEZ6L,STMN2,CD47,BA $\mathrm{X}$,SELENOM,DLK1,UBA6,P CSK1N,ND3,ZC3HAV1,ZNF8 3,ZNF516,S100A6,NSUN6,PD K4,CPE,OCLN,TIAL1,PGRM C2,NPIPA1,SKIL,TLE5,RPS3 A,LMO1,RPS2,HLAA,CXXC4,PGAM5,PPP1R14C ,VEGFA,MIER1,NME3,PEMT ,MAN1A1,OVCA2,PARM1,C D44,SLC22A17,NDN,LSAMP, DCUN1D4,NDRG1,IGFBP5, R HOB,RPL7,MLXIPL,JUNB,K CNA5,POLR2J2,APP,TIA1,R ANBP3,RAD52,ARGLU1,CD 36,RPL36A,NENF,MBNL2,F ADS2,WSB1,SREBF1,TMEM 167A,DDX17,NR4A1,APLP1, MAP2,TLK1,PCSK2,INSM1,I NO80E,PLOD2,RPS10,HLAB,EIF1AX,DDX18,ARID1B,S UMF2,SPINT2,STXBP5,GPBP 1L1,SRRM2,UBXN6,CST3, T MEM123,PRSS3,RAB8A,PTP N18,NUDT4B,DYNC2I1,EMC 10,DNASE2,CHGB,PDK3,PL D3,FCGRT,RPS27,ATP8A1,T LE3,ZFX,CYB5R3,RAB3GAP 2,NUDT4,USP7,MEX3D,SUN 1,ITGAV,LUC7L3,SEZ6L2,C DK10,ELF2,ARL4C,CCDC18 6,ATAD3C,RPL39,EEF2,PAF AH1B1,MCTS1,TNRC6B,RR EB1,ITM2B,SRSF3,PDCD4,EI F5A,KRT10,DPH1,NRP1,PAK 3,HNRNPAB,OTUD4,FOSB,C PT1A,ILF3,DOC2A,A1BG,K MT2E,ALDH1B1,ZNF189,PD CD2,ITSN2,CLSTN1,ESRRA, ABCA1,PI4KA,PNISR,VWA1 ,SLF2,RPS26,GNAO1,NISCH, DNMT1,MCU,USP27X,CSK MT,TOP1,MYH9,SYNPO,AT P2A2,GAA,TRA2A,LENG8,S FTPA1,PIKFYVE,MAFG,U2A F2,SLC35E2B,LPCAT4,MIDN ,HOOK3,HNRNPH1,NBPF12, TNRC6A,TCTN2,SSTR3,ZSW IM1,NPIPA5,FBXO44,SIPA1L 3,HMGB1,ZXDC,MAN2B2,B CL2L2-

PABPN1,MAPT,ZCCHC3,GA NAB,RPL41,PABPN1,NAA40 ,B4GALT5,CELF3,PRKDC,HI 
bioRxiv preprint doi: https://doi.org/10.1101/2021.08.12.456106; this version posted August 17, 2021. The copyright holder for this preprint (which was not certified by peer review) is the author/funder. All rights reserved. No reuse allowed without permission.

GO:0012505

VEP1,NOL3,UBN2,SNRNP70, TMEM159,MAGI1,FURIN,WI PF2,CEBPZOS,HNRNPL,MC PH1,HCFC1,CACNA1 A,SYT7 ,GGCX,RPL28,TFAP4,SACS, CITED2,NFASC,B2M,SON,G RAMD4,SLC18A2,GLCCI1,B RD1,TRMT9B,TMUB1,CAPN 12,CSNK1G2,SSBP4,RNF152, MAP3K12,DECR2,SLC6A17, NBPF20,MPRIP,BCL6,SSR4, TAOK2,BMP6,ECHDC3,KLF 13,NPIPB11,APOL4,ZNF783, ND1,RPL23A,TMEM79,RGP D4,MZF1,KSR2,INTS6L,NCO R2

101 NPY,VGF,APOH,RPL21,SH3 GL1,CHGA,ANXA2,SEZ6L,S TMN2,CD47,BAX,SELENOM ,PCSK1N,S100A6,CPE,PGRM C2,NPIPA1,SKIL,RPS3A,HL A-

A,VEGFA,PEMT,MAN1A1,P ARM1,CD44,NDRG1,IGFBP5 ,RHOB,KCNA5,APP,RANBP3 ,CD36,RPL36A,NENF,FADS2 ,SREBF1,TMEM167A,NR4A1 ,PCSK2,PLOD2,HLA-

B,SUMF2,STXBP5,UBXN6,C ST3,PRSS3,RAB8A,EMC10,C HGB,PLD3,FCGRT,ATP8A1, CYB5R3,RAB3GAP2,SUN1,I TGAV,SEZ6L2,CCDC186,EE F2,PAFAH1B1,ITM2B,EIF5A, NRP1,PAK3,DOC2A,A1BG,I TSN2, CLSTN1,ABCA1, VWA 1,RPS26,NISCH,SYNPO,ATP 2A2,GAA,SFTPA1,PIKFYVE, SLC35E2B,LPCAT4,HOOK3, TNRC6A,SIPA1L3,HMGB1,G ANAB,RPL41,B4GALT5,NOL 3,TMEM159,FURIN,SYT7,G GCX,NFASC,B2M,GRAMD4, SLC18A2,TMUB1,SLC6A17, BCL6,SSR4,TMEM79,RGPD4 compound binding
CTBP1,RPL21,NME7,RPL17, PHF1,ALYREF,RUNX1T1,A NXA2,THAP5,UBA6,ZC3HA V1,ZNF83,ZNF516,NSUN6,P DK4,TIAL1,PGRMC2,SKIL,R PS3A,RPS2,HLA-

A,CXXC4,MIER1,NME3,ND N,RHOB,RPL7,MLXIPL,JUN B,POLR2J2,APP,TIA1,RAD52 ,RPL36A,MBNL2,SREBF1,D DX17,NR4A1,TLK1,INSM1,R PS10,EIF1AX,DDX18,ARID1 B,GPBP1L1,SRRM2,RAB8A, NUDT4B,DNASE2,PDK3,RPS 27,ATP8A1,ZFX,CYB5R3,NU DT4,ATP13A3,MEX3D,LUC7 L3,CDK10,ELF2,ARL4C,ATA D3C,RPL39,EEF2,MCTS1,TN RC6B,RREB1,ITM2B,SRSF3, PDCD4,EIF5A,DDR1,PAK3,H NRNPAB,OTUD4,FOSB,ILF3 ,ALDH1B1,ZNF189,PDCD2,E SRRA,ABCA1,PI4KA,PNISR, RPS26,GNAO1,DNMT1,TOP1 ,MYH9,ATP2A2,TRA2A,PIK 
bioRxiv preprint doi: https://doi.org/10.1101/2021.08.12.456106; this version posted August 17, 2021. The copyright holder for this preprint (which was not certified by peer review) is the author/funder. All rights reserved. No reuse allowed without permission.

GO:0005515

MF

protein binding

0.543492863

0.264806155
FYVE,MAFG,U2AF2,HNRNP H1,TNRC6A,HMGB1,ZXDC, BCL2L2-

PABPN1,MAPT,ZCCHC3,GA NAB,RPL41,PABPN1,CELF3, PRKDC,HIVEP1,NOL3,SNRN P70,RBM33,MAGI1,HNRNPL ,HCFC1,RPL28,TFAP4,SON,T RMT9B,CSNK1G2,SSBP4,M AP3K12,BCL6,AHDC1,TAOK 2,KLF13,ZNF783,RPL23A,M ZF1,KSR2,NCOR2

CTBP1,PCMTD1,GAS2,CPNE 8,NPY,IGFBP2,TWSG1,VGF, APOH,MZT2B,RPL21,NME7, MZT2A,SH3GL1,RPL17,PHF 1,SRGAP2C,RUNX1T1,ANX A2,THAP5,COX7A1,SEZ6L,S TMN2,CD47,BAX,SELENOM ,DLK1,UBA6,PCSK1N,ND3,Z C3HAV1,ZNF83,ZNF516,S10 0A6,FXYD5,PDK4,CPE,OCL N,TIAL1,CDCP1,PGRMC2,S KIL,TLE5,RPS3A,LMO1,RPS 2,HLA-

A,PGAM5,NPDC1,VEGFA,M IER1,NME3,PEMT,PARM1,C D44,ANKRD36,SLC22A17,N DN,LSAMP,DCUN1D4,NDR G1,IGFBP5,RHOB,RPL7,ML XIPL,JUNB,KCNA5,POLR2J2 ,APP,TIA1,RANBP3,RAD52, ARGLU1,CD36,RPL36A,NEN F,TMEM45B,MBNL2,FADS2, WSB1,SREBF1,TMEM167A, DDX17,NR4A1,APLP1,CDH1 0,MAP2,TLK1,ATP1B1,PCSK 2,INSM1,INO80E,RPS10,AN KRD36C,HLA-

B,EIF1AX,DDX18,ARID1B,S UMF2,STXBP5,GPBP1L1,SR RM2,UBXN6,CST3,TMEM12 3,MPP6,PRSS3,RAB8A,PTPN 18,DYNC2I1,CHGB,PDK3,PL D3,FCGRT,ALCAM,RPS27,A TP8A1,TLE3,CYB5R3,RAB3 GAP2,NUDT4,USP7,ADGRG 1,SUN1,ITGAV,LUC7L3,CD K10,ELF2,ARL4C,FAM102A, EEF2,SAMD12,PAFAH1B1,M CTS1,TNRC6B,ITM2B,SRSF3 ,PDCD4,FAM229B,EIF5A,KR T10,DPH1,NRP1,DDR1,PAK3 ,HNRNPAB,OTUD4,FOSB,CP T1A,ILF3,DOC2A,KMT2E,PD CD2,ITSN2,CLSTN1,ESRRA, ABCA1,PI4KA,VWA1,SLF2, RPS26,GNAO1,NISCH,DNM T1,MCU,CSKMT,TOP1,MYH 9,SYNPO,ATP2A2,TRA2A,L ENG8,SFTPA1,PIKFYVE,MA FG,U2AF2,ST14,MIDN,HOO K3,HNRNPH1,TNRC6A,SST R3,WDR17,FBXO44,SIPA1L3 ,HMGB1,ZXDC,MAN2B2,PP P1R37,BCL2L2-

PABPN1,MAPT,ZCCHC3,GA NAB,RPL41,PABPN1,NAA40 ,PRKDC,HIVEP1,KIAA0895L ,NOL3,SNRNP70,TMEM159, 
bioRxiv preprint doi: https://doi.org/10.1101/2021.08.12.456106; this version posted August 17, 2021. The copyright holder for this preprint (which was not certified by peer review) is the author/funder. All rights reserved. No reuse allowed without permission.

MAGI1,FURIN,WIPF2,UMA D1,HNRNPL,MCPH1,HCFC1, CACNA1A,SYT7,RPL28,TFA P4,RGL2,SDK1,SACS,ANKR D18A,CITED2,NFASC,B2M,S ON,GRAMD4,SLC18A2,RGL 3,BRD1,TMUB1,CSNK1G2,S SBP4,RNF152,MAP3K12,DE CR2,PLXNB2,SLC6A17,MPR IP,BCL6,AHDC1,TAOK2,SE MA6A,BMP6,SHISAL1,KLF1 3,APOL4,ZNF783,ND1,RPL23

A,TMEM79,RGPD4,MZF1,KS R2,NCOR2,TENM3

GO:0051234 BP $\quad \begin{gathered}\text { establishment of } \\ \text { localization }\end{gathered}$

Down regulated genes 0.000213201 3.671209808

116

RPS4Y1,FXYD2,FXYD6-
FXYD2,FTL,SAR1A,TUBA4 A,RBP4,GSTP1,VAMP8,PSM B7,CYB5A,UQCC2,RPS28,C AMK2D,G6PC2,BCAP31,AS AH1,RPL9,ATP6V1B2,DNAJ C15,VPS25,ATP5PB,PSMC4, TMED6,ATP6V1D,UCHL1,PS MC5,SLC25A5,NDUFA9,PPT 1,SSR2,ARRDC3,ARL6IP1,PS MD7,TIMM17A,ATP5F1C,AT P6V1E1,RAB21,CTSA,NIT2, ATP5MC1,MPC1,PSMD6,CLI C1,REEP5,IDH1,PSMB5,XRC C6,PSMB3,PRDX6,CLU,TTR, GRB2,RAB3B,ATP5PO,CYST M1,TRAPPC2L,PSMA4,NAP A,VAT1,UBE2B,CAP1,TXN,P SMB2,SCAMP3,DYNLRB1,L AMTOR1,GLUL,NEU1,SVBP ,NR0B2,ZMPSTE24,IER3IP1, CAPZB,FTH1,DNAJA1,PSM D12,COX6B1,IBTK,SQSTM1, ARCN1,ATP5F1B,GABARAP ,HSPA5,COTL1,PEF1,SPCS2, NSFL1C,HSPA8,RAB3GAP1, COA8,EIF5A2,AIFM1,GCNT3 ,PSMF1,PKM,CDC23,CANX, GPI,UFD1,PXK,TUBA1C,HS P90AB1,TMED4,PDZD8,COX 8A,AP3S2,XPOT,COX4I1,AL DOA,LDLRAP1,CD63,RPL14, UBC,ATP5MC2,CORO1C PS28,CAMK2D,G6PC2,BCAP 31,ASAH1,RPL9,ATP6V1B2, DNAJC15,VPS25,EIF1AY,AT P5PB,CDC42BPA,PSMC4,AT P6V1D,UCHL1,PSMC5,NDU FA9,PPT1,PIR,MLLT11,SARS 1,ARRDC3,TSPYL5,ARL6IP1 ,TOX4,PSMD7,TIMM17A,BL VRB,ATP5F1C,SH3BGRL3,P RPS2,MRPL54,NDUFA12,AT P6V1E1,PRDX1,CTSA,NIT2, BUD23,ATP5MC1,LCLAT1,U BE2L5,MPC1,PSMD6,GBA,E NO1,ESD,FDPS,IDH1,HOPX, PSMB5,MRPS35,XRCC6,PSM B3,PRDX6,ZNF165,NDUFV3, CLU,GLMP,MDH2,EIF3K,TT R,PTGR2,GNPDA1,GHITM,H 
bioRxiv preprint doi: https://doi.org/10.1101/2021.08.12.456106; this version posted August 17, 2021. The copyright holder for this preprint (which was not certified by peer review) is the author/funder. All rights reserved. No reuse allowed without permission.

PF1,GRB2,RAB3B,RPS27AP5 ,MDH1,ATP5PO,POLR3K,UB E2L6,PSMA4,SCD,KLHL41,P IGP,SUCLG1,TXN2,UBE2B, GTF2A2,DAP,ACADM,TXN, BLVRA,PSMB2,COA3,UQCR H,MGST3,MRPS15,LAMTOR 1,GLUL,PCMTD2,NEU1,ALG 3,ORC3,GTF2B,EXOSC1,FA RSA,FKBP1C,SVBP,NR0B2,Z MPSTE24,GAPDH,LBHD1,D NAJA1,PPIL1,PSMD12,COX6 B1,NDUFB7,IBTK,SQSTM1, ARG2,MORF4L2,DHDDS,RN F6,ATP5F1B,GABARAP,HSP A5,RAD23A,MPP1,NSMCE2, PEF1,MBIP,TATDN3,H2BC1 2,PRDX5,ZNF410,SPCS2,GA LT,BEX1,NSFL1C,MTFR1L, HSPA8,POLE3,H2AC19,RAB 3GAP1,COA8,EIF5A2,AIFM1 ,PPP1R1A,GCNT3,PRSS1,TC EAL4,PSMF1,USP9Y,PKM,S CNM1,CDC23,SPINK4,NQO1 ,ETV6,MRPS11,GPI,TRUB1, UFD1,PXK,ZNF326,NANS,H SP90AB1,COX8A,PARN,PLA 1A,COX4I1,ALDOA,LDLRAP 1,TPI1,PRORP,NQO2,CD63,R PL14,UBC,ATP5MC2,UQCR HL,CORO1C,HMBS,ETV5 RPS4Y1,FTL,SAR1A,TUBA4 A,MT2A,IFI30,CNOT6L,RBP 4,GPX2,GSTP1,IFI27L2,MTC H2,VAMP8,SAT1,HEPACAM 2,PSMB7,CYB5A,UQCC2,ET FB,SCGN,PPIB,RPS28,CAMK 2D,G6PC2,MTRNR2L12,DDX 3Y,BCAP31,ASAH1,RPL9,AT P6V1B2,DNAJC15,VPS25,AT P5PB,CDC42BPA,PSMC4,TM ED6,ATP6V1D,UCHL1,PSMC 5,SLC25A5,ATXN7L3B,NDU FA9,PPT1,PIR,MLLT11,SARS 1,TMEM106C,SSR2,ARRDC3 ,PCP4,ARL6IP1,PSMD7,TIM M17A,BLVRB,ATP5F1C,SH3 BGRL3,PRPS2,MRPL54,NDU FA12,ATP6V1E1, GRAMD2B, RAB21,PRDX1,CTSA,NIT2,B UD23,ATP5MC1,LCLAT1,MP C1,PSMD6,CLIC1,GBA,ENO 1,ESD,REEP5,FDPS,IDH1,HO PX,PSMB5,MRPS35,XRCC6, PSMB3,PRDX6,NDUFV3,CL U,CDV3,GLMP,PLEKHB2,M DH2,EIF3K,TTR,PTGR2,GNP DA1,GHITM,GRB2,MT1E,RA B3B,RPS27AP5,MDH1,ATP5 PO,POLR3K,UBE2L6,CYST M1,TRAPPC2L,PSMA4,SCD, KLHL41,REG1 A,PIGP,SUCL G1,NAPA,VAT1,TXN2,UBE2 B,PRXL2A,ACADM,CAP1,T XN,BLVRA,PSMB2,SCAMP3 ,COA3,DYNLRB1,UQCRH,M GST3,MRPS15,LAMTOR1,G LUL,PCMTD2,NEU1,ALG3,E XOSC1,FARSA,FKBP1C,SVB P,NR0B2,PTGFRN,ZMPSTE2 
bioRxiv preprint doi: https://doi.org/10.1101/2021.08.12.456106; this version posted August 17, 2021. The copyright holder for this preprint (which was not certified by peer review) is the author/funder. All rights reserved. No reuse allowed without permission.

intracellular anatomical structure
4,GAPDH,IER3IP1,CAPZB,F TH1,DNAJA1,PSMD12,COX6 B1,NDUFB7,IBTK,SQSTM1, ARG2,DHDDS,ARCN1,RNF6, ATP5F1B,GABARAP,HSPA5, RAD23A,COTL1,MPP1,MTR NR2L1,PEF1,MBIP,H2BC12,P RDX5,TUBG1,SPCS2,GALT, BEX1,NSFL1C,MTFR1L,HSP A8,RAB3GAP1,COA8,COX14 ,EIF5A2,MT1G,AIFM1,PPP1R 1A,GCNT3,PSMF1,CCDC28B ,USP9Y,PKM,CDC23,CANX, NQO1,CTNNAL1,ETV6,MRP S11,GPI,TRUB1,CRIP1,UFD1, PXK,TUBA1C,MTRNR2L8,N ANS,EDARADD,HSP90AB1, TMED4,PDZD8,COX8A,CHC HD6,AP3S2,XPOT,PARN,PL A1A,WDR73,COX4I1,ALDO A,LDLRAP1,MTRNR2L10,TP I1,PRORP,NQO2,CD63,RPL1 4,UBC,ATP5MC2,UQCRHL,C ORO1C,HMBS

RPS4Y1,PTBP2,FTL,SAR1A, TUBA4A,MT2A,IFI30,CNOT 6L,RBP4,GPX2,GSTP1,IFI27L 2,MTCH2,VAMP8,SAT1,HEP ACAM2,PSMB7,CYB5A,UQC C2,ETFB,SCGN,USP22,PPIB, RTF2,RPS28,CAMK2D,G6PC 2,MTRNR2L12,DDX3Y,BCA P31,ASAH1,RPL9,ATP6V1B2 ,DNAJC15,VPS25,ATP5PB,C DC42BPA,PSMC4,TMED6,A TP6V1D,UCHL1,PSMC5,SLC 25A5,ATXN7L3B,NDUFA9,P PT1,PIR,MLLT11,SARS1,TM EM106C,SSR2,ARRDC3,TSP YL5,PCP4,ARL6IP1,TOX4,PS MD7,TIMM17A,BLVRB,ATP 5F1C,SH3BGRL3,PRPS2,MR PL54,NDUFA12,ATP6V1E1,G RAMD2B,RAB21,PRDX1,CT SA,NIT2,BUD23,ATP5MC1,L CLAT1,UBE2L5,MPC1,PSMD 6,CLIC1,THYN1,GBA,ENO1, ESD,REEP5,FDPS,IDH1,HOP X,PSMB5,MRPS35,XRCC6,P SMB3,PRDX6,ZNF165,NDUF V3,CLU,CDV3,GLMP,PLEK HB2,MDH2,EIF3K,TTR,SDR3 9U1,PTGR2,GNPDA1,GHITM ,HPF1,GRB2,MT1E,RAB3B,R PS27AP5,MDH1,ATP5PO,PO LR3K,UBE2L6,CYSTM1,C11 ORF54,TRAPPC2L,PSMA4,S CD,KLHL41,REG1A,PIGP,SU CLG1,NAPA,VAT1,TXN2,UB E2B,PRXL2A,GTF2A2,ACAD M,CAP1,TXN,BLVRA,PSMB 2,SCAMP3,COA3,DYNLRB1, UQCRH,MGST3,MRPS15,LA MTOR1,GLUL,PCMTD2,NEU 1,ALG3,ORC3,GTF2B,EXOS C1,FARSA,FKBP1C,SVBP,N R0B2,PTGFRN,ZMPSTE24,G APDH,IER3IP1,CAPZB,LBH D1,FTH1,DNAJA1,PPIL1,PS MD12,COX6B1,NDUFB7,IBT 
bioRxiv preprint doi: https://doi.org/10.1101/2021.08.12.456106; this version posted August 17, 2021. The copyright holder for this preprint (which was not certified by peer review) is the author/funder. All rights reserved. No reuse allowed without permission.

GO:0003824 MF

catalytic activity

$6.46 \mathrm{E}-08$

7.189593031

130
K,SQSTM1,ARG2,MORF4L2, DHDDS,ARCN1,RNF6,ATP5 F1B,GABARAP,HSPA5,RAD 23A,COTL1,MPP1,NSMCE2, MTRNR2L1,PEF1,MBIP,TAT DN3,H2BC12,PRDX5,ZNF410 ,TUBG1,SPCS2,GALT,BEX1, NSFL1C,MTFR1L,HSPA8,PO LE3,H2AC19,RAB3GAP1,CO A8,COX14,EIF5A2,MT1G,AI FM1,PPP1R1A,GCNT3,TCEA L4,PSMF1,CCDC28B,USP9Y, PKM,SCNM1,CDC23,CANX, NQO1,CTNNAL1,ETV6,MRP S11,GPI,TRUB1,CRIP1,UFD1, PXK,ZNF326,TUBA1C,MTR NR2L8,NANS,EDARADD,HS P90AB1,TMED4,PDZD8,COX 8A,CHCHD6,AP3S2,XPOT,P ARN,PLA1A,WDR73,COX4I1 ,ALDOA,LDLRAP1,MTRNR2 L10,TPI1,PRORP,NQO2,CD6 3,RPL14,UBC,ATP5MC2,UQ CRHL,CORO1C,HMBS,ETV5 SAR1A,TUBA4A,IFI30,CNOT 6L,GPX2,GSTP1,SAT1,PSMB 7,CYB5A,ETFB,USP22,PPIB, CAMK2D,G6PC2,DDX3Y,AS AH1,ATP6V1B2,ATP5PB,CD C42BPA,PSMC4,UCHL1,PSM C5,NDUFA9,PPT1,PIR,SARS 1,PSMD7,BLVRB,ATP5F1C,S H3BGRL3,PRPS2,NDUFA12, ATP6V1E1,RAB21,PRDX1,C TSA,NIT2,BUD23,ATP5MC1, LCLAT1,UBE2L5,PSMD6,GB A,ENO1,ESD,FDPS,IDH1,PS MB5,XRCC6,PSMB3,PRDX6, NDUFV3,MDH2,SDR39U1,P TGR2,GNPDA1,RAB3B,MDH 1,ATP5PO,POLR3K,UBE2L6, C11ORF54,PSMA4,SCD,PIGP ,SUCLG1,VAT1,TXN2,NTPC R,UBE2B,ACADM,TXN,BLV RA,TMEM68,PSMB2,DYNLR B1,UQCRH,MGST3,GLUL,P CMTD2,NEU1,ALG3,GTF2B, FARSA,FKBP1C,ZMPSTE24, GAPDH,FTH1,PPIL1,COX6B 1,NDUFB7,SQSTM1,ARG2,D HDDS,RNF6, ATP5F1B,HSPA 5,MPP1,NSMCE2,TATDN3,P RDX5,TUBG1,SPCS2,GALT, HSPA8,POLE3,AIFM1,GCNT 3,PRSS1,USP9Y,PKM,CDC23 ,NQO1,GPI,TRUB1,UFD1,PX K,TUBA1C,NANS,COX8A,P ARN,PLA1A,COX4I1,ALDO A,TPI1,PRORP,NQO2,ATP5 MC2,UQCRHL,HMBS

GO:0005515 MF
0.001861874
2.730049815
231
RPS4Y1,SST,PTBP2,FXYD2, FTL,SAR1A,TUBA4A,MT2A, IFI30,CNOT6L,RBP4,IAPP,G STP1,MTCH2,VAMP8,SAT1, HEPACAM2,PSMB7,CYB5A, UQCC2,ETFB,SCGN,USP22,P PIB,RTF2,RPS28,CAMK2D,M TRNR2L12,BCAP31,ASAH1, RPL9,ATP6V1B2,DNAJC15,V PS25,EIF1AY,ATP5PB,CDC4 
bioRxiv preprint doi: https://doi.org/10.1101/2021.08.12.456106; this version posted August 17, 2021. The copyright holder for this preprint (which was not certified by peer review) is the author/funder. All rights reserved. No reuse allowed without permission.

2BPA,PSMC4,ATP6V1D,UCH L1,PSMC5,SLC25A5,ATXN7 L3B,NDUFA9,PPT1,PIR,MLL T11,SARS1,TMEM106C,SSR2 ,ARRDC3,TSPYL5,PCP4,ARL 6IP1,TOX4,TSPAN7,PSMD7, BLVRB,ATP5F1C,SH3BGRL 3,PRPS2,MRPL54,NDUFA12, ATP6V1E1,GRAMD2B,RAB2 1,PRDX1,BUD23,ATP5MC1, LCLAT1,UBE2L5,MPC1,PSM D6,CLIC1,GBA,ENO1,ESD,R EEP5,FDPS,IDH1,HOPX,PSM B5,XRCC6,PSMB3,PRDX6,Z NF165,NDUFV3,CLU,PLEKH B2,MDH2,EIF3K,TTR,PTGR2 ,GNPDA1,GHITM,HPF1,GRB 2,MT1E,RAB3B,RPS27AP5,M DH1,ATP5PO,POLR3K,UBE2 L6,CYSTM1,C11ORF54,TRA PPC2L,PSMA4,SCD,KLHL41, REG1A,PIGP,NAPA,VAT1,T XN2,UBE2B,CUTA,GTF2A2, DAP,ACADM,CAP1,TXN,ER ICH5,BLVRA,PSMB2,SCAM P3,COA3,DYNLRB1,UQCRH, MGST3,LAMTOR1,GLUL,PC MTD2,NEU1,ALG3,ORC3,GT F2B,EXOSC1,FARSA,SVBP, NR0B2,PTGFRN,ZMPSTE24, GAPDH,IER3IP1,CAPZB,LB HD1,FTH1,DNAJA1,PPIL1,PS MD12,NDUFB7,IBTK,SQST M1,ARG2,MORF4L2,DHDDS ,ARCN1,RNF6,ATP5F1B,GA BARAP,HSPA5,RAD23A,CO TL1,MPP1,NSMCE2,MTRNR 2L1,PEF1,MBIP,H2BC12,PRD X5,CRYBB2,ZNF410,TUBG1, GALT,BEX1,NSFL1C,TMEM 183A,MTFR1L,HSPA8,POLE 3,H2AC19,RAB3GAP1,COX1 4,EIF5A2,MT1G,AIFM1,PPP1 R1A,TCEAL4,PSMF1,CCDC2 8B,USP9Y,PKM,SCNM1,CDC 23,CANX,SPINK4,NQO1,CT NNAL1,ETV6,MRPS11,GPI,U FD1,PXK,ZNF326,TUBA1C, MTRNR2L8,EDARADD,HSP 90AB1,PDZD8,COX8A,CHC HD6,XPOT,WDR89,PARN,W DR73,COX4I1,ALDOA,TME M45A,LDLRAP1,MTRNR2L1 0,TPI1,PRORP,NQO2,CD63,R PL14,UBC,ATP5MC2,CORO1 C,HMBS,ETV5 
bioRxiv preprint doi: https://doi.org/10.1101/2021.08.12.456106; this version posted August 17, 2021. The copyright holder for this preprint (which was not certified by peer review) is the author/funder. All rights reserved. No reuse allowed without permission.

Table 3 The enriched pathway terms of the up and down regulated differentially expressed genes

\begin{tabular}{|c|c|c|c|c|c|}
\hline Pathway ID & Pathway Name & Adjusted p value & $\begin{array}{l}\text { Negative } \log 10 \text { of } \\
\text { adjusted p value }\end{array}$ & $\begin{array}{c}\text { Gene } \\
\text { Count }\end{array}$ & Gene \\
\hline \multicolumn{6}{|c|}{ Up regulated genes } \\
\hline REAC:R-HSA-392499 & Metabolism of proteins & 0.013327181 & 1.875261715 & 55 & $\begin{array}{c}\text { CTBP1,IGFBP2,VGF,RPL } \\
\text { 21,RPL17,UBA6,CPE,RPS } \\
\text { 3A,RPS2,HLA- } \\
\text { A,MAN1A1,LSAMP,DCU } \\
\text { N1D4,IGFBP5,RPL7,APP, } \\
\text { RAD52,RPL36A,WSB1,D } \\
\text { DX17,PCSK2,INO80E,RP } \\
\text { S10,EIF1AX,SUMF2,CST } \\
\text { 3,RAB8A,CHGB,RPS27,U } \\
\text { SP7,RPL39,EEF2,ITM2B, } \\
\text { EIF5A,DPH1,VWA1,RPS } \\
\text { 26,GNAO1,DNMT1,TOP1 } \\
\text {,SFTPA1,FBXO44,GANA } \\
\text { B,RPL41,B4GALT5,PRK } \\
\text { DC,FURIN,HCFC1,GGCX } \\
\text {,RPL28,B2M,RNF152,SSR } \\
\text { 4,RPL23A,NCOR2 }\end{array}$ \\
\hline REAC:R-HSA-9029569 & $\begin{array}{l}\mathrm{NR} 1 \mathrm{H} 3 \text { \& NR1H2 } \\
\text { regulate gene } \\
\text { expression linked to } \\
\text { cholesterol transport } \\
\text { and efflux }\end{array}$ & 0.125045697 & 0.902931247 & 5 & $\begin{array}{c}\text { ARL4C,TNRC6B,ABCA1, } \\
\text { TNRC6A,NCOR2 }\end{array}$ \\
\hline REAC:R-HSA-422475 & Axon guidance & 0.132834136 & 0.876690304 & 21 & $\begin{array}{c}\text { RPL21,RPL17,RPS3A,RP } \\
\text { S2,RHOB,RPL7,RPL36A, } \\
\text { RPS10,ALCAM,RPS27,IT } \\
\text { GAV,RPL39,NRP1,PAK3, } \\
\text { RPS26,MYH9,RPL41,RPL } \\
\text { 28,NFASC,SEMA6A,RPL } \\
\text { 23A }\end{array}$ \\
\hline REAC:R-HSA-73857 & $\begin{array}{l}\text { RNA Polymerase II } \\
\text { Transcription }\end{array}$ & 1 & 0 & 25 & $\begin{array}{c}\text { NPY,BAX,OCLN,SKIL,L } \\
\text { MO1,VEGFA,NDRG1,JU } \\
\text { NB,SREBF1,NR4A1,ARI } \\
\text { D1B,USP7,ELF2,TNRC6B } \\
\text {,SRSF3,KMT2E,ZNF189, } \\
\text { ESRRA,U2AF2,TNRC6A, } \\
\text { PABPN1,CITED2,BRD1, } \\
\text { BCL6,NCOR2 }\end{array}$ \\
\hline REAC:R-HSA-1852241 & $\begin{array}{l}\text { Organelle biogenesis } \\
\text { and maintenance }\end{array}$ & 1 & 0 & 7 & $\begin{array}{c}\text { RAB8A,DYNC2I1,PAFA } \\
\text { H1B1,ESRRA,TCTN2,SS } \\
\text { TR3,HCFC1 }\end{array}$ \\
\hline REAC:R-HSA-6798695 & $\begin{array}{c}\text { Neutrophil } \\
\text { degranulation }\end{array}$ & 1 & 0 & 16 & $\begin{array}{c}\text { ANXA2,CD47,CD44,CD3 } \\
\text { 6,HLA- } \\
\text { B,CST3,PRSS3,ATP8A1,C } \\
\text { YB5R3,ITGAV,EEF2,A1B } \\
\text { G,GAA,HMGB1,NFASC, } \\
\text { B2M } \\
\end{array}$ \\
\hline \multicolumn{6}{|c|}{ Down regulated genes } \\
\hline REAC:R-HSA-1430728 & Metabolism & $2.56 \mathrm{E}-11$ & 10.59159661 & 77 & $\begin{array}{c}\text { RPS4Y1,RBP4,GPX2,GST } \\
\text { P1,SAT1,PSMB7,CYB5A, } \\
\text { ETFB,RPS28,G6PC2,ASA } \\
\text { H1,RPL9,ATP5PB,PSMC4 } \\
\text {,PSMC5,NDUFA9,PPT1,S } \\
\text { ARS1,PSMD7,BLVRB,AT } \\
\text { P5F1C,PRPS2,NDUFA12, } \\
\text { CTSA,ATP5MC1,LCLAT } \\
\text { 1,MPC1,PSMD6,GBA,EN } \\
\text { O1,ESD,FDPS,IDH1,PSM } \\
\text { B5,PSMB3,NDUFV3,MD } \\
\text { H2,TTR,PTGR2,GNPDA1, } \\
\text { MDH1,ATP5PO,PSMA4,S } \\
\text { CD,SUCLG1,TXN2,ACA } \\
\text { DM,TXN,BLVRA,PSMB2 } \\
\text {,UQCRH,MGST3,GLUL, } \\
\text { NEU1,GAPDH,PSMD12, }\end{array}$ \\
\hline
\end{tabular}




\begin{tabular}{|c|c|c|c|c|c|}
\hline & & & & & $\begin{array}{c}\text { COX6B1,NDUFB7,ARG2, } \\
\text { ATP5F1B,GALT,COX14, } \\
\text { PRSS1,PSMF1,NQO1,GPI } \\
\text {,HSP90AB1,COX8A,PLA } \\
\text { 1A,COX4I1,ALDOA,TPI1 } \\
\text {,NQO2,RPL14,UBC,ATP5 } \\
\text { MC2,HMBS }\end{array}$ \\
\hline REAC:R-HSA-1428517 & $\begin{array}{l}\text { The citric acid (TCA) } \\
\text { cycle and respiratory } \\
\text { electron transport }\end{array}$ & $2.21 \mathrm{E}-08$ & 7.655421329 & 19 & $\begin{array}{c}\text { ETFB,ATP5PB,NDUFA9, } \\
\text { ATP5F1C,NDUFA12,ATP } \\
\text { 5MC1,MPC1,NDUFV3,M } \\
\text { DH2,ATP5PO,SUCLG1,U } \\
\text { QCRH,COX6B1,NDUFB7 } \\
\text {,ATP5F1B,COX14,COX8 } \\
\text { A,COX4I1,ATP5MC2 }\end{array}$ \\
\hline 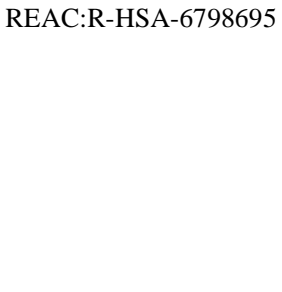 & $\begin{array}{c}\text { Neutrophil } \\
\text { degranulation }\end{array}$ & $1.20688 \mathrm{E}-06$ & 5.918337455 & 28 & $\begin{array}{c}\text { FTL,GSTP1,VAMP8,PSM } \\
\text { B7,ASAH1,ATP6V1D,PS } \\
\text { MD7,CTSA,NIT2,PSMD6, } \\
\text { IDH1,XRCC6,PRDX6,TT } \\
\text { R,CYSTM1,VAT1,CAP1, } \\
\text { LAMTOR1,NEU1,FTH1,P } \\
\text { SMD12,COTL1,HSPA8,P } \\
\text { KM,GPI,HSP90AB1,ALD } \\
\text { OA,CD63 }\end{array}$ \\
\hline REAC:R-HSA-70263 & Gluconeogenesis & $1.32437 \mathrm{E}-05$ & 4.877991388 & 8 & $\begin{array}{c}\text { G6PC2,ENO1,MDH2,MD } \\
\text { H1,GAPDH,GPI,ALDOA, } \\
\text { TPI1 }\end{array}$ \\
\hline REAC:R-HSA-392499 & Metabolism of proteins & 0.00012311 & 3.909706731 & 60 & $\begin{array}{c}\text { RPS4Y1,TUBA4A,IAPP,P } \\
\text { SMB7,ETFB,USP22,RPS2 } \\
\text { 8,RPL9,PSMC4,UCHL1,P } \\
\text { SMC5,SARS1,SSR2,PSM } \\
\text { D7,MRPL54,RAB21,CTS } \\
\text { A,PSMD6,GBA,PSMB5,M } \\
\text { RPS35,PSMB3,EIF3K,TT } \\
\text { R,RAB3B,UBE2L6,TRAP } \\
\text { PC2L,PSMA4,KLHL41,PI } \\
\text { GP,NAPA,UBE2B,TXN,P } \\
\text { SMB2,MRPS15,NEU1,AL } \\
\text { G3,EXOSC1,FARSA,CAP } \\
\text { ZB,PSMD12,DHDDS,AR } \\
\text { CN1,HSPA5,RAD23A,NS } \\
\text { MCE2,H2BC12,SPCS2,HS } \\
\text { PA8,EIF5A2,GCNT3,PSM } \\
\text { F1,CANX,MRPS11,UFD1, } \\
\text { TUBA1C,NANS,PARN,R } \\
\text { PL14,UBC }\end{array}$ \\
\hline REAC:R-HSA-168256 & Immune System & 0.008098179 & 2.091612637 & 58 & $\begin{array}{l}\text { FTL,TUBA4A,MT2A,IFI3 } \\
\text { 0,GSTP1,VAMP8,PSMB7, } \\
\text { CAMK2D,BCAP31,ASAH } \\
\text { 1,ATP6V1B2,PSMC4,ATP } \\
\text { 6V1D,PSMC5,PSMD7,AT } \\
\text { P6V1E1,CTSA,NIT2,PSM } \\
\text { D6,IDH1,PSMB5,XRCC6, } \\
\text { PSMB3,PRDX6,CLU,TTR } \\
\text {,GRB2,POLR3K,UBE2L6, } \\
\text { CYSTM1,PSMA4,KLHL4 } \\
\text { 1,VAT1,UBE2B,CAP1,TX } \\
\text { N,PSMB2,LAMTOR1,NE } \\
\text { U1,CAPZB,FTH1,PSMD1 } \\
\text { 2,SQSTM1,RNF6,HSPA5, } \\
\text { COTL1,HSPA8,PSMF1,P } \\
\text { KM,CDC23,CANX,GPI,T } \\
\text { UBA1C,EDARADD,HSP9 } \\
\text { 0AB1,ALDOA,CD63,UBC }\end{array}$ \\
\hline
\end{tabular}


Table 4 Topology table for up and down regulated genes.

\begin{tabular}{|c|c|c|c|c|c|}
\hline Regulation & Node & Degree & Betweenness & Stress & Closeness \\
\hline $\mathrm{Up}$ & APP & 674 & 0.277552 & 48171576 & 0.396397 \\
\hline Up & MYH9 & 231 & 0.067132 & 12987566 & 0.351087 \\
\hline Up & TCTN2 & 203 & 0.074204 & 9822804 & 0.31559 \\
\hline Up & USP7 & 156 & 0.048917 & 10011292 & 0.341756 \\
\hline Up & SYNPO & 148 & 0.019807 & 5325396 & 0.315343 \\
\hline Up & BCL6 & 99 & 0.03129 & 4924434 & 0.316788 \\
\hline $\mathrm{Up}$ & PRKDC & 97 & 0.02396 & 5704444 & 0.339213 \\
\hline Up & $\mathrm{U} 2 \mathrm{AF} 2$ & 77 & 0.016653 & 3792650 & 0.316448 \\
\hline Up & SKIL & 72 & 0.021529 & 2766174 & 0.31763 \\
\hline Up & CTBP1 & 72 & 0.018919 & 3933722 & 0.30334 \\
\hline Up & TOP1 & 66 & 0.012706 & 3485932 & 0.318522 \\
\hline Up & NDRG1 & 65 & 0.014232 & 2582316 & 0.327508 \\
\hline Up & NCOR2 & 62 & 0.014748 & 2563224 & 0.327727 \\
\hline $\mathrm{Up}$ & ILF3 & 62 & 0.010796 & 3729048 & 0.325197 \\
\hline Up & MAPT & 59 & 0.011654 & 2038018 & 0.335304 \\
\hline Up & SNRNP70 & 56 & 0.013306 & 2811964 & 0.337737 \\
\hline Up & NME7 & 54 & 0.009971 & 2818468 & 0.302345 \\
\hline Up & $\mathrm{HCFC} 1$ & 54 & 0.011189 & 4114590 & 0.285724 \\
\hline Up & SRRM2 & 53 & 0.008517 & 2842260 & 0.304719 \\
\hline Up & DDX17 & 48 & 0.010257 & 2309956 & 0.34835 \\
\hline Up & RUNX1T1 & 45 & 0.007377 & 1300474 & 0.298327 \\
\hline Up & TNRC6B & 44 & 0.005765 & 1772074 & 0.294513 \\
\hline $\mathrm{Up}$ & RPS3A & 43 & 0.008663 & 1580346 & 0.314044 \\
\hline Up & BAX & 43 & 0.010013 & 1360956 & 0.305287 \\
\hline Up & ANXA2 & 42 & 0.006725 & 1415220 & 0.32746 \\
\hline Up & RAB8A & 38 & 0.009675 & 2880488 & 0.28541 \\
\hline Up & ALYREF & 37 & 0.006723 & 3260410 & 0.299114 \\
\hline $\mathrm{Up}$ & OTUD4 & 36 & 0.009901 & 1095992 & 0.306175 \\
\hline Up & TNRC6A & 36 & 0.006285 & 1066772 & 0.298629 \\
\hline Up & LMO1 & 36 & 0.007004 & 1983992 & 0.281738 \\
\hline Up & NR4A1 & 35 & 0.007386 & 1366096 & 0.293516 \\
\hline Up & DNMT1 & 35 & 0.007153 & 1311716 & 0.318247 \\
\hline Up & JUNB & 34 & 0.007201 & 2171380 & 0.289501 \\
\hline Up & HNRNPH1 & 34 & 0.004039 & 1126254 & 0.310822 \\
\hline Up & HNRNPL & 33 & 0.002406 & 639204 & 0.306684 \\
\hline $\mathrm{Up}$ & EEF2 & 32 & 0.00508 & 1312314 & 0.31811 \\
\hline Up & RPS2 & 32 & 0.005007 & 944774 & 0.30743 \\
\hline $\mathrm{Up}$ & PGAM5 & 32 & 0.004601 & 1343578 & 0.295695 \\
\hline Up & CD44 & 31 & 0.005854 & 812632 & 0.311523 \\
\hline Up & B2M & 31 & 0.005781 & 1559068 & 0.265885 \\
\hline Up & RAD52 & 30 & 0.004293 & 852988 & 0.296289 \\
\hline Up & ATP2A2 & 30 & 0.007054 & 1516120 & 0.312823 \\
\hline $\mathrm{Up}$ & SREBF1 & 30 & 0.007025 & 2186330 & 0.278526 \\
\hline Up & PAFAH1B1 & 29 & 0.005215 & 2372866 & 0.276438 \\
\hline Up & NDN & 29 & 0.007043 & 1329464 & 0.296547 \\
\hline Up & SRSF3 & 28 & 0.003437 & 1013722 & 0.303174 \\
\hline Up & APLP1 & 27 & 0.006221 & 892288 & 0.276818 \\
\hline Up & GANAB & 27 & 0.004094 & 990330 & 0.298347 \\
\hline Up & RPL7 & 26 & 0.003381 & 933236 & 0.310757 \\
\hline Up & MPRIP & 26 & 0.001472 & 342632 & 0.295873 \\
\hline Up & INO80E & 25 & 0.005901 & 1721260 & 0.272453 \\
\hline Up & CACNA1A & 24 & 0.010596 & 1171628 & 0.281863 \\
\hline Up & CHGB & 24 & 0.006952 & 765394 & 0.299337 \\
\hline Up & RPL28 & 24 & 0.002372 & 585818 & 0.299074 \\
\hline Up & ITSN2 & 24 & 0.003281 & 939596 & 0.286093 \\
\hline Up & RPS10 & 23 & 0.004922 & 897446 & 0.326132 \\
\hline Up & RPL23A & 23 & 0.003289 & 505840 & 0.311962 \\
\hline Up & PHF1 & 22 & 0.003983 & 1034682 & 0.277426 \\
\hline Up & HNRNPAB & 22 & 0.001844 & 495324 & 0.3108 \\
\hline Up & SH3GL1 & 22 & 0.003033 & 986094 & 0.270008 \\
\hline Up & HMGB 1 & 21 & 0.002117 & 776702 & 0.290681 \\
\hline Up & PDK3 & 19 & 0.002946 & 742934 & 0.275937 \\
\hline Up & ARID1B & 19 & 0.004 & 716712 & 0.264217 \\
\hline Up & ABCA1 & 18 & 0.003966 & 549762 & 0.275216 \\
\hline Up & ESRRA & 18 & 0.002502 & 368532 & 0.276023 \\
\hline Up & TRA2A & 18 & 0.001473 & 605004 & 0.285005 \\
\hline
\end{tabular}




\begin{tabular}{|c|c|c|c|c|c|}
\hline Up & MAGI1 & 18 & 0.00426 & 637328 & 0.277722 \\
\hline Up & VEGFA & 17 & 0.004134 & 836256 & 0.248525 \\
\hline Up & ZC3HAV1 & 17 & 0.001292 & 489318 & 0.274227 \\
\hline Up & HIVEP1 & 16 & 0.001767 & 378796 & 0.2718 \\
\hline Up & SIPA1L3 & 16 & 0.001056 & 218866 & 0.285465 \\
\hline Up & MPP6 & 16 & 0.002628 & 324224 & 0.275972 \\
\hline Up & RPL17 & 16 & 0.001736 & 515376 & 0.297165 \\
\hline Up & SSR4 & 16 & 0.001986 & 441016 & 0.283617 \\
\hline Up & RPS27 & 15 & 0.002603 & 522416 & 0.297905 \\
\hline Up & SON & 15 & $4.63 \mathrm{E}-04$ & 263370 & 0.282512 \\
\hline Up & PDCD4 & 15 & 0.001508 & 323916 & 0.276732 \\
\hline Up & TMEM79 & 15 & 0.004325 & 604778 & 0.229337 \\
\hline Up & MAFG & 14 & 0.002447 & 382134 & 0.252123 \\
\hline Up & SGSM2 & 14 & 0.002229 & 327358 & 0.278544 \\
\hline Up & NOL3 & 14 & $6.71 \mathrm{E}-04$ & 214960 & 0.264091 \\
\hline Up & S100A6 & 14 & $9.74 \mathrm{E}-04$ & 248722 & 0.280861 \\
\hline Up & MZT2A & 14 & $2.68 \mathrm{E}-04$ & 75218 & 0.276801 \\
\hline Up & RPL21 & 14 & 0.001091 & 579282 & 0.289843 \\
\hline Up & МCPH1 & 14 & $8.71 \mathrm{E}-04$ & 244188 & 0.255857 \\
\hline Up & LUC7L3 & 13 & 0.001174 & 368838 & 0.272386 \\
\hline $\mathrm{Up}$ & DDX18 & 13 & 0.001648 & 394268 & 0.31722 \\
\hline Up & TLE3 & 13 & 0.002428 & 330598 & 0.309193 \\
\hline Up & EIF5A & 13 & 0.002018 & 470016 & 0.279742 \\
\hline Up & LENG8 & 13 & 0.001599 & 412736 & 0.24473 \\
\hline Up & OCLN & 12 & 0.001253 & 314884 & 0.263462 \\
\hline Up & PABPN1 & 12 & 0.001338 & 370074 & 0.285705 \\
\hline Up & BRD1 & 11 & 0.001735 & 432360 & 0.250156 \\
\hline Up & KRT10 & 11 & $5.29 \mathrm{E}-04$ & 212650 & 0.28389 \\
\hline Up & RPS26 & 11 & $6.46 \mathrm{E}-04$ & 207408 & 0.291102 \\
\hline Up & TMEM209 & 11 & 0.002671 & 362732 & 0.281917 \\
\hline $\mathrm{Up}$ & TLK1 & 11 & 0.001007 & 270716 & 0.252627 \\
\hline Up & NPDC1 & 11 & 7.46E-04 & 230746 & 0.250595 \\
\hline Up & ST14 & 11 & 0.001157 & 228876 & 0.261871 \\
\hline Up & UBA6 & 10 & 0.00209 & 401360 & 0.269055 \\
\hline Up & MAP3К 12 & 10 & 0.00226 & 336206 & 0.272201 \\
\hline Up & MAP2 & 10 & 0.001373 & 254464 & 0.319327 \\
\hline Up & ITGAV & 10 & 0.00199 & 532090 & 0.270371 \\
\hline Up & CPE & 10 & 0.001881 & 615956 & 0.227778 \\
\hline Up & TFAP4 & 10 & 7.77E-04 & 213056 & 0.26184 \\
\hline Up & MIER1 & 10 & 0.0015 & 272476 & 0.264123 \\
\hline Up & CPT1A & 9 & $5.45 \mathrm{E}-04$ & 93620 & 0.276438 \\
\hline Up & RGL2 & 9 & $6.06 \mathrm{E}-04$ & 170470 & 0.251865 \\
\hline Up & CYB5R3 & 9 & $9.29 \mathrm{E}-04$ & 184034 & 0.256748 \\
\hline $\mathrm{Up}$ & DDR1 & 9 & 0.001327 & 189372 & 0.266558 \\
\hline Up & ATP1B1 & 9 & 0.001955 & 400240 & 0.267073 \\
\hline Up & NME3 & 9 & 0.001643 & 194338 & 0.301808 \\
\hline $\mathrm{Up}$ & MZT2B & 9 & $1.10 \mathrm{E}-04$ & 28768 & 0.258413 \\
\hline Up & ALDH1B1 & 9 & $9.67 \mathrm{E}-04$ & 319144 & 0.277583 \\
\hline Up & PI4KA & 9 & $7.40 \mathrm{E}-04$ & 268444 & 0.277879 \\
\hline Up & CSNK1G2 & 9 & 0.001421 & 396030 & 0.252931 \\
\hline Up & CITED2 & 9 & 0.002327 & 530770 & 0.263431 \\
\hline Up & RANBP3 & 9 & 0.001499 & 304686 & 0.236853 \\
\hline Up & NRP1 & 8 & $8.45 \mathrm{E}-04$ & 148358 & 0.258398 \\
\hline $\mathrm{Up}$ & PGRMC2 & 8 & $4.66 \mathrm{E}-04$ & 87082 & 0.262275 \\
\hline Up & HLA-B & 5 & 0 & 0 & 0.210049 \\
\hline Up & HLA-A & 4 & $7.39 \mathrm{E}-05$ & 16916 & 0.249408 \\
\hline Up & EIF1AX & 1 & 0 & 0 & 0.28389 \\
\hline Up & ARL4C & 1 & 0 & 0 & 0.28389 \\
\hline Up & RPL41 & 1 & 0 & 0 & 0.28389 \\
\hline Up & UBXN6 & 1 & 0 & 0 & 0.28389 \\
\hline Up & CDK10 & 1 & 0 & 0 & 0.267235 \\
\hline Up & DPH1 & 1 & 0 & 0 & 0.266639 \\
\hline Up & AHDC1 & 1 & 0 & 0 & 0.259871 \\
\hline Up & SEZ6L2 & 1 & 0 & 0 & 0.191166 \\
\hline Up & PDCD2 & 1 & 0 & 0 & 0.222239 \\
\hline Up & PTPN18 & 1 & 0 & 0 & 0.285576 \\
\hline Up & NISCH & 1 & 0 & 0 & 0.285576 \\
\hline Up & RBM33 & 1 & 0 & 0 & 0.285576 \\
\hline Up & WIPF2 & 1 & 0 & 0 & 0.285576 \\
\hline Up & $\mathrm{MCU}$ & 1 & 0 & 0 & 0.225479 \\
\hline
\end{tabular}




\begin{tabular}{|c|c|c|c|c|c|}
\hline Up & ZZEF1 & 1 & 0 & 0 & 0.241075 \\
\hline Up & FCGRT & 1 & 0 & 0 & 0.210049 \\
\hline Up & EMC10 & 1 & 0 & 0 & 0.239898 \\
\hline Up & PLD3 & 1 & 0 & 0 & 0.239898 \\
\hline Up & FADS2 & 1 & 0 & 0 & 0.239898 \\
\hline Up & FAM102A & 1 & 0 & 0 & 0.212614 \\
\hline Up & SEMA6A & 1 & 0 & 0 & 0.222463 \\
\hline Up & ZFX & 1 & 0 & 0 & 0.232008 \\
\hline $\mathrm{Up}$ & USP27X & 1 & 0 & 0 & 0.21869 \\
\hline Down & GRB2 & 431 & 0.172947 & 23419584 & 0.399693 \\
\hline Down & HSP90AB 1 & 225 & 0.07414 & 15655320 & 0.364663 \\
\hline Down & UBC & 224 & 0.075316 & 15138294 & 0.356148 \\
\hline Down & HSPA5 & 144 & 0.05737 & 10318564 & 0.363554 \\
\hline Down & SQSTM1 & 123 & 0.036494 & 6909982 & 0.339317 \\
\hline Down & XRCC6 & 121 & 0.034438 & 8751842 & 0.335228 \\
\hline Down & HSPA8 & 120 & 0.03154 & 6567910 & 0.365537 \\
\hline Down & TUBA1C & 91 & 0.023847 & 3670590 & 0.328896 \\
\hline Down & TUBG1 & 81 & 0.017666 & 3231832 & 0.324267 \\
\hline Down & PSMC5 & 80 & 0.015146 & 3450624 & 0.332456 \\
\hline Down & CSNK2B & 77 & 0.019998 & 5358078 & 0.32002 \\
\hline Down & $\mathrm{CDC} 23$ & 75 & 0.021091 & 6346650 & 0.302076 \\
\hline Down & SAT1 & 69 & 0.01963 & 4672960 & 0.296746 \\
\hline Down & GAPDH & 63 & 0.012495 & 2722934 & 0.342046 \\
\hline Down & GABARAP & 62 & 0.01438 & 2298584 & 0.299175 \\
\hline Down & RAD23A & 56 & 0.009202 & 1854168 & 0.312778 \\
\hline Down & PKM & 51 & 0.009281 & 2445062 & 0.320972 \\
\hline Down & DNAJA1 & 51 & 0.008274 & 2322170 & 0.320763 \\
\hline Down & PSMB3 & 50 & 0.005865 & 1322226 & 0.308051 \\
\hline Down & EXOSC1 & 50 & 0.01119 & 2195338 & 0.294709 \\
\hline Down & DDIT3 & 48 & 0.01172 & 2529152 & 0.297345 \\
\hline Down & NDUFA9 & 47 & 0.013121 & 3147348 & 0.291102 \\
\hline Down & CANX & 46 & 0.01141 & 2049224 & 0.314089 \\
\hline Down & IBTK & 45 & 0.008641 & 1736696 & 0.290891 \\
\hline Down & SCNM1 & 45 & 0.006692 & 2252600 & 0.281594 \\
\hline Down & PSMC4 & 42 & 0.003699 & 829472 & 0.31331 \\
\hline Down & NDUFA12 & 42 & 0.004926 & 813880 & 0.250837 \\
\hline Down & MBIP & 42 & 0.01045 & 2311340 & 0.274601 \\
\hline Down & PSMD7 & 41 & 0.002834 & 722504 & 0.302179 \\
\hline Down & USP22 & 41 & 0.011629 & 3407576 & 0.279884 \\
\hline Down & PSMD6 & 40 & 0.001629 & 559916 & 0.281863 \\
\hline Down & CLU & 40 & 0.00841 & 1216580 & 0.309431 \\
\hline Down & AIFM1 & 39 & 0.005419 & 1729814 & 0.299966 \\
\hline Down & MORF4L2 & 39 & 0.011082 & 2538970 & 0.275662 \\
\hline Down & PRDX1 & 38 & 0.005407 & 1341464 & 0.312403 \\
\hline Down & ARL6IP1 & 37 & 0.012555 & 1641598 & 0.244635 \\
\hline Down & CAPZB & 36 & 0.004358 & 1050292 & 0.311742 \\
\hline Down & PSMD12 & 34 & 0.001447 & 422448 & 0.305161 \\
\hline Down & PSMB7 & 34 & 0.001154 & 364868 & 0.289577 \\
\hline Down & BCAP31 & 34 & 0.013785 & 1768344 & 0.327824 \\
\hline Down & PSMB5 & 34 & 0.003403 & 666674 & 0.313199 \\
\hline Down & NR0B2 & 34 & 0.005798 & 1517314 & 0.302138 \\
\hline Down & TUBA4A & 33 & 0.005178 & 1530624 & 0.307217 \\
\hline Down & RNF6 & 33 & 0.003643 & 1333208 & 0.262166 \\
\hline Down & MPP1 & 32 & 0.007264 & 815422 & 0.302924 \\
\hline Down & CAMK2D & 32 & 0.008412 & 1997208 & 0.289805 \\
\hline Down & PSMF1 & 32 & 0.006012 & 1557236 & 0.280594 \\
\hline Down & ALDOA & 31 & 0.004458 & 960392 & 0.311391 \\
\hline Down & PSMA4 & 30 & 0.002283 & 522348 & 0.297505 \\
\hline Down & PSMB2 & 30 & 0.003431 & 769210 & 0.296309 \\
\hline Down & UCHL1 & 28 & 0.00501 & 791348 & 0.328067 \\
\hline Down & TXN2 & 28 & 0.00596 & 1364924 & 0.272084 \\
\hline Down & ORC3 & 28 & 0.005692 & 1623144 & 0.284273 \\
\hline Down & CLIC1 & 27 & 0.004327 & 824568 & 0.304447 \\
\hline Down & UBE2L6 & 27 & 0.006391 & 1958890 & 0.274499 \\
\hline Down & GBA & 26 & 0.004796 & 875116 & 0.282061 \\
\hline Down & ENO1 & 26 & 0.00367 & 1143078 & 0.306876 \\
\hline Down & RPL14 & 26 & 0.004161 & 1610674 & 0.298569 \\
\hline Down & FTH1 & 24 & 0.004084 & 777832 & 0.276783 \\
\hline Down & TXN & 24 & 0.003003 & 482510 & 0.302717 \\
\hline Down & GSTP1 & 24 & 0.004232 & 1080546 & 0.295201 \\
\hline
\end{tabular}




\begin{tabular}{|c|c|c|c|c|c|}
\hline Down & REEP5 & 24 & 0.005234 & 1041918 & 0.267817 \\
\hline Down & TOX4 & 23 & 0.005025 & 1370332 & 0.276058 \\
\hline Down & TTR & 23 & 0.003317 & 617718 & 0.272823 \\
\hline Down & CORO1C & 23 & 0.001258 & 341072 & 0.296269 \\
\hline Down & GTF2B & 22 & 0.004837 & 1919700 & 0.246228 \\
\hline Down & PPIB & 21 & 0.002633 & 702460 & 0.286557 \\
\hline Down & UFD1 & 20 & 0.00202 & 299278 & 0.298952 \\
\hline Down & GLUL & 20 & 0.003636 & 572524 & 0.266767 \\
\hline Down & SCAMP3 & 19 & 0.002153 & 497590 & 0.274738 \\
\hline Down & FTL & 19 & 0.004867 & 440140 & 0.298006 \\
\hline Down & SLC25A5 & 19 & 0.001986 & 352068 & 0.310844 \\
\hline Down & UBE2B & 19 & 0.002118 & 572844 & 0.260713 \\
\hline Down & ZNF326 & 19 & 0.002394 & 916478 & 0.295359 \\
\hline Down & LAMTOR1 & 19 & 0.004398 & 814628 & 0.252454 \\
\hline Down & ZNF410 & 18 & 0.004751 & 566192 & 0.302386 \\
\hline Down & PRDX6 & 18 & 0.002313 & 594114 & 0.280327 \\
\hline Down & DRG1 & 18 & 0.002816 & 810156 & 0.295122 \\
\hline Down & ATP6V1B2 & 18 & 0.002914 & 816976 & 0.270388 \\
\hline Down & ZNF165 & 18 & 0.003519 & 739876 & 0.262493 \\
\hline Down & NDUFV3 & 18 & 0.001755 & 335550 & 0.259292 \\
\hline Down & EIF3K & 18 & 0.004959 & 1105612 & 0.27343 \\
\hline Down & NSFL1C & 17 & 0.003491 & 339954 & 0.287189 \\
\hline Down & ARCN1 & 17 & 0.002733 & 778374 & 0.290204 \\
\hline Down & TPI1 & 17 & 0.001365 & 553820 & 0.293848 \\
\hline Down & ARRDC3 & 17 & 0.001321 & 468292 & 0.265518 \\
\hline Down & NDUFB8 & 16 & 0.001576 & 271076 & 0.25175 \\
\hline Down & PRDX5 & 15 & 0.00314 & 356484 & 0.304824 \\
\hline Down & RPS28 & 15 & 0.00171 & 509708 & 0.276317 \\
\hline Down & TCEAL4 & 15 & 0.002744 & 249400 & 0.281451 \\
\hline Down & VAMP8 & 15 & 0.003131 & 687744 & 0.270437 \\
\hline Down & TRAPPC2L & 14 & 0.004206 & 559988 & 0.293516 \\
\hline Down & CNOT6L & 14 & 0.002421 & 339456 & 0.257721 \\
\hline Down & ATP6V1D & 14 & 0.002838 & 320770 & 0.28589 \\
\hline Down & DYNLRB1 & 14 & 0.001865 & 358956 & 0.26184 \\
\hline Down & EDARADD & 13 & 0.001601 & 322314 & 0.258051 \\
\hline Down & PEF1 & 13 & 0.001577 & 414800 & 0.268957 \\
\hline Down & FARSA & 13 & 0.001697 & 508804 & 0.2652 \\
\hline Down & POLE3 & 12 & 0.004074 & 517276 & 0.286019 \\
\hline Down & COX4I1 & 12 & 0.002449 & 321508 & 0.261561 \\
\hline Down & ETV5 & 12 & 0.003438 & 1053244 & 0.236334 \\
\hline Down & NAPA & 12 & 0.002141 & 556788 & 0.283217 \\
\hline Down & VPS25 & 12 & 0.002068 & 519502 & 0.245014 \\
\hline Down & BEX1 & 12 & 0.001246 & 267736 & 0.267979 \\
\hline Down & XPOT & 11 & 0.001347 & 381778 & 0.281774 \\
\hline Down & MT2A & 11 & 0.001882 & 359724 & 0.241562 \\
\hline Down & NDUFB7 & 11 & 0.001 & 155788 & 0.238231 \\
\hline Down & MRPS35 & 11 & 0.00194 & 415706 & 0.264107 \\
\hline Down & MRPS15 & 11 & 0.001587 & 179036 & 0.276058 \\
\hline Down & PLEKHB2 & 11 & 0.001437 & 374900 & 0.236057 \\
\hline Down & NSMCE2 & 11 & 0.001999 & 798156 & 0.237464 \\
\hline Down & CTNNAL1 & 11 & 0.001959 & 302074 & 0.253119 \\
\hline Down & PPIL1 & 11 & 0.001172 & 393624 & 0.278019 \\
\hline Down & PRPS2 & 10 & 0.001596 & 384080 & 0.259383 \\
\hline Down & COX6B1 & 10 & $5.69 \mathrm{E}-04$ & 148866 & 0.236765 \\
\hline Down & ETV6 & 10 & 0.002363 & 207722 & 0.296408 \\
\hline Down & CAP1 & 10 & $5.76 \mathrm{E}-04$ & 164992 & 0.273972 \\
\hline Down & SPCS2 & 10 & 0.001427 & 294448 & 0.282801 \\
\hline Down & GRAMD2B & 10 & 0.002536 & 387376 & 0.231425 \\
\hline Down & CDC42BPA & 10 & 0.001848 & 460620 & 0.252858 \\
\hline Down & ATP6V1E1 & 2 & $1.68 \mathrm{E}-05$ & 7358 & 0.256421 \\
\hline Down & MPC1 & 1 & 0 & 0 & 0.230293 \\
\hline Down & TRUB1 & 1 & 0 & 0 & 0.28389 \\
\hline Down & NANS & 1 & 0 & 0 & 0.267235 \\
\hline Down & MDH1 & 1 & 0 & 0 & 0.267235 \\
\hline Down & GHITM & 1 & 0 & 0 & 0.266639 \\
\hline Down & $\mathrm{COA} 3$ & 1 & 0 & 0 & 0.207341 \\
\hline Down & NEU1 & 1 & 0 & 0 & 0.224518 \\
\hline Down & UQCC2 & 1 & 0 & 0 & 0.285576 \\
\hline Down & RBP4 & 1 & 0 & 0 & 0.214355 \\
\hline Down & CUTA & 1 & 0 & 0 & 0.226925 \\
\hline
\end{tabular}




\begin{tabular}{llllll} 
Down & GPX2 & 1 & 0 & 0 & 0.228591 \\
Down & PXK & 1 & 0 & 0 & 0.230257 \\
Down & TSPYL5 & 1 & 0 & 0 & 0.254722 \\
Down & ALG3 & 1 & 0 & 0 & 0.239898 \\
Down & ZMPSTE24 & 1 & 0 & 0 & 0.239898 \\
Down & SCD & 1 & 0 & 0 & 0.239898 \\
Down & UQCRH & 1 & 0 & 0 & 0.200544 \\
Down & EIF5A2 & 1 & 0 & 0 & 0.232008 \\
Down & ATXN7L3B & 1 & 0 & 0.21869 \\
\hline
\end{tabular}

Table 5 miRNA - target gene and TF - target gene interaction

\begin{tabular}{|c|c|c|c|c|c|c|c|}
\hline Regulation & Target Genes & Degree & MicroRNA & Regulation & Target Genes & Degree & TF \\
\hline $\mathrm{Up}$ & PRKDC & 163 & hsa-mir-142-5p & Up & BCL6 & 60 & NOTCH1 \\
\hline Up & MYH9 & 126 & hsa-mir-181b-3p & Up & MYH9 & 53 & PPARD \\
\hline Up & APP & 125 & hsa-mir-216b-5p & Up & NCOR2 & 50 & HIF1A \\
\hline Up & ILF3 & 107 & hsa-mir-3157-3p & Up & APP & 45 & SMARCA4 \\
\hline $\mathrm{Up}$ & SKIL & 91 & hsa-mir-1294 & $\mathrm{Up}$ & NDRG1 & 44 & SUZ12 \\
\hline $\mathrm{Up}$ & NCOR 2 & 81 & hsa-mir-4708-3p & $\mathrm{Up}$ & TOP1 & 41 & CREM \\
\hline Up & U2AF2 & 65 & hsa-mir-196a-5p & Up & ILF3 & 41 & DACH1 \\
\hline $\mathrm{Up}$ & NDRG1 & 60 & hsa-mir-374a-5p & $\mathrm{Up}$ & MAPT & 38 & YAP1 \\
\hline Up & TOP1 & 45 & hsa-mir-424-5p & Up & SKIL & 37 & GATA2 \\
\hline Up & CTBP1 & 45 & hsa-mir-944 & Up & PRKDC & 36 & NUCKS1 \\
\hline Up & BCL6 & 35 & hsa-mir-4701-3p & Up & СТВP1 & 35 & ELF1 \\
\hline Up & USP7 & 34 & hsa-mir-93-5p & Up & $\mathrm{U} 2 \mathrm{AF} 2$ & 34 & KDM6A \\
\hline $\mathrm{Up}$ & MAPT & 23 & hsa-mir-2278 & $\mathrm{Up}$ & SYNPO & 28 & SMAD4 \\
\hline $\mathrm{Up}$ & SYNPO & 15 & hsa-mir-138-5p & $\mathrm{Up}$ & USP7 & 27 & NANOG \\
\hline Up & TCTN2 & 9 & hsa-mir-34a-5p & Up & TCTN2 & 10 & SRF \\
\hline Down & HSPA8 & 116 & hsa-mir-3661 & Down & UBC & 64 & TAF7L \\
\hline Down & HSP90AB1 & 103 & hsa-mir-200a-3p & Down & HSP90AB1 & 49 & RUNX2 \\
\hline Down & SQSTM1 & 94 & hsa-mir-520d-5p & Down & TUBA1C & 47 & MITF \\
\hline Down & HSPA5 & 88 & hsa-mir-573 & Down & HSPA5 & 44 & YAP1 \\
\hline Down & GRB2 & 65 & hsa-mir-1291 & Down & HSPA8 & 39 & E2F1 \\
\hline Down & SAT1 & 56 & hsa-mir-301b-3p & Down & GAPDH & 38 & SOX11 \\
\hline Down & $\mathrm{UBC}$ & 55 & hsa-mir-9-5p & Down & GABARAP & 38 & HOXB4 \\
\hline Down & GAPDH & 54 & hsa-mir-5690 & Down & GRB2 & 37 & TFAP2A \\
\hline Down & TUBA1C & 53 & hsa-mir-603 & Down & CSNK2B & 35 & THAP11 \\
\hline Down & $\mathrm{CDC} 23$ & 51 & hsa-mir-376a-5p & Down & PSMC5 & 33 & STAT4 \\
\hline Down & TUBG1 & 32 & hsa-mir-182-5p & Down & SQSTM1 & 30 & EP300 \\
\hline Down & XRCC6 & 31 & hsa-mir-618 & Down & CDC23 & 27 & TEAD4 \\
\hline Down & GABARAP & 26 & hsa-mir-34b-3p & Down & SAT1 & 25 & SALL4 \\
\hline Down & PSMC5 & 10 & hsa-mir-452-5p & Down & XRCC6 & 23 & YY1 \\
\hline Down & CSNK2B & 9 & hsa-mir-149-3p & Down & TUBG1 & 22 & SOX 2 \\
\hline
\end{tabular}

\section{Figures}



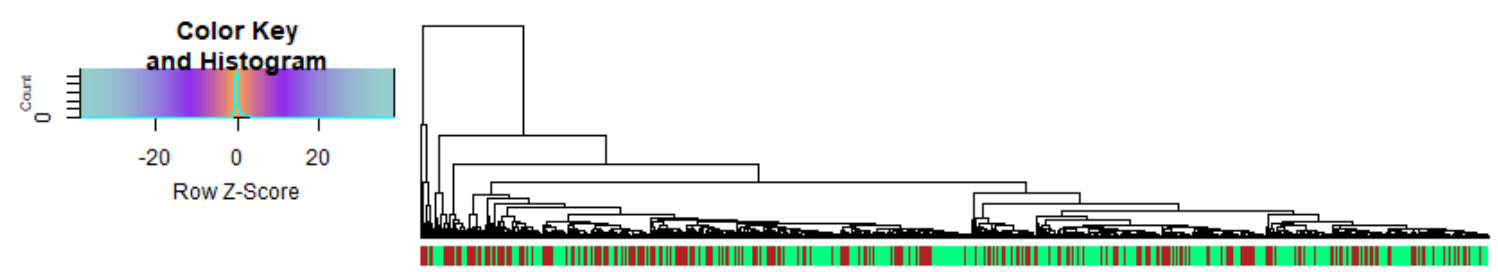

Fig. 1. Heat map of differentially expressed genes. Legend on the top left indicate log fold change of genes. (A1 A651= normal control samples; B1 - B949 = T2DM samples)

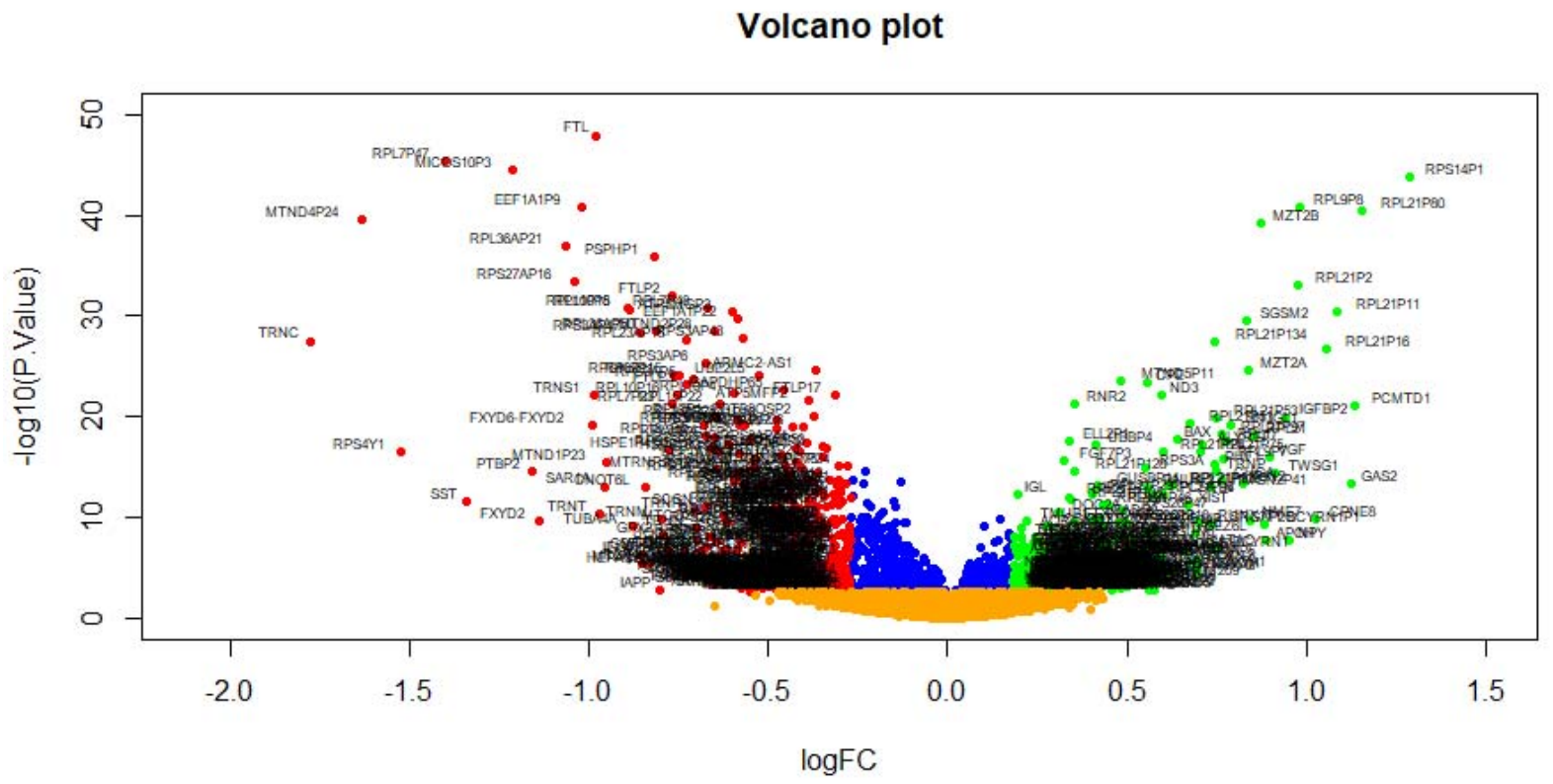

Fig. 2. Volcano plot of differentially expressed genes. Genes with a significant change of more than two-fold were selected. Green dot represented up regulated significant genes and red dot represented down regulated significant genes. 


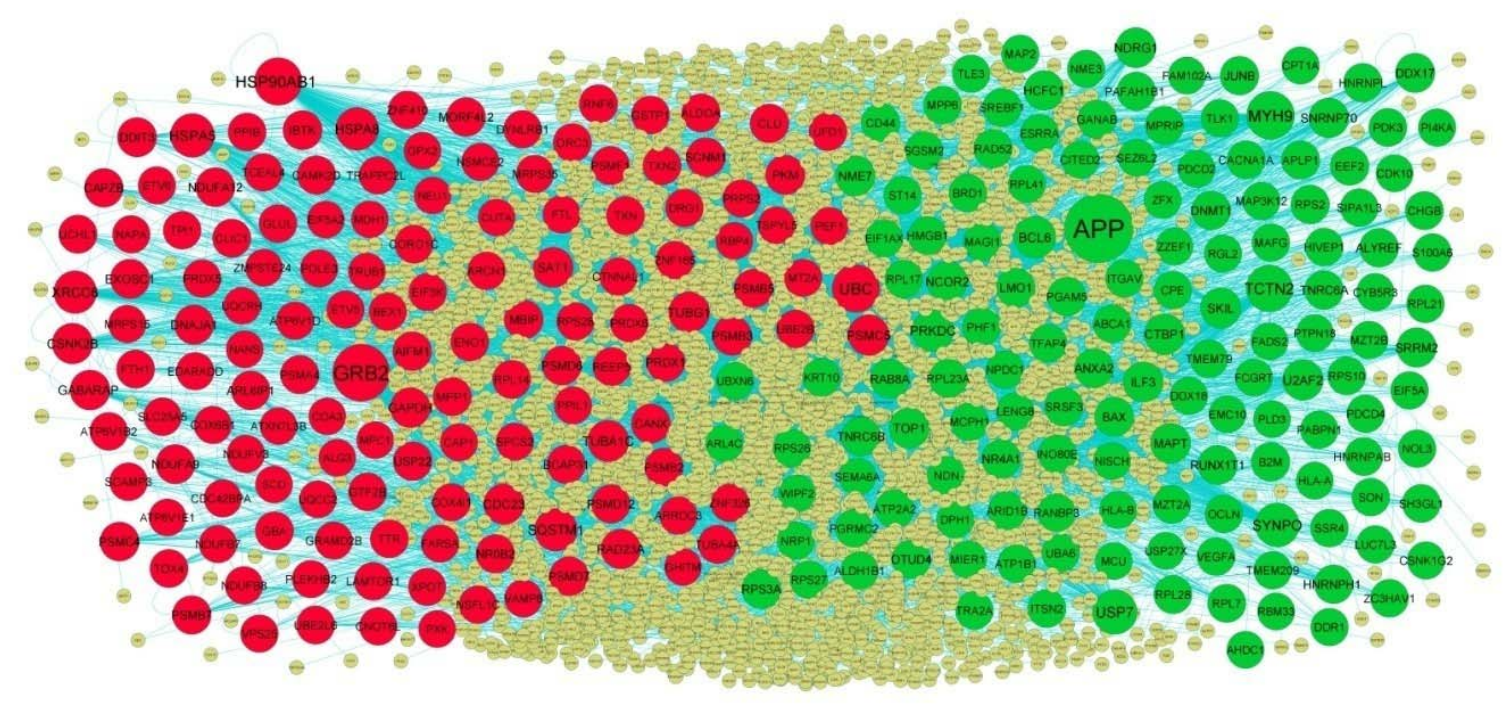

Fig. 3. PPI network of DEGs. The PPI network of DEGs was constructed using Cytoscap. Up regulated genes are marked in green; down regulated genes are marked in red

A

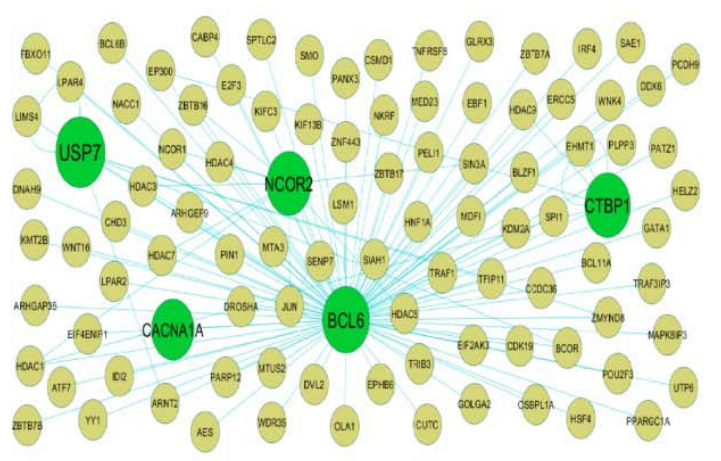

B

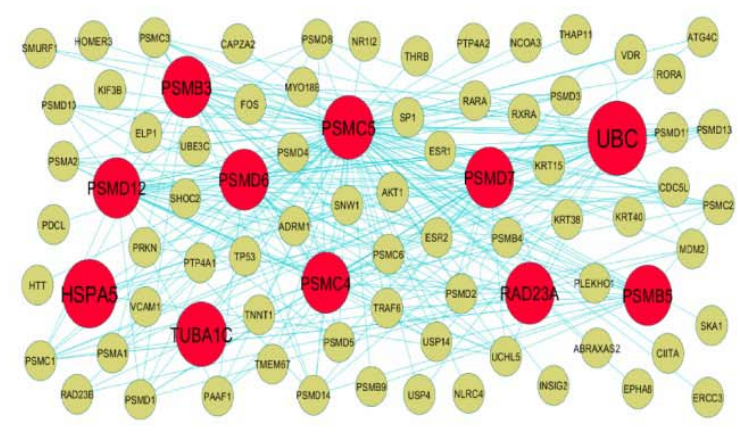

Fig. 4. Modules of isolated form PPI of DEGs. (A) The most significant module was obtained from PPI network with 98 nodes and 117 edges for up regulated genes (B) The most significant module was obtained from PPI network with 81 nodes and 248 edges for down regulated genes. Up regulated genes are marked in green; down regulated genes are marked in red. 
bioRxiv preprint doi: https://doi.org/10.1101/2021.08.12.456106; this version posted August 17, 2021. The copyright holder for this preprint (which was not certified by peer review) is the author/funder. All rights reserved. No reuse allowed without permission.

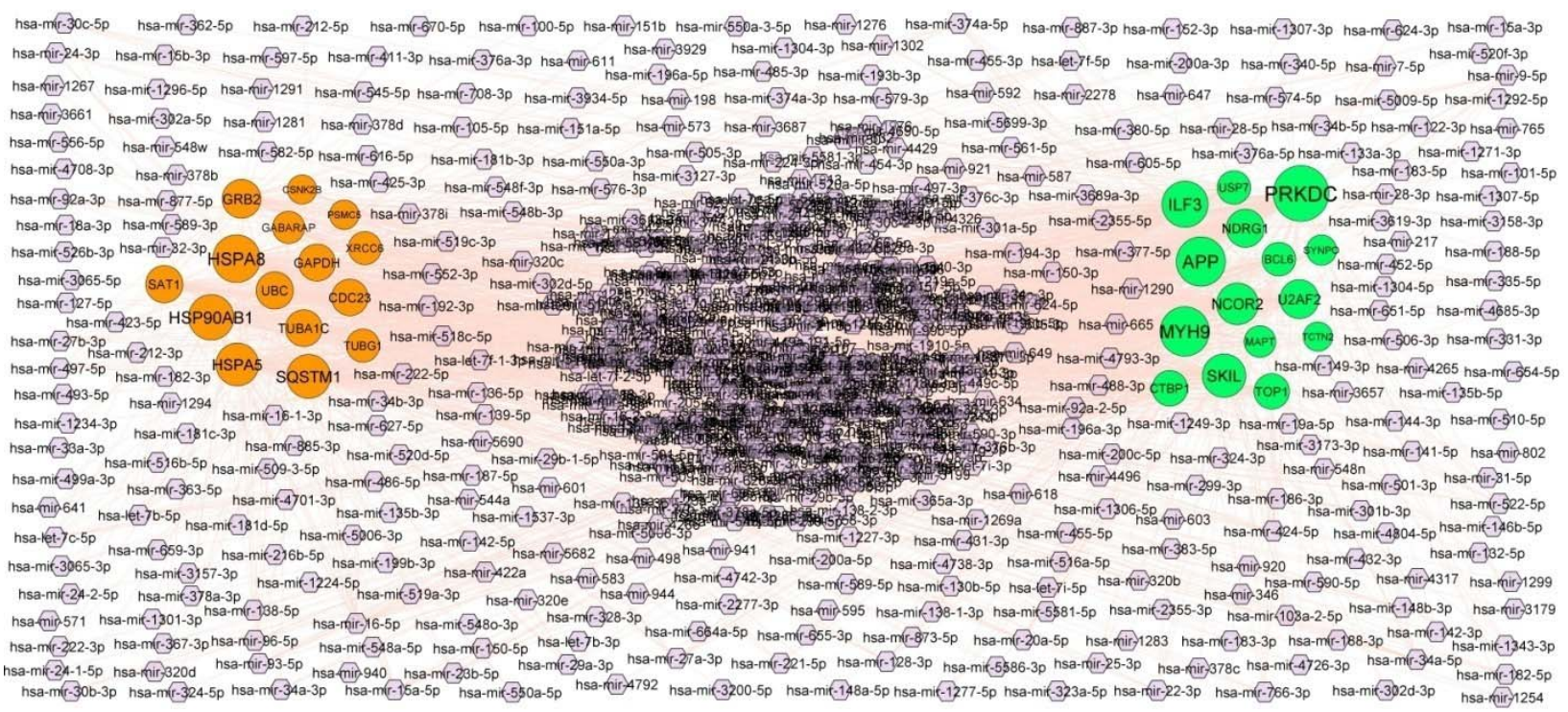

Fig. 5. MiRNA - hub gene regulatory network. The chocolate color diamond nodes represent the key miRNAs; up regulated genes are marked in green; down regulated genes are marked in red.

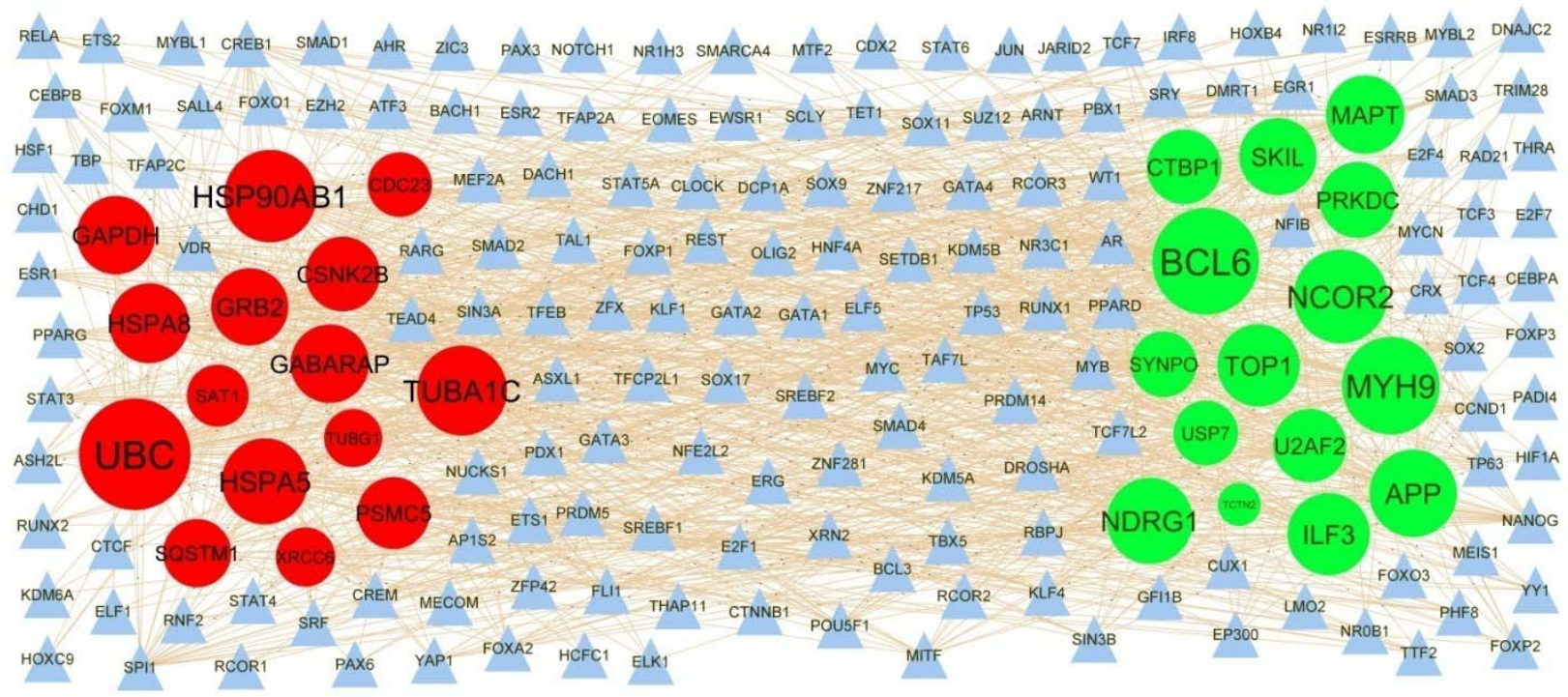

Fig. 6. TF - hub gene regulatory network. The blue color triangle nodes represent the key TFs; up regulated genes are marked in green; down regulated genes are marked in red. 

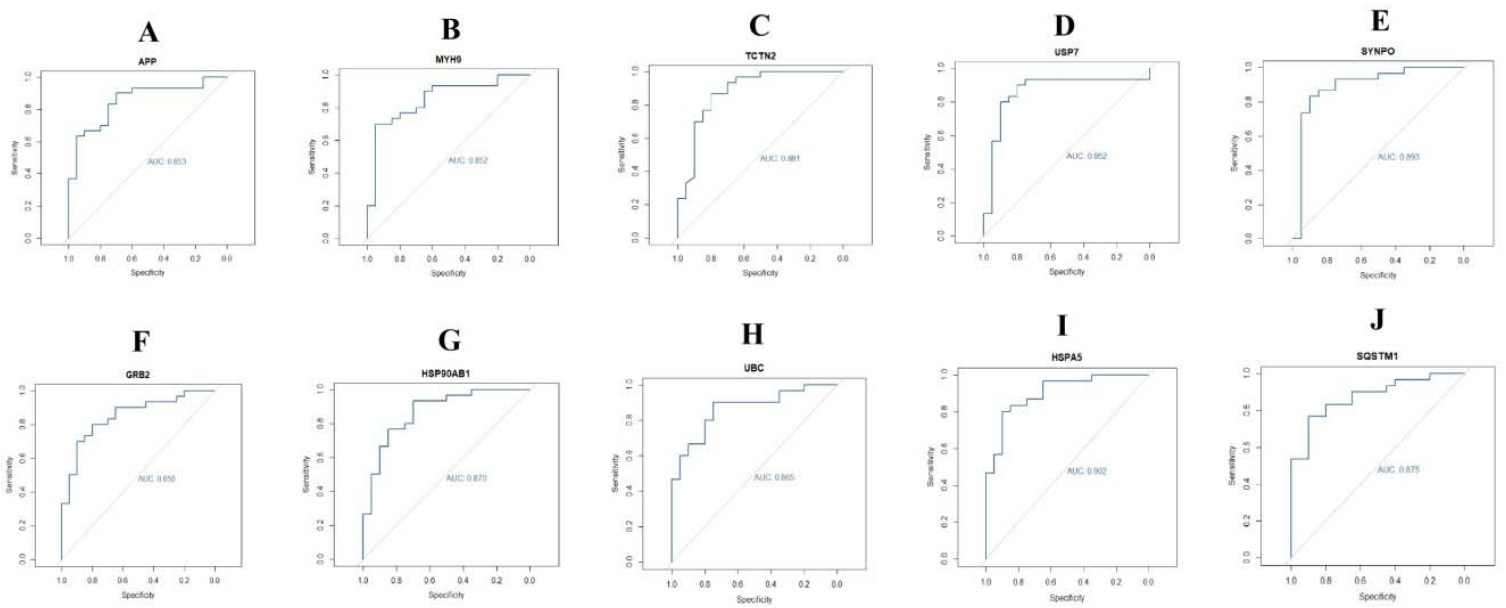

Fig. 7 ROC curve validated the sensitivity, specificity of hub genes as a predictive biomarker for T2DM. A) APP B) MYH9 C) TCTN2 D) USP7 E) SYNPO F) GRB2 G) HSP90AB1 H) UBC I) HSPA5 J) SQSTM1 